\title{
Recovering memories of childhood sexual abuse : from cognitive mechanisms to classification
}

Citation for published version (APA):

Raymaekers, L. H. C. (2013). Recovering memories of childhood sexual abuse : from cognitive mechanisms to classification. [Doctoral Thesis, Maastricht University]. Univesitaire Pers Maastricht. https://doi.org/10.26481/dis.20130426lr

Document status and date:

Published: 01/01/2013

DOI:

10.26481/dis.20130426lr

Document Version:

Publisher's PDF, also known as Version of record

\section{Please check the document version of this publication:}

- A submitted manuscript is the version of the article upon submission and before peer-review. There can be important differences between the submitted version and the official published version of record.

People interested in the research are advised to contact the author for the final version of the publication, or visit the DOI to the publisher's website.

- The final author version and the galley proof are versions of the publication after peer review.

- The final published version features the final layout of the paper including the volume, issue and page numbers.

Link to publication

\footnotetext{
General rights rights.

- You may freely distribute the URL identifying the publication in the public portal. please follow below link for the End User Agreement:

www.umlib.nl/taverne-license

Take down policy

If you believe that this document breaches copyright please contact us at:

repository@maastrichtuniversity.nl

providing details and we will investigate your claim.
}

Copyright and moral rights for the publications made accessible in the public portal are retained by the authors and/or other copyright owners and it is a condition of accessing publications that users recognise and abide by the legal requirements associated with these

- Users may download and print one copy of any publication from the public portal for the purpose of private study or research.

- You may not further distribute the material or use it for any profit-making activity or commercial gain

If the publication is distributed under the terms of Article $25 \mathrm{fa}$ of the Dutch Copyright Act, indicated by the "Taverne" license above, 


\section{RECOVERING MEMORIES OF CHILDHOOD SEXUAL ABUSE}

FROM COGNITIVE MECHANISMS TO CLASSIFICATION 


\section{Colophon}

Coverdesign by Tom Smeets \& Linsey Raymaekers

Production by Datawyse | Universitaire Pers Maastricht

(c) 2013 Linsey Raymaekers, Maastricht

ISBN 9789461592200

All rights are reserved. No part of this book may be reproduced or transmitted in any form or by any means, without written permission from the author or, when appropriate, the publisher of the article. 


\title{
RECOVERING MEMORIES OF CHILDHOOD SEXUAL ABUSE
}

\author{
FROM COGNITIVE MECHANISMS TO CLASSIFICATION
}

\section{PROEFSCHRIFT}

ter verkrijging van de graad van doctor aan de Universiteit Maastricht, op gezag van de Rector Magnificus, Prof. dr. L.L.G. Soete volgens het besluit van het College van Decanen, in het openbaar te verdedigen op vrijdag 26 april 2013 om 12.00 uur

door

Linsey Hilde Charley Raymaekers

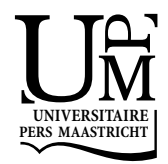




\section{Promotor}

Prof. dr. H.L.G.J. Merckelbach

\section{Copromotoren}

Dr. T. Smeets

Dr. M.J.V. Peters

\section{Beoordelingscommissie}

Prof. dr. C. de Ruiter (voorzitter)

Prof. dr. I.M. Engelhard (Utrecht University)

Dr. M. Jelicic

Prof. dr. P. Muris

Prof. dr. E. Rassin (Erasmus University Rotterdam)

The research presented in this dissertation was supported by a grant from The Netherlands Organization for Scientific Research (NWO, grant number 40006 024) awarded to Prof. dr. H.L.G.J. Merckelbach. 


\section{CONTENTS}

CHAPTER 1 General Introduction

PART I COGNITIVE MECHANISMS

CHAPTER 2 Autobiographical Memory Specificity

CHAPTER 3 Underestimation of Prior Remembering and Susceptibility to False Memories

CHAPTER 4 Underestimation of Prior Remembering and Source Monitoring

CHAPTER 5 Undergraduates' Recovered Memory Experiences and Beliefs about Memory

CHAPTER 6 Classifying Recovered Memory Reports

CHAPTER 7 General Discussion

APPENDIX Assessing Memories of Childhood Sexual Abuse:

Revised Questionnaire

Summary

Samenvatting

129

References

Dankwoord

Curriculum Vitae

List of Publications 



\section{CHAPTER 1}

\section{GENERAL INTRODUCTION}

This chapter is a translated and extended version of the following article:

Raymaekers, L., et al. (2008). Hervonden herinneringen: de stand van zaken

[Recovered memories: Current findings]. Tijdschrift voor Psychotherapie, 4, 242-259. 
The impact of trauma on memory has attracted much attention in the fields of psychology, psychiatry, and the law. Especially the question whether or not traumatic memories can be forgotten and later recovered has evoked much controversy (McNally, 2003a). An individual is said to have recovered memories when: (a) he or she reports to have remembered traumatic childhood experiences after having been unable to recall these memories for a long period of time (i.e., dissociative amnesia; American Psychiatric Association [DSM-IV-TR], 2000, pp. 520-523), (b) he or she relates these past experiences to current psychological complaints (e.g., depressive symptoms), and (c) suggestive therapeutic practices (e.g., hypnosis) or other special circumstances (e.g., presence of suitable retrieval cues) have contributed to remembering the events (Merckelbach, Crombag, Raymaekers, Smeets, \& Horselenberg, 2010). Recovered memories can result in dramatic outcomes when legal matters are involved. One of the most infamous legal cases involving recovered memories is outlined below.

\section{THE PAUL INGRAM CASE}

In 1988, county deputy sheriff (i.e., the third highest position in the sheriff's office), and fundamental Christian, Paul Ingram was accused of sexual and satanic ritual abuse of his two daughters. The initial accusations occurred in a religious context (i.e., bible camp) and were raised by a Christian speaker who received a divine message stating that Ingram's daughter Ericka had been sexually abused during childhood. The abuse had allegedly been carried out by Paul Ingram and had supposedly occurred over many years. In the following months, Ericka started to tell others that she had been abused. The accusations finally reached the sheriff's office, upon which the sheriff immediately decided to question Ingram's children (i.e., his two daughters and three sons). During these interrogations, Ingram's other daughter, Julie, also confessed that she had been sexually abused during poker parties that took place at their home. As time passed by, the claims became more and more bizarre, ultimately involving numerous satanic rape events and abortions allegedly carried out by Ingram, amongst others.

Initially, while being questioned by his fellow officers whom he knew and trusted, Ingram denied any knowledge of and involvement in the alleged crimes. He was then told that it was not unusual for people to repress memories of such crimes, which eventually led to a shift in his denial from "I didn't do it" to "I don't remember doing it" (Ofshe \& Watters, 1994, p. 167). And so, after five months, as he became convinced that it was possible to repress memories, Ingram admitted to having sexually abused his daughters. However, he still did not have any memories of the crimes. As detectives were getting annoyed by the fact that Ingram failed to remember any details of the events, they started to rely on relaxation and imagination techniques that were supposed to help Ingram get his memories back. By visualizing scenes that were suggested by the detectives, Ingram started to develop memories about the abuse.

Around this time, social psychologist Richard Ofshe was hired by the prosecution to analyze the case. Throughout the course of his examination, he repeatedly inter- 
viewed Ingram and his two daughters. He believed that the girls were not telling the truth and became convinced that Ingram had been manipulated into making false confessions. He decided to put his hypothesis to the test by confronting Ingram with a fake abuse scenario. That is, after making sure that nothing like this ever happened to Ericka and Julie, Ofshe asked Ingram about an incident in which Ingram forced his daughters to have sexual intercourse with one of their brothers while he was watching them. Though Ingram initially failed to "remember" this event, he confessed to the incident the following day after extensive memory work had taken place, consisting of repeatedly visualizing the pertinent scenes. In his expert report, Ofshe warned that an innocent man was about to be convicted.

Though he initially denied everything, Ingram pleaded guilty to all charges after endless hours of interrogation. Motivated by his own desire to recover the memories as he was convinced that he hadn't raised his daughters to lie, Ingram confessed to the crimes and pleaded guilty without a trial. With time passing by, however, Ingram started to doubt his "memories". Ultimately, he asked to withdraw his guilty plea but by then it was already too late. He was convicted to a life sentence of 20 years (for more information on this case, see Ofshe \& Watters, 1994).

Paul Ingram became a victim of the child and satanic ritual abuse hysteria of the late 1980s (see, for a comparison of satanic ritual abuse cases in the United States versus The Netherlands, Beetstra, 2004, 2009). He was released from prison on April 8 , 2003 after serving a large part of his sentence. His case is now known as one of the most notorious recovered memory cases in the history of the United States.

\section{RECOVERED MEMORY DEBATE}

Cases like the one of Paul Ingram brought questions concerning the validity of recovered memories to the public's attention. This led the field of traumatic memory to become riveted with controversy and debate (McNally, 2003a). Two extreme positions characterized this debate. According to the first, the repression interpretation, traumatic memories can be repressed by special memory mechanisms (i.e., repression, dissociation) only to be accurately recovered later in life (e.g., Brown, Scheflin, \& Whitfield, 1999; Terr, 1991; Van der Kolk, 1994). Defense mechanisms are believed to block out traumatic memories from awareness resulting in victims being incapable of recalling these memories until it is considered psychologically safe to do so (McNally \& Geraerts, 2009). Researchers on this side of the debate are sometimes referred to as $B e-$ lievers (Loftus \& Ketcham, 1994).

Contrasting this view was the second position, the false memory interpretation, catalyzed by the assumption held by many academics that traumatic memories are seldom, if ever, truly forgotten (McNally, 2003a; Peace \& Porter, 2004; Porter \& Peace, 2007; Wagenaar \& Groeneweg, 1990). Therefore, advocates of this position often argue that recovered memories do not correspond to real events and are mere prod- 
ucts of suggestive therapeutic practices (McNally \& Geraerts, 2009). Researchers on this side of the debate are sometimes referred to as Skeptics (Loftus \& Ketcham, 1994).

The intensity of the debate has very much decreased over the past decade as research in the field of traumatic memory started to accumulate and therapy-induced incest accusations started to dissipate (Lindsay \& Read, 2001; McHugh, Lief, Freyd, \& Fetkewicz, 2004). Below, the current scientific status of the two recovered memory interpretations, and how these extreme positions started to move closer to one another, will be described. Later on, a third interpretation of recovered memories that neither relies on "special" memory mechanisms (i.e., repression), nor on the assumption of false memories will be explained. This latter interpretation of recovered memories (see McNally \& Geraerts, 2009) has gained much interest over the past few years as it emphasizes the heterogeneity of recovered memory experiences and is not concerned with "proving" that recovered memories are either false memories or memories referring to authentic experiences. Its focus is on explaining the alleged amnesic period typical for people reporting recovered memories in terms of ordinary memory mechanisms, as opposed to special memory mechanisms (i.e., repression), which renders this interpretation less controversial than the former, extreme interpretations of recovered memories (i.e., repression and false memory accounts).

\section{THE REPRESSION INTERPRETATION}

The repression interpretation has not received much credit over the past few years. Solid scientific proof providing direct evidence for repression or dissociation as the drivers of amnesia is generally lacking (Bonanno, 2006; Giesbrecht, Lynn, Lilienfeld, \& Merckelbach, 2008; Hayne, Garry, \& Loftus, 2006; Kihlstrom, 2006; McNally, 2003a, 2004a, 2006; Merckelbach \& Muris, 2001; Piper, Lillevik, \& Kritzer, 2008; Pope \& Hudson, 1995; Rofé, 2008).

The concept of recovered memories implies that people who have such memories were at least for a period of time amnesic for them (Brewin \& Andrews, 1998). Traditionally, the dominant view is that this amnesia is a byproduct of repression, dissociative coping, or pathological inhibition. With this conceptualization, two questions arise. The first is whether functional amnesia for aversive life events is a well-documented phenomenon. Some say it is (Brown et al., 1999; Terr, 1991; Van der Kolk, 1994), but many other authors have argued against this view (Bonanno, 2006; Hayne et al., 2006; Kihlstrom, 2006; McNally, 2003a, 2006; Piper et al., 2008; Pope \& Hudson, 1995; Rofé, 2008). The current dissertation will not address the details of this discussion. More relevant for this thesis is the second question of whether one could make the case that people with recovered memories are especially skilled at inhibiting emotional material. McNally, Clancy, and Schacter (2001) examined whether women reporting repressed memories (i.e., harboring the belief that one was sexually abused during childhood without having any memories or images about the events) and recovered memories of childhood sexual abuse (CSA) exhibit an avoidant coping style for traumatic material 
relative to controls (i.e., people without CSA experiences). The authors investigated this issue by means of an item-cueing directed forgetting task in which participants were instructed to either remember or forget presented words (i.e., intermixed trauma, positive, and neutral words). Results showed that people reporting repressed or recovered memories were not especially prone to forgetting trauma-related words when instructed to do so (see also McNally, Ristuccia, \& Perlman, 2005). It is safe to conclude that such populations show similar rates of forgetting (i.e., normal forgetting) compared to healthy controls, and that this is true irrespective of the valence of the used materials (see also McNally et al., 2001; McNally, Metzger, Lasko, Clancy, \& Pitman, 1998; McNally et al., 2005). This lack of superior directed forgetting in individuals with recovered memories casts doubt on the idea that recovered memories can be understood as a return of what was repressed.

Although evidence for the repression account is generally absent, there existed, at least until a few years ago, a widespread belief among laypeople, undergraduates, legal professionals, and even psychotherapists, that emotionally provocative events can be forgotten but nevertheless may have profound effects on current behavior (Magnussen et al., 2006; Merckelbach \& Wessel, 1998; Naka \& Maki, 2006; Rubin \& Berntsen, 2007; see also Garry, Loftus, \& Brown, 1994). This is rather worrisome given that some authors suggest that unrealistic assumptions about memory functioning, that are not derived from a consensus among memory researchers (Zola, 1997), may contribute to the emergence of recovered memories (Lindsay \& Read, 1994; Loftus, 1993). One of the subsidiary aims of scientific research on recovered memories is the dissemination of knowledge to governmental agencies, health professionals, and society in general. Therefore, one may assume that the accumulation of knowledge during the past decade would have led to debunking faulty assumptions about recovered memory and that recovered experiences would be less often reported in the general population. At least until a few years ago, such changing patterns were not evident (e.g., Magnussen et al., 2006; Naka \& Maki, 2006). One wonders to what extent the public still maintains unrealistic assumptions about memory.

\section{THE FALSE MEMORY INTERPRETATION}

The phenomenon that people start to remember things that have never happened to them (i.e., false memory) has been described in several populations over the past decade. For example, many studies have shown that it is relatively easy to make both children and adults believe and even fully remember events that they have never witnessed or experienced (e.g., Hyman, Husband, \& Billings, 1995; Jelicic et al., 2006; Lindsay, Hagen, Read, Wade, \& Garry, 2004; Loftus \& Ketcham, 1994; Ost, Vrij, Costall, \& Bull, 2002; Otgaar, Candel, Scoboria, \& Merckelbach, 2010; but see Smeets, Merckelbach, Horselenberg, \& Jelicic, 2005).

Laboratory studies have also shown that even extreme and implausible memories can be implanted in people's minds. These may refer to satanic ritual abuse (Shaffer $\&$ 
Cozolino, 1992), alien abduction (Clancy, 2005; Otgaar, Candel, Merckelbach, \& Wade, 2008), and previous-life experiences (Spanos, Menary, Gabora, DeBreuil, \& Dewhirst, 1991; see also Meyersburg, Bogdan, Gallo, \& McNally, 2009 and Peters, Horselenberg, Jelicic, \& Merckelbach, 2007 for evidence on heightened susceptibility to false memories and source monitoring problems in people reporting past life experiences). Often suggestive techniques (e.g., hypnosis; Spanos et al., 1991) seem to play a key role in the development of these memories. Remarkable is the finding that such memory development goes hand in hand with strong emotions. For example, McNally and colleagues (2004) showed that the recollection of highly implausible traumatic experiences (i.e., having been abducted by aliens) goes along with elevated psychophysiological response patterns indicative of intense emotion (e.g., elevated heart rate, increased skin conductance, etc.). These authors concluded that the erroneous memory of having experienced a traumatic event is, in terms of emotional responses, comparable to recalling memories of corroborated trauma (e.g., military combat-related experiences). Thus, the emotional significance of a memory cannot be taken as evidence for the veracity of that memory.

In addition to the acceptance of fictitious memories as part of one's own autobiography, people sometimes dismiss their recovered memories as a result of new insights. That is, they come to realize that these memories were suggested to them by their therapists. These people are called retractors (or recanters/returners; Ost, Costall, \& Bull, 2002; Ost \& Nunkoosing, 2010). Interestingly, there is an asymmetry in the process of recovery and retraction in that it takes more time to retract a memory than to recover it. Moreover, retractors consistently report that the social pressure to retract is significantly less than to recover memories of abuse (Ost et al., 2002).

Taken together, a vast amount of research has demonstrated the malleability of memory and the importance of this topic for the recovered memory field (Loftus, 2004, 2005; Loftus \& Cahill, 2007; Loftus \& Ketcham, 1994; for an extensive review, see McNally, 2003a, chapters $2 \& 8$; see, for information on false memory research in relation to eyewitness testimony, Frenda, Nichols, \& Loftus, 2011). As a result, researchers decided upon exploring the development of false memories in people reporting recovered memories.

\section{FALSE MEMORIES IN PEOPLE REPORTING RECOVERED MEMORIES}

Until a decade ago, clinicians, lawyers, and researchers' opinions about the nature and origin of recovered memories were merely based on studies of genuine and false memories in undergraduate samples. Scientific knowledge based upon people actually reporting recovered memory experiences was generally absent (McNally, 2003b). One possible reason for this could have to do with clinicians lacking the expertise necessary for conducting laboratory research in addition to experimental psychologists having only limited access to trauma populations (McNally, Clancy, \& Barrett, 2004). 
Being well aware of the need for exploratory methods to illuminate mechanisms for remembering and forgetting among people reporting histories of trauma (McNally, $2003 \mathrm{~b})$, studies examining the cognitive functioning of people reporting recovered memories of CSA began to prosper. For example, Clancy, Schacter, McNally, and Pitman (2000) used the Deese-Roediger-McDermott (DRM) task (Deese, 1959; Roediger \& McDermott, 1995) that has been shown to be a very effective tool in eliciting false memories. During this task, participants are required to study a list of words, all of which are strong associates of a non-presented critical lure. For example, participants are instructed to study words like injection, sharp, pain, thread, and so forth, but the word needle is not given. The rationale behind this paradigm is that presenting the semantically associated words activates a concept that is common to all words on the lists (i.e., the critical lure), in this case needle. A basic finding is that participants often falsely recall and/or recognize the non-presented lures on a later memory test. Clancy et al. (2000) found that individuals reporting recovered CSA memories more often falsely recognized the non-presented critical lures relative to individuals with continuous memories of CSA and control subjects with no history of sexual abuse (but see Freyd \& Gleaves, 1996; for false memory development with respect to trauma-related DRM lists in adolescents and adults with histories of CSA, see Goodman et al., 2011). As noted before, the finding of enhanced false memory propensity in people reporting recovered memories of CSA also holds for people with recovered memories of previous life experiences (Meyersburg et al., 2009). Thus, Meyersburg and colleagues (2009) found that people reporting memories of past lives exhibited significantly higher false recall and recognition rates in the DRM paradigm than controls. This is reminiscent of Peters et al.'s (2007) finding that relative to a control group, participants with previous-life memories exhibited a stronger tendency to judge names of previously presented non-famous people as famous on the so called false fame task.

Source confusion has been put forward as a possible explanation for the development of false memories (e.g., Hyman et al., 2005). Source confusion occurs when a person makes an incorrect judgment about the source of his/her information (Johnson, Hashtroudi, \& Lindsay, 1993). Performing the DRM task, for example, requires participants to make a distinction between internally generated associations and authentic memories of the studied words (e.g., Roediger, Watson, McDermott, \& Gallo, 2001). This is a difficult task as internal associations often come about rather easily. Some authors have argued that, due to this fluent association process, the risk of source confusion by which the association is wrongfully attributed to a "real" memory increases (e.g., Johnson et al., 1993; but see chapter 7 of this dissertation, pp. 157-158). Based on findings outlined above, several scholars have argued that people with recovered memories might be especially prone to source confusion (e.g., Belli \& Loftus, 1994). It seems that, even more than others, they tend to confuse an internally generated thought with an authentic memory. 


\section{RECOVERED MEMORIES WITH AUTHENTIC ELEMENTS}

Notwithstanding the weak evidence for the underlying mechanisms postulated by the repression account, and the growing amount of evidence concerning false memory propensity in people reporting recovered memories, recovered memory reports with authentic elements seem to exist.

For example, Jonathan Schooler and his co-workers published case studies of individuals reporting to have experienced the discovery of actually long-forgotten memories of abuse that were apparently authentic (e.g. Schooler, Ambadar, \& Bendiksen, 1997a; Schooler, 2001; Shobe \& Schooler, 2001). Importantly, collateral evidence was found to corroborate these recovered abuse events. Another remarkable observation was that these people reporting recovered CSA memories already mentioned their experiences to their partner, family or friends before the "recovery" of the abuse episodes. It appeared that these individuals forgot having remembered the traumatic event, producing an illusion of amnesia (Schooler, Bendiksen, \& Ambadar, 1997b). Based on these observations, Schooler (1999) hypothesized that this underestimation (i.e., forgetting) of prior remembering may explain the seemingly forgotten CSA memories, a phenomenon which is known as the "Forgot-It-All-Along" (FIA) effect (Arnold \& Lindsay, 2002; Schooler et al., 1997a).

On the basis of the findings and speculations outlined above, Merckelbach and colleagues (2006) carried out a study employing an autobiographical FIA task that was originally developed by Parks (1999). Specifically, people were asked to report vivid memories for some childhood events (e.g., favourite game as a child). After a delay of one hour or two days, subjects were asked whether they had recently thought about any of these and several other events. Despite recalling the events either an hour or two days before, many subjects reported not having thought about the events for years. For example, after a delay of two days, $22 \%$ of the participants had a mean dating estimate of "one year ago" or longer (see also Abenavoli \& Henkel, 2009; Arnold \& Lindsay, 2002, 2005). Importantly, the authors compared individuals reporting continuous CSA memories with those reporting recovered memories of CSA. It was found that people who reported having recovered memories of CSA were more likely to forget remembering the recent events in their laboratory tasks. These findings support Schooler's idea (1999) that the FIA bias is typical for at least some individuals reporting recovered memories of CSA.

The study by Merckelbach and colleagues (2006) is silent about why people reporting recovered memories of CSA show a stronger tendency to underestimate their prior remembering. An important issue is whether this FIA effect is a distinct phenomenon or whether it reflects a general lack of metamemory (i.e., thinking about ones own memory processes) functioning, most notably source monitoring. Thus, one could speculate that when people lack these metamemory skills, they will also tend to underestimate prior recall attempts. Research examining this possibility is therefore warranted. 
Taken together, evidence for the mechanisms underlying recovered memories that are postulated by the repression account is weak. However, a significant portion of abuse victims report that there was a period in their lives in which they had no memories of the abuse (e.g., Briere \& Conte, 1993; Loftus, Polonsky, \& Fullilove, 1994). Anecdotal data seem to support the idea that at least a subset of recovered memory reports refers to memories that might be accurate but of which the accessibility was underestimated due to the FIA mechanism. But we also know that people with recovered memories exhibit a heightened sensitivity to experience false memories. These two lines of research, the superior false memory effects in the laboratory and the enhanced forgetting of prior remembering in people reporting recovered memories, suggest that there may be multiple pathways to recovered memory reports.

\section{DIFFERENT TYPES OF RECOVERED MEMORY EXPERIENCES}

Recovered memories of CSA do not form a unitary phenomenon. At least two different types of recovered memory experiences have been identified (e.g., Schooler, 2001; Schooler et al., 1997a; Sivers, Schooler, \& Freyd, 2002). In the recovered in therapy type, people gradually come to believe that they experienced CSA and think they must have forgotten about it for a long time. Here, memories are often recovered due to suggestive therapeutic practices such as hypnosis, dream interpretation, guided imagery, etc. The second, spontaneously recovered memory type concerns suddenly recalled CSA memories outside a therapeutic context that are usually accompanied with feelings of shock and surprise. Here, it is plausible that individuals recovered experiences as a result of having encountered certain retrieval cues such as a movie fragment or a specific contextual cue (e.g., re-entering the room where the abuse took place).

A recent study (Geraerts et al., 2009) aimed to test the potential differences in recovered memory experiences. The authors examined whether different cognitive mechanisms underlie different types of recovered memory experiences. Based on previous research, they hypothesized that especially people reporting CSA memories recovered in therapy may be prone to false memory effects. People reporting spontaneously recovered memories - outside of therapy - on the other hand were expected to be especially vulnerable to underestimating (i.e., forgetting) their prior memories. The findings supported the hypotheses and suggested that people who reported CSA memories recovered during therapy exhibited more pronounced false memory effects on the DRM task relative to spontaneously recovered CSA memories, people with continuous CSA memories and controls. Also, this in therapy recovered memory group seemed to score within the normal range on the FIA task. In contrast, people with spontaneously recovered memories were found to be more prone to the underestimation of their prior remembering (FIA effect) relative to the other groups. Interestingly, the spontaneously recovered memory group did not show enhanced false memory effects on the DRM task. 
These data indicate a seemingly clear distinction between qualitatively different cognitive profiles in the two types of recovered memories of CSA. As Schooler and coworkers (Schooler, 2001; Sivers et al., 2002) had argued before, it can be concluded that there exist different pathways to recovered memory experiences, with some being more likely to reflect the temporal misinterpretation of authentic events, and others the unintentional fabrication of fictitious memories. Note, however, that Geraerts et al. (2009) assumed that false memories in DRM tasks and forgetting of prior remembering in FIA tasks are non-overlapping phenomena, although no study has ever tested this. Another important remaining question is whether the two types of recovered memories go hand in hand with distinct personality traits. If this were the case, then memory measures such as the DRM and FIA tasks might be further developed so that they, when being combined with an adequate personality assessment battery, can be informative for a therapist. It would be extremely helpful if a therapist, on the basis of sound diagnostic tests, could decide whether or not it would be wise to expose a patient to certain therapeutic interventions.

\section{A THIRD INTERPRETATION OF RECOVERED MEMORIES}

As the repression interpretation of recovered memories is lacking scientific foundation and the false memory interpretation cannot account for recovered memories with authentic elements, a third interpretation of recovered memories has recently been postulated (see McNally \& Geraerts, 2009). This interpretation does not involve special memory mechanisms (i.e., repression) or false memory interpretations. It is less controversial than the former rather extreme accounts due to its focus on ordinary memory mechanisms as opposed to special memory mechanisms (e.g., repression). It is also more widely applicable to recovered memory experiences as it does not argue that recovered memories correspond to either genuine (i.e., repression interpretation) or false memories (i.e., false memory interpretation). More specifically, it attempts to explain recovered memory experiences that likely refer to real (i.e., genuine) events without denying the existence of false memories of CSA. Basically, this alternative interpretation of recovered memories is based on the notion that at least a subset of people with recovered memories has not initially experienced their CSA as traumatic (see Clancy, 2010). This lack of traumatic impact might explain why people come to believe in harboring repressed memories of abuse. That is, CSA events that were not experienced as traumatic at time of occurrence (e.g., possible age-related lack of understanding) might be regarded as recovered memories when re-labeling or reinterpretation of the memories takes place. Thus, some episodes of abuse may be forgotten because they were not traumatic. However, when proper reminders (i.e., contextual cues) are encountered and memories come to mind, the recollection may nevertheless be accompanied with shock and disgust evoking a feeling of "recovering" repressed memories (while in fact constituting a re-labeling of memories that were always present, yet not thought about in this particular way). Apart from or in addition 
to the lack of traumatic impact, people with recovered memories tend to underestimate their prior instances of remembering (Merckelbach et al., 2006; Schooler et al., 1997a). Although these people present themselves with recovered memories, they apparently were not amnesic for their abuse. Important for this discussion is the notion that not thinking about something is not the same as being unable to remember it (e.g., McNally, 2003a). Again, an ordinary memory mechanism is able to explain the alleged amnesia that characterizes people with recovered memories.

An important implication of the abovementioned recovered memory interpretation is that it encourages "a case-specific focus" with respect to evaluating recovered memory reports (see also Alison, Kebell, \& Lewis, 2006, p. 419). Specifically, circumstances surrounding recovery are considered even more important than they were before. The stipulation of various routes to recovered memory experiences can be considered important for the classification of recovered memory reports. With this in mind, it seems unlikely that recovered memory experiences can be subdivided in just two broad categories.

\section{GENERAL CONCEPTUAL PROBLEMS IMPEDING RESEARCH ON RECOVERED MEMORIES}

The recovered memory field is not only known for its intensity of debate, but also for its confusing nature. One major problem for researchers who deal with recovered memory reports has to do with the lack of definitional precision of the core recovered memory elements. Defining terms such as trauma, repression, dissociation, amnesia, forgetting, and recovery poses a challenge for academics (Memon \& Young, 1997). For example, what counts as a traumatic stressor has proven to be a highly contentious issue (for an overview, see McNally, 2004b). Examples illustrating the lack of definitional precision in repression relate to whether repression should be considered a truly unconscious process and whether its observation in the clinical context is the same as laboratory-induced memory inhibition (Erdelyi, 2006; McNally, 2003a). Related to this, research needed to provide a more solid scientific basis for special mechanisms, such as repression or dissociation, is hampered because these terms are applied to an extremely wide range of observed phenomena (e.g., Spiegel \& McHugh, 1995).

As argued earlier, people are not always accurate in determining their own prior memory states (e.g., Merckelbach et al., 2006). This makes the task to distinguish between true forgetting and a mere illusion of forgetting challenging. Moreover, prior accessibility of a memory is difficult to determine, as a continuum of possible prior memory states can be distinguished ranging from a mere impression of unavailability of memories to complete incapability of recalling the event(s) (Schooler, 1994). Also, several studies suggest that people do not really understand the way in which they remember events. For example, a study by Read and Lindsay (2000) showed that retrospective and subjective judgments about the accessibility of memories of out- 
standing events (e.g., high school graduation) can be experimentally manipulated by memory work. Specifically, in that study, participants reported to have been amnesic for $26 \%$ of the events prior to memory work, whereas after a period of enhanced memory work (i.e., retrieve memories of the event, find pictures, and discuss it with friends and family), they reported to have been amnesic for $70 \%$ of the events. This finding suggests that enhanced memory work may induce an impression of amnesia in healthy people.

Another important issue complicating the recovered memory field concerns the confusion of two conceptually distinct memory dimensions: memory accuracy and memory persistence (Freyd, 1998). Memory accuracy refers to the degree to which a memory is historically true ranging from being largely false to being largely true. Memory persistence, on the other hand, refers to the degree of accessibility of a memory at different points in time ranging from complete unavailability to continuous availability. These conceptual dimensions are often entangled (see figure 1). Such an entanglement may result in people a priori equating continuously available memories with accurate memories and recovered memories with false memories without, for example, looking at the context of memory recovery or the nature of the continuously available memories.

Note furthermore that several factors seem to underlie memory accuracy and memory persistence. Thus, memories seem to vary in their degree of accuracy and persistence. Consequently, absolute memory accuracy (i.e., memories being perfectly true) and full memory persistence (i.e., memories being completely available) occur only rarely (Freyd, 1998). 


\begin{abstract}
MEMORY ACCURACY
'Recovered' memory

MEMORY PERSISTENCE

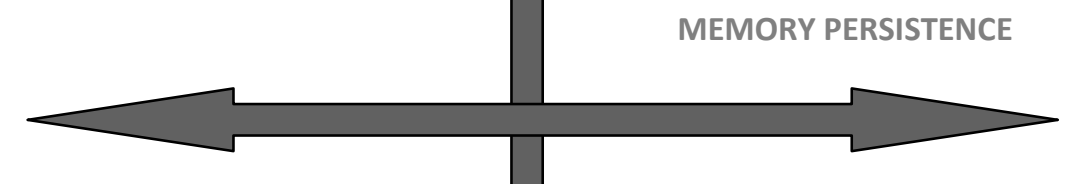

Continuously available

\section{False memory}

Figure 1.1. Illustration of the conflation of two separate memory dimensions. Note that although the dimensions are shown as if they were orthogonal, empirical research still needs to conclusively show how these dimensions are related to one another in memory for real events. This illustration probably constitutes an oversimplification as both dimensions are believed to interact in complex ways. Copyright, Jennifer J. Freyd (1996). Reprinted with permission.

The identification of different types of recovered memories introduces yet another problem. So far, research has relied on global descriptions rather than detailed decision trees for differentiating between continuous memories and spontaneous versus in therapy-recovered memories (e.g., Geraerts et al., 2009). As a result, categorizing recovered memory reports became an inherently subjective process. Its reliability may be especially jeopardized by cases that are ambiguous. Indeed, in practice, clear-cut criteria for classifying a recovered memory are rare (Alison et al., 2006; see also Freyd, 1998). Note also that self-definitions of recovered memories cannot be accepted at face value. A case in point is the research by Melchert (1999) who found that how people describe the mechanisms that purportedly underlie their recovered memories is much dependent on the questions you ask them. Thus, if repression is stipulated, some will endorse repression, but if ordinary forgetting is stipulated some will endorse that phenomenon. Given that the classification of recovered memory reports occurs on the basis of self-report (i.e., semi-structured memory interview), prudence is in order. So far, no study has tested the validity of the present classification procedure, an important consideration that merits further investigation.
\end{abstract}




\section{THE VALIDITY OF RECOVERED MEMORIES}

The two types of recovered memory experiences mentioned above are suggested to be associated with differences in corroborative evidence. More precisely, some authors claim that CSA memories recovered spontaneously are more likely to reflect genuine events relative to CSA memories recovered during the course of suggestive therapy (Geraerts et al., 2007). However, the types of corroborative evidence that these authors describe do not meet the legal standards for evidence. For example, the collateral evidence is often characterized by 'hearsay' features (i.e., stories of family or friends that echo the recovered memories; Merckelbach et al., 2010).

According to Lindsay and Read (2001), the validity of recovered memories can be estimated by weighing a constellation of factors such as: (a) the presence or absence of converging evidence, (b) the context of recovery (i.e., the less suggestive memoryrecovery work involved, the greater the credibility of the memories), (c) the nature and clarity of the memories with detailed and integrated recollections being more credible, (d) the likelihood of the events being forgotten if they had actually occurred (e.g., overall memorability of the alleged events, probability that the person would have encountered suitable retrieval cues/reminders, when and how often the abuse is said to have occurred, etc.), (e) the developmental period that the memories refer to, with higher credibility given to memories representing events that have occurred after the age of four or five as the inability of adults to recall the earliest memories of their lives is well-documented (i.e., childhood amnesia; see, for more information, McNally, 2003a), and (f) the base rate of the alleged type of abuse.

In conclusion, as scientific consensus over the validity of recovered memories is lacking, maintaining a case-specific focus is necessary in evaluating recovered memory reports. That is, several factors need to be taken into account when determining the credibility of these reports. Furthermore, relying on general models to discuss individual cases should be done in a cautious way (Alison et al., 2006), given the potential high impact consequences. For that reason, it should be desirable to have each case evaluated by an expert panel when a recovered memory enters the legal domain. Indeed, in the Netherlands, a Public Prosecutor ('Officier van Justitie') handling a recovered memory case nowadays has to present that case to an expert team known as the 'Landelijke Expertisegroep Bijzondere Zedenzaken' (LEBZ, see below).

\section{LANDELIJKE EXPERTISEGROEP BIJZONDERE ZEDENZAKEN}

As the case of Paul Ingram demonstrates, recovered memories can sometimes have consequences in a criminal or civil legal procedure. Importantly, this case shows that criminal charges based on recovered memories can "successfully" be brought against alleged abusers. Research employing mock trials, which will be summarized in more detail below, shows that in an adversarial context, jurors do not find the idea of trauma repression and recovery a priori impossible, although defense experts may 
help to balance their judgements (e.g., Buck \& Warren, 2010). Given the potential dramatic consequences of being abused or being wrongfully accused of abuse, it is crucially important that the criminal justice system is able to sort out recovered memory claims that are likely based on authentic events from those that are not. As noted above, in the Netherlands, allegations involving recovered memory claims are nearly always referred to the LEBZ. The task of the experts is to advise the Public Prosecutor on whether or not to pursue the criminal investigation, amongst other things. Below, we briefly describe how this expert team came into being.

In the 1980's, there was a strong increase in recovered memory claims resulting from therapeutic practices. At that time, the taboo surrounding CSA started to subside and victims were receiving increasingly more attention. The strong victim-oriented approach characterizing the judicial arena, in combination with the recovered memory debate fueling the academic world, often led to heated discussions between prosecution experts and defense experts (Nierop \& van den Eshof, 2010).

Hereupon, in 1999, the LEBZ was formed by the Board of General Prosecutors (in Dutch: College van Procureurs-Generaal). Regulations formulated by the Board are such that the LEBZ has to be consulted by the Public Prosecutor whenever one of the following circumstances emerges: (a) aspects of recovered memories of childhood abuse, (b) aspects of memories of childhood sexual abuse occurring before the age of three and, (c) aspects of ritual abuse (Nierop \& van den Eshof, 2008). Over the past decade, over 600 reports, of which a non-trivial proportion involved recovered memories, were evaluated by this expert team. More specifically, 22 reports ( $16 \% ; N=141$ ) involving aspects of recovered memories in the 2003-2007 period were analyzed. With respect to the 2008-2011 period, the LEBZ evaluated 213 cases of which 39 (18\%) involved "problematic memories" (i.e., statements involving aspects of recovered memories, statements involving sexual abuse events occurring more than 8 years prior to reporting the alleged crime to the police, and statements involving memories about sexual abuse occurring before the age of 3). Specifically, 17 reports ( $8 \%$ of the 213 cases) included aspects of recovered memories. These statistics might seem modest, but they show that recovered memory cases with serious legal complications still occur, even to this day.

As to the protocol, members of the LEBZ first individually study a case file. Next, the case is discussed within a plenary meeting in which all of the members report on the case on the basis of their own expertise. When all experts have put forward their perspective on the case, a final report is sent to the Public Prosecutor. Specifically, the reports of the LEBZ intend to advise the Public Prosecutor whether or not to pursue the criminal investigation and whether or not to prosecute the defendant (see, for more information on the LEBZ, Nierop \& van den Eshof, 2008).

On July 6, 2000, the Dutch minister of Health, Welfare, and Sports requested advice from the Health Council concerning the scientific status of therapies involving recovered memories of CSA (Gezondheidsraad, 2004). The Health Council responded 
to this request by summarizing important research findings and ultimately postulating several conclusions and guidelines (see, for a summary, Gezondheidsraad, 2004, pp. 19-24). A main focus was on the role of psychotherapy in reporting recovered memory experiences. The report of the Health Council described how the growing attention concerning childhood sexual abuse in the 1980's led therapists to become almost fixated on using these traumatic experiences as a way of explaining current psychological complaints. For example, a Dutch survey study (Höing, Van Engen, Ensink, Vennix, \& Vanwesenbeeck, 2003) investigating 'the modus operandus' in the treatment of CSA patients ( $N=190$ therapists) found that in approximately $80 \%$ of these cases, traumatic memories were addressed during the therapy sessions. In more than $50 \%$ of the cases, interventions attempted to recover traumatic memories. Guided imagery and body-related techniques were employed in approximately $35 \%$ of the cases, thereby constituting the most regularly used techniques. Dream interpretation and regression therapy were also frequently used techniques in everyday clinical practice. Reliance on suggestive therapeutic techniques in combination with the belief that the patient has latent traumatic memories might encourage the therapist to follow a risky course. These statistics indicate that the potential for suggestive maneuvers is rather substantial and that patients with recovered memories of CSA might still be present in the Dutch psychotherapeutic quarters. Nevertheless, only in rare cases, such memories led to a delayed reporting of the abuse to the police. Today, it is even rarer that the Public Prosecutor will decide to pursue a case on the basis of such memories. This probably has to do with the establishment of the LEBZ.

Recovered memories ending up in the legal arena are not always identifiable as such. Therefore, it may happen that a case file fails to reach the LEBZ. Expert witnesses consulted in such a case may then advise the Public Prosecutor to hand over the case to the LEBZ.

\section{THE ROLE OF THE EXPERT WITNESS}

Many difficulties arise in assessing the validity of any witness or victim account that contains recovered memory elements and surfaces as a piece of evidence in a court of law. Foremost, as stated before, recovered memories ending up in the legal arena are not always recognized as such. Only seldom, it is obvious from the start that eyewitnesses' or victims' reports involve recovered memories. Therefore, expert witnesses always have to consider the possibility of a recovered memory when they are asked to evaluate the reliability of a witness or victim testimony in a sexual abuse case (for more information, see Merckelbach et al., 2010). Other difficulties related to eyewitnesses' or victims' accounts include the identification of the process of remembering (i.e., how the plaintiff or the victim claims to have remembered the events), establishing the extent to which others (e.g., a therapist) may have shaped the account, and applying general research findings to specific cases (Alison et al., 2006). 
It is not only in criminal, but also in civil cases (e.g., request for financial compensation due to traumatic harm) that experts can be appointed by the judge to write a report about the validity of CSA memories. A professional expert witness should ideally be able to present several possible scenarios that can bear on the case at hand and weigh them against each other (but see Nierop, van den Eshof, \& Brandt, 2006). He or she should be able to provide a probability estimate of each scenario in terms of their correspondence to reality (Crombag \& Wagenaar, 2000; Rassin, 2001, 2010).

In order to write an informative report for the court, a couple of points need to be taken into account (see Merckelbach et al., 2010). Foremost, experts need to realize that a courtroom is very different from, for example, a clinical environment. That is, in a hospital, the most substantial mistake one can make is not to take notice of a latent disease (i.e., a false negative), whereas in criminal law, the most significant mistake would be to convict an innocent suspect (i.e., a false positive; Rassin \& Merckelbach, 1999). Secondly, explanations provided by an expert should always be scientifically founded. Though it might be tempting to endorse hypotheses that would sound plausible in a clinical conference, expert witness testimony calls for stricter standards (see Grove \& Loyd, 2006; Meehl, 1997). Thirdly, when in the case at hand, recovered memories are a distinct possibility, an expert should always investigate the context of recovery. For example, if suggestive therapeutic practices (e.g., hypnosis, dream interpretation, etc.) were involved, then the context may have contributed to false memories. Note that although potential interference from therapists should always be considered, it is neither a necessary nor a sufficient condition for false accounts to be produced (Alison et al., 2006, p. 424; Nierop \& van den Eshof, 2010). Fourth, as false memories can be experienced as very compelling by patients, experts should never rely on dogmatic assertions made by patients regarding their memory experiences. So, even though someone can come across as very persuasive, the expert nevertheless has to be cautious in drawing firm conclusions about the accuracy of the victim's allegations. Also, psychiatric diagnoses (e.g., Post Traumatic Stress Disorder; PTSD) can never be regarded as a fortiori evidence for the validity of the memories. That is, dramatic consequences (i.e., PTSD) are not necessarily the result of an authentic trauma history but can also be the outcome of a trauma brought up by a therapist (see, for evidence supporting the notion that merely believing that one has been traumatized may result in emotional responses similar to those provoked by the recollection of a genuine trauma, McNally et al., 2004).

Practical issues complicating the work to report on the validity of recovered memories involve the accessibility and extensiveness of the therapy files at hand. For example, the content of these files may not always shed proper light on the nature of the therapeutic treatment and is sometimes too confined to rule out the possibility that the therapist encouraged source confusion (i.e., evoked false memories).

The bottom line of this section is that the expert witness who is asked to evaluate cases in which recovered memories might play a role faces many potential difficulties. 
These difficulties can be reduced by research, implying that the ongoing scientific study of people who claim to have recovered a memory of a traumatic event is an important endeavor not only for academia, but also for the legal field.

\section{HOW JURORS PERCEIVE RECOVERED MEMORY TESTIMONY}

Despite the lack of definitional precision of core elements constituting recovered memory claims, recovered memory testimony may well be compelling to laypeople (Coleman, Stevens, \& Reeder, 2001). But just how compelling are recovered memory testimonies to jurors?

An important factor that is believed to influence the validity of recovered memory testimony is gender of the juror. Several studies (e.g., Griffith, 1999; Loftus, Weingardt, \& Hoffman, 1993) showed that female mock jurors are characterized by a tendency to respond more favourably (i.e., more sympathetic) than males toward recovered memory claims. This effect seems to be very robust as it has been documented across various ethnic backgrounds, different abuse contexts, and seems to be invariant to the victim's age (Golding, Sanchez, \& Sego, 1999; Golding, Sego, Sanchez, \& Hasemann, 1995).

Bornstein and Muller (2001) attempted to extend previous findings by exploring the effects of alleged victim and perpetrator gender on the impact of recovered memory testimony. The authors used a jury simulation design to assess how jurors perceive recovered memory cases. Specifically, participants were instructed to read a summary of a sexual abuse trial. Within this summary, three variables were manipulated: the complainant's gender, the defendant's gender, and whether the complainants' memory of the alleged events had been recovered or continuous (i.e., remembered all along). Participants were asked to come up with a verdict and rate the culpability and credibility of the parties. Results showed that recovered memory testimony led to lower perceived culpability and higher perceived credibility of the defendant compared to a continuous memory scenario. Moreover, the complainant reporting recovered memories was perceived as less likely to be telling the truth and thus less credible. The interaction with the complainants' and defendants' gender was found to moderate the results with the type of testimony (recovered versus continuous) only exerting an effect in cases of alleged heterosexual (but not homosexual) abuse.

In a recent study, Buck and Warren (2010) observed that the expert for the defense is more influential than the plaintiff's expert in cases involving recovered memories of CSA. More specifically, the presence of a defense expert led to fewer guilty verdicts and lower ratings of the likelihood of abuse, lower ratings of the plaintiff's credibility, and higher ratings of the defendant's credibility.

Taken together, recovered memory testimony may not be as compelling as previously assumed. Foremost, recovered memory testimony appears to be related to lower perceived credibility of the complainant. The complainant is also perceived as being less likely to tell the truth when claims are based on recovered memories. This 
effect appears to be moderated by the gender interaction between complainant and defendant: the effect was found only in case of alleged heterosexual abuse. Female jurors are believed to act more favourably towards recovered memory claims. Finally, experts of the defense party exert a greater influential role that the plaintiff's experts as their statements were shown to effectively reduce the number of pro-plaintiff verdicts and the plaintiff's credibility.

Again, the bottom line is that research on the origins, cognitive profiles, and types of recovered memories is important because triers of fact may profit from such research when they have to decide on relevant cases at hand.

\section{CONCLUDING REMARKS}

The intensity of the recovered memory debate has decreased over the past few years because people no longer seem to treat sexual abuse cases as if the process of remembering involves either complete fabrication or indisputable truth (Ost, 2010). Nowadays, researchers seem to have reconciled themselves with the idea that it is impossible to retrospectively prove the existence of prior amnesia (i.e., inaccessibility or unavailability of traumatic memories) in a person reporting recovered memories. It is now realized that the alleged mechanism of recovered memories does not lend itself to scholarly analysis and discussion because it is so disparately referred to (e.g., dissociative amnesia, massive repression, repression, psychogenic amnesia, etc.; see Piper et al., 2008). The validity of retrospective studies claiming to document amnesia was also clearly compromised, as experimental studies started to show that prolonged retrieval attempts could inflate judgments of amnesia, eventually undermining the specificity of episodic autobiographical memory (Belli, Winkielman, Read, Schwarz, \& Lynn, 1998; Read \& Lindsay, 2000; Van Oorsouw, 2006, pp. 73-81).

Partly because of the conceptual problems surrounding the key elements that constitute recovered memories, research is now mainly focused on exploring what mechanisms may underlie the impression of amnesia (i.e., alleged amnesia) typically reported by people with recovered memories (i.e., how alleged recovered memories occur and how they are perceived). The issue of which cognitive mechanisms underlie recovered memory experiences should therefore be separated from the question of whether or not it is possible to repress and later recover traumatic memories in the first place (Schooler, 1994). Another important shift in research attention involves the identification of different types of recovered memory experiences (for case vignettes suggestive of different recovered memory experiences, see Schooler et al., 1997a). However, as self-definition of recovered memories cannot be accepted at face value and clear-cut guidelines for how to classify recovered memory reports are generally lacking, the reliability of the current classification procedure can be considered questionable. Given the conceptual problems surrounding recovered memory claims as well as differing opinions on the matter, there is the danger that certain biases could contaminate results leading to an even greater confusion within the recovered mem- 
ory field. Thus, the identification of different types of recovered memory experiences seems an urgent matter but has scarcely been taken up by researchers. As recovered memory reports are only seldom straightforward and uncomplicated, it is expected that making clear-cut categorizations of such reports is a process rife with subjective judgments. Nevertheless, the reliability of such categorizations has never been tested empirically.

Finally, the accumulation of knowledge during the past decade might have led to the deflation of faulty assumptions about general memory functioning, and recovered memories in particular. Research shows that, at least until a few years ago, people tended to hold unrealistic assumptions about memory, which is suggested to contribute to the development of recovered memories (Lindsay \& Read, 1994; Loftus, 1993). It is important to explore whether wrong beliefs about memory are still present among people today. Indeed, a subsidiary aim of the present thesis will be to look at the base rate of recovered memory reports in undergraduates and to evaluate their beliefs about general memory functioning.

Taken together, a fairly new, important and exciting approach to the recovered memory debate involves the application of cognitive psychology methods to the field. These methods cannot determine whether recovered memories are true or not (Schooler, 1994) yet they can inform us about mechanisms underlying alleged repression and recovery processes as well as false memory development in people reporting recovered memories (McNally, 2003b). The identification and classification of recovered memory reports remains another important avenue for future research. Specifically, whether the presently applied classification approach turns out to be reliable warrants further examination.

\section{OUTLINE OF THE PRESENT DISSERTATION}

With these considerations in mind, the aim of the current dissertation is twofold, namely: (a) enhancing our understanding of the cognitive mechanisms underlying recovered memory experiences, and (b) examining whether the currently applied recovered memory classification procedure is reliable. Hence, besides the introductory chapter and a final discussion chapter, this thesis is composed of two main parts. Part 1 involves data about cognitive mechanisms underlying recovered CSA memories. It consists of three chapters in which methods of cognitive psychology are implemented to explore (the illusion of) forgetting in people reporting recovered memories. These chapters focus on autobiographical memory specificity (chapter 2 ), the susceptibility to develop false memories and underestimation of prior remembering (chapter 3 ), and underestimation of prior remembering in relation to source monitoring abilities (chapter 4).

Part 2 focuses on the occurrence of spontaneously recovered memory experiences and beliefs concerning trauma and memory in undergraduates (chapter 5) as well as the classification of recovered memory experiences (chapter 6). As already 
mentioned, this part mainly addresses conceptual and subjective problems. These problems are thought to be inherent to the definition of recovered memories, and potentially cause experimental pitfalls for research within the field. Finally, the appendix describes a revised interview method for classifying recovered memories that may inform future research. 



\section{PART I}

COGNITIVE MECHANISMS 



\section{CHAPTER 2}

AUTOBIOGRAPHICAL MEMORY SPECIFICITY

This chapter is an adapted version of:

Raymaekers, L., Smeets, T., Peters, M.J.V., \& Merckelbach, H. (2010). Autobiographical memory specificity among people with recovered memories of childhood sexual abuse. Journal of Behavior Therapy and Experimental Psychiatry, 41, 338-344. doi: 10.1016/j.jbtep.2010.03.004. 


\section{SUMMARY}

Individuals who report to have recovered memories of childhood sexual abuse (CSA) almost by definition believe that these memories were previously inaccessible to them. We examined whether poor autobiographical memory specificity for all kinds of events (i.e., events not necessarily related to CSA) may underlie such impressions of amnesia. Thus, we examined whether people who report recovered memories of CSA $(n=44)$ would exhibit more difficulty retrieving specific autobiographical memories compared to people who never forgot their abuse experiences (continuous memory group; $n=42$ ) and people without a history of abuse (controls; $n=26$ ). The standard Autobiographical Memory Test (AMT) was administered to these 3 groups along with measures of depression and posttraumatic stress disorder symptomatology. Controls were significantly better at retrieving specific autobiographical memories relative to individuals with continuous and recovered CSA memories, who did not differ from each other. Thus, reduced autobiographical memory specificity was not particularly pronounced in people with recovered memories of CSA. Poor autobiographical memory specificity is unlikely to explain the impression of amnesia reported by this group.

\section{INTRODUCTION}

While conducting a study on mood-congruent memory in suicidal patients, Williams and Broadbent (1986) accidentally discovered that many of their participants tended to produce overgeneral autobiographical memories. An individual is said to have such overgeneral memories if he/she experiences difficulties in retrieving specific autobiographical memories, i.e., memories of personally experienced events happening at a particular place and lasting less than a day (i.e., specific autobiographical memories; Williams \& Broadbent, 1986). Research addressing this phenomenon is important because the relative inability to retrieve specific autobiographical memories has been found to be associated with a poor problem-solving ability in clinical patients (e.g., Pollock \& Williams, 2001; Sutherland \& Bryant, 2008), poor ability to imagine future events (for review, see Williams et al., 1996), and poor long-term outcome in clinically depressed patients (e.g., Peeters, Wessel, Merckelbach, \& Boon-Vermeeren, 2002).

Many clinicians have suggested that a history of trauma, particularly during childhood, leads to changes in memory functioning (e.g., Van der Kolk \& Van der Hart, 1995). These changes are believed to serve a protective role in that they reduce the emotional impact associated with traumatic experiences. According to Williams (1996), poor autobiographical memory specificity would also serve a regulatory function. The idea here is that retrieving autobiographical memories in a less specific way minimizes their negative connotations. Traumatized individuals experiencing this would therefore adopt a less specific retrieval style (see for further details Raes, Hermans, de Decker, Eelen, \& Williams, 2003). 
Empirical support for the idea that trauma history is critical for poor autobiographical memory specificity is, however, mixed. Indeed, there appears to be no consistent relationship between trauma exposure and a less specific retrieval style, implying that a mere history of trauma is not a sufficient condition for this style (e.g., McNally, Litz, Prassas, Shin, \& Weathers, 1994; McNally, Lasko, Macklin, \& Pitman, 1995). Rather, psychopathological symptoms often associated with a trauma history (e.g., posttraumatic stress disorder, depression) appear to be the driving force behind this phenomenon (for review, see Moore \& Zoellner, 2007; see also Kleim \& Ehlers, 2008). For example, McNally and colleagues (1994) observed reduced autobiographical memory specificity in Vietnam combat veterans with posttraumatic stress disorder (PTSD) relative to well-adjusted veterans without PTSD (for similar results in people suffering from acute stress disorder see Harvey, Bryant, \& Dang, 1998). Another study by McNally et al. (1995) on veterans with PTSD further supports this link. Additionally, studies have documented a relationship between a less specific autobiographical retrieval style and depression (e.g., Wessel, Meeren, Peeters, Arntz, \& Merckelbach, 2001).

One particular group that has received only little research attention when it comes to autobiographical memory specificity is the group of patients who say they have recovered memories of childhood sexual abuse (CSA). According to Schooler (1999; p. 205), "An individual who reports recovering a memory for trauma is really indicating two sentiments: (a) that abuse occurred and (b) that there was a period of time in which the memory was not available." It is interesting to speculate about the second part of Schooler's definition. More specifically, the question arises why people have the sentiment that autobiographical details are not available to them, i.e., why they have an impression of amnesia (Loftus, Joslyn, \& Polage, 1998).

Some authors have speculated that a less specific retrieval style may underlie the subjective experience of amnesia typically reported by people who recover CSA memories (e.g., Dalenberg, 1996; Rassin, Merckelbach, \& Muris, 2000). To the best of our knowledge, only one study has looked at autobiographical memory specificity in people with recovered memories (McNally et al., 2006). McNally and colleagues tested people without a history of abuse and people with continuous memories, recovered memories or repressed memories of CSA. The people with recovered memories reported to have recovered long-forgotten memories of CSA, while the repressed group consisted of adults who believed they had been sexually abused during childhood, but had no memories of CSA. Although McNally et al. (2006) did not find a clear-cut pattern of a less specific retrieval style in their groups, there were indications that the repressed group tended to experience the greatest difficulty in retrieving specific memories.

Using the Autobiographical Memory Test (AMT; Williams \& Broadbent, 1986), we examined to what extent people reporting continuous memories of CSA, people with recovered CSA memories, and controls experience difficulties retrieving specific memories from their past. We tested the idea that people reporting recovered CSA 
memories would display a less specific retrieval style relative to the other two groups. Finding such a pattern could account for the impression of amnesia that people with recovered memories have.

\section{METHOD}

\section{Participants}

We recruited individuals with a history of CSA through advertisements in local newspapers. The advertisements invited people to participate in our research when they had a history of CSA that had never been forgotten or had recovered memories of being sexually abused as a child. CSA was defined as the presence of "hand/mouth to genital" and "genital to genital" contact imposed upon the victim before the age of 18 People who thought to qualify for one of these groups were invited to come to our lab. In order to control for issues such as childhood sexual curiosity, only individuals who reported a reasonable age gap between themselves and the perpetrator(s) at time of the events, were included. Controls were recruited by means of internet advertisements and flyers distributed in several public places. The study was approved by the standing ethical committee of the Faculty of Psychology and Neuroscience, Maastricht University.

Based on a semi-structured memory interview (e.g., Geraerts et al., 2009), participants were assigned to one of the three groups: (a) the continuous memory group consisting of participants who stated that they had never forgotten about their abuse $(n=42)$, (b) the recovered memory group consisting of people who claimed there was a period in their life in which they apparently had no memory for the abuse $(n=44)$. This group entailed both participants who claimed that they had spontaneously recalled CSA memories outside a therapeutic context $(n=28)$ and participants who stated that they had gradually recovered their memories of abuse during treatment, provoked by therapeutic techniques or as a result of actively attempting to reconstruct the 'empty holes' in their memory $(n=16)$, and finally (c) the control group consisting of participants who reported no history of abuse in either childhood or adulthood $(n=$ 26). Participants that could not be properly classified into one of the three groups due to a mixed profile, were excluded from the study $(n=8)$. An example of a mixed profile would be someone who is reporting continuous memories for event $A$ (e.g., abuse by an uncle) in combination with recovered memories for event B (e.g., abuse by the father). Importantly, given that we were interested in whether reduced autobiographical memory specificity might account for the impression of amnesia reported by people with recovered memories, we examined whether our participants had a history of traumatic brain injury that might provide an organic reason for the amnesia (see McNally, 2005). None of the participants with recovered CSA memories reported to have experienced traumatic brain injury in the past. 
During the semi-structured memory interview, people were inquired about the nature and duration of their CSA experiences. We explored whether our CSA groups differed in terms of self-reported age at onset and ending of their abuse. In case of multiple CSA experiences (i.e., different abusive experiences caused by different perpetrators starting at different ages), we decided to focus on the self-reported beginning and ending of the first (earliest) CSA experience reported.

Twelve percent of the people in the continuous group, $11 \%$ of the people in the spontaneously recovered memory group, and $0 \%$ of the people in the recovered in therapy group failed to provide information about the age at onset of the abuse. Moreover, $14 \%$ of the people in the continuous group, $11 \%$ of the people in the spontaneously recovered memory group, and $19 \%$ of the people in the recovered in therapy group failed to provide information about how old they were when the abuse ended. Mean ages at beginning of the first CSA experience in people reporting continuous memories, spontaneously recovered memories, and memories recovered in therapy were 8.5 years $(S D=3.7)$, 9 years $(S D=3.4)$, and 6.2 years $(S D=3.8)$, respectively. Mean ages at ending of the first CSA experience in people reporting continuous memories, spontaneously recovered memories, and memories recovered in therapy were 13.8 years $(S D=4.6), 12.5$ years $(S D=3.8)$, and 8.2 years $(S D=4.6)$, respectively. A borderline significant group effect was found with respect to the age at onset of CSA, $F(2,75)^{1}=3.01, p=0.06, \eta_{p}{ }^{2}=0.07$. Post-hoc analyses (LSD) showed that people with in therapy recovered memories of abuse differed from people with continuous and spontaneously recovered memories of abuse (all $p s<0.05$ ). No significant difference between people with continuous and spontaneously recovered memories of abuse was found $(p=0.60)$.

With respect to the age at the ending of the CSA, a significant effect of group was found, $F(2,73)^{1}=8.09, p<0.001, \eta_{p}{ }^{2}=0.18$. Post-hoc analyses (LSD) showed that people with in therapy recovered memories of abuse differed from people with continuous and people with spontaneously recovered memories of abuse (all $p s<0.01$ ). No significant difference between people with continuous and spontaneously recovered memories of abuse was found $(p=0.24)$.

The final sample consisted of 112 participants: 42 (30 women) in the continuous memory group (mean age $=47.5$ years, $S D=1.7), 44$ (32 women) in the recovered memory group (mean age $=48.7$ years, $S D=1.6$ ), and 26 (18 women) in the control group (mean age $=43.2$ years, $S D=2.9$ ). There were no significant age differences between the groups, $F(2,109)=1.84, p=0.16$. Neither were there significant differences with respect to education level between the groups, $F(2,109)=0.02, p=0.98$.

\footnotetext{
${ }^{1}$ Due to missing values, these degrees of freedom fluctuate and deviate from the total subsample of continuous and recovered memories.
} 
Furthermore, there were no group differences in the proportion of women, $\chi^{2}(2)=$ $0.10, p=0.95$.

\section{Materials}

The Autobiographical Memory Test (AMT)

The AMT requires participants to retrieve a specific personal memory in response to positive and negative cue words (e.g., happy, lonely). We used a Dutch version (Wessel et al., 2001) of the AMT (Williams \& Broadbent, 1986). This version consists of 10 emotional cue words, five of them being positive cue words (happy, satisfied, safe, successful, interested) and five of them being negative cue words (lonely, hurt, grief, rejected, awful). Each cue word appeared in capital letters on a separate $10 \times 25 \mathrm{~cm}$ card, and was additionally read aloud by the experimenter. Positive and negative cue words were presented in an alternated fashion. A stopwatch was activated as soon as the experimenter showed the word to the participant. Participants were allowed one minute to respond. The trial was ended whenever a participant came up with a specific memory or until one minute elapsed. Response times were recorded.

A specific memory was defined as the recollection of an event from one's life pertaining to a certain context and taking place within one day (Williams \& Broadbent, 1986). Despite the instruction to recollect specific memories, some participants tend to come up with overgeneral memory responses. Such responses can involve categorical responses referring to groups of events sharing common elements (e.g., "When I go dancing") or extended responses comprising events lasting longer than one day (e.g., "My holiday to Spain last year"; for more examples, see Williams \& Broadbent, 1986).

Indices of memory specificity vary across studies. Some studies focus on the generality rate - often collapsing across general categorical and general extended memories - whereas others focus on the specificity rate. Given that these two measures are often not functionally equivalent, it is difficult to directly compare data from different studies (e.g., van Vreeswijk \& de Wilde, 2004). Nevertheless, these two measures are often used interchangeably in the literature (e.g., Moore \& Zoellner, 2007). In the current study, we primarily focused on the number of specific autobiographical memory responses because this appears to be the most widely used measure of autobiographical memory specificity (e.g., Moore \& Zoellner, 2007). For sake of completeness, rates of omissions (i.e., when a participant failed to respond), other responses (also known in the literature as 'no-memory responses'; e.g., associations, a definition of the word, etc.), and same event descriptions (referring to an event or experience that was already described in response to another cue word) are also reported. Additionally, overgeneral memory responses are reported. A memory was categorized as overgeneral when it referred to a series of repeated events (categoric) or to an event that lasted longer than a day (extended; see for example Sutherland \& Bryant, 2007). 
Our main analyses focussed on the mean number of specific autobiographical memories with the results pertaining to the initial responses to the cue words. All responses were audio taped and later scored by the first author. A subset of 40 cases was additionally scored by a second independent rater to assess interrater reliability of the scoring procedure. This was done by calculating intra-class correlation coefficients (ICCs; Shrout \& Fleis, 1979). ICCs ranged from 0.76 (lonely) to 0.98 (happy). For the total number of specific memories, a high level of agreement between the judges was observed: $\mathrm{ICC}=0.88$.

\section{Beck Depression Inventory (BDI)}

The BDI (Beck, Ward, Mendelson, Mock, \& Erbaugh, 1961) is a 21-item questionnaire addressing current depressive symptoms (i.e., from the previous week). Its four-choice statements describe depressive symptoms in increasing severity (scored 0-3; range 063). Participants were asked to mark the statements that described best how they felt the previous week. The psychometrically sound properties of the BDI have been documented extensively (e.g., Beck, Steer, \& Garbin, 1988).

Posttraumatic stress disorder Symptom Scale - Self Report (PSS-SR)

The PSS-SR (Foa, Riggs, Dancu, \& Rothbaum, 1993) is a 17-item questionnaire describing PTSD symptoms corresponding to the DSM-IV. These symptoms are rated on a 4point severity scale $(0=$ not at all; $3=$ almost always; range $0-51)$. The sum of these ratings yields a PTSD symptom severity score. Wohlfarth, van den Brink, Winkel, and ter Smitten (2003) provide data as to the satisfactory psychometric properties of the PSS-SR.

\section{Procedure}

All participants gave informed consent and were tested individually. They first filled out the BDI and the PSS-SR. Note that as the PSS-SR deals with reactions to traumatic experiences, it would be inappropriate to interpret the data from control participants. Therefore, the PSS-SR data from the control participants will not be addressed further here. As to the AMT, participants were told that they would be given 10 cue words. They were asked to retrieve a specific personal memory in response to each word and were told that they would have one minute for each response. Participants were explicitly instructed that a specific memory referred to a personally experienced event that happened within a particular time frame and context (i.e., within a day; Williams \& Broadbent, 1986) and the experimenter provided examples of memories that would and would not qualify as a specific autobiographical memory. In order to familiarize participants with the task, they were then given practice trials with neutral cue words (e.g., car) and received feedback on their performance. We proceeded with the AMT proper after participants had succeeded in retrieving at least three specific memories during the practice trial. 


\section{Design and analyses}

AMT scores were subjected to a 3 (Group: continuous memory, recovered memory, control) $\times 2$ (Valence: positive, negative) Analysis of Variance (ANOVA), with the latter factor being a repeated measurement. Moreover, we conducted one-way ANOVAs to evaluate group differences in BDI and PSS-SR scores. Furthermore, correlations were calculated to examine the associations between the number of specific autobiographical memories and measures of depression (BDI) and PTSD (PSS-SR). Additional explorative analyses were conducted focusing on AMT scores of people with different types of recovered memories (i.e., spontaneously recovered vs. recovered in therapy). We also looked at the content of the specific AMT responses reported by our participants. Specific autobiographical memories relating to events occurring before age 18 were classified as childhood related specific memories, whereas specific autobiographical memories relating to events occurring after age 18 were classified as adulthood related memories. If specific autobiographical memories pertained to events related to the subject's history of CSA, they were classified as trauma related, whereas responses referring to events not related to the subject's CSA history were classified as nontrauma related memories.

\section{RESULTS}

\section{Number of specific memories retrieved}

The current study focuses on the ability to retrieve specific autobiographical memories. If a person retrieved a specific personal memory within one minute, its response was coded as specific. Table 1 shows mean number of specific memories retrieved on the AMT for each group. The ANOVA revealed main effects of Group, $F(2,109)=4.09$, $p<0.05, \eta_{p}{ }^{2}=0.07$, and Valence, $F(1,109)=4.78, p<0.05, \eta_{p}{ }^{2}=0.04$. The interaction between Group and Valence fell short of significance, $F(2,109)=1.92, p=0.15$.

Post-hoc analyses (LSD) indicated that the control group retrieved more specific autobiographical memories than did the continuous memory group and the recovered memory group, (both $p s<0.05$ ). The continuous and the recovered memory group did not differ in terms of autobiographical memory specificity.

Omissions, same event, other responses, and overgeneral memories

If a person failed to retrieve a specific personal memory within the given time frame, his/her response was coded as (a) 'omission' in case (s)he failed to respond, (b) 'same events' when (s)he reported events or experiences that were already described in response to another cue word, (c) 'other responses' when participants reported associations, a definition of a word, etc., and (d) 'overgeneral' in case the response referred to groups of events sharing common elements or events lasting longer than one day. For these other AMT parameters, results can be summarized as follows (see also Table 1). With respect to omissions and same events reported, no main effects of Valence 
could be observed, $F(1,109)=0.35, p=0.56$ and $F(1,109)=0.88, p=0.35$, respectively. Neither were there main effects of Group, $F(2,109)=0.69, p=0.50$ and $F(2$, $109)=0.92, p=0.40$, respectively. Furthermore, there were no significant interaction effects between Group and Valence, $F(2,109)=0.13, p=0.88$ and $F(2,109)=0.26, p=$ 0.78 , for omissions and same events, respectively.

With respect to the other responses category, we found main effects of Valence $F(1,109)=24.63, p<0.001, \eta_{p}^{2}=0.18$ and $\operatorname{Group} F(2,109)=3.66, p<0.05, \eta_{p}{ }^{2}=0.06$. Moreover, a significant interaction effect between Group and Valence $F(2,109)=3.31$, $p<0.05, \eta_{p}{ }^{2}=0.06$ was found. For positive cue words, a significant effect of Group was observed, $F(2,109)=3.92, p<0.05, \eta_{p}^{2}=0.07$. Post-hoc analyses (LSD) of group differences for positive cue words revealed that controls reported significantly less 'other responses' than people with recovered memories $(p<0.01)$ and they tended to report less such responses than people with continuous memories $(p=0.06)$. For negative cue words, no significant effect of Group was found, $F(2,109)=1.20, p=0.31$.

For the overgeneral memories, a significant main effect of Valence was found, $F(1$, 109) $=24.94, p<0.001, \eta_{p}{ }^{2}=0.17$ in the absence of a main effect of Group $F(2,109)=$ $2.23, p=0.11$ or a Group by Valence interaction, $F(2,109)=0.23, p=0.80$. Overgeneral memories were more prevalent in response to negative cue words compared to positive cue words $(p<0.05)$.

\section{TABLE 1}

Mean AMT scores and mean questionnaire scores for controls and participants reporting continuous CSA memories and recovered CSA memories. Standard deviations are given between parentheses.

\begin{tabular}{|c|c|c|c|}
\hline & $\begin{array}{l}\text { Controls } \\
(n=26)\end{array}$ & $\begin{array}{l}\text { Continuous group } \\
(n=42)\end{array}$ & $\begin{array}{l}\text { Recovered group } \\
(n=44)\end{array}$ \\
\hline Specific memories total & $5.58(2.51)$ & $3.79(2.38)$ & $4.07(2.86)$ \\
\hline Positive specific memories & $3.12(1.36)$ & $1.98(1.45)$ & $2.05(1.40)$ \\
\hline Negative specific memories & $2.46(1.50)$ & $1.81(1.27)$ & $2.02(1.72)$ \\
\hline Omissions & $0.35(0.74)$ & $0.48(0.77)$ & $0.30(0.66)$ \\
\hline Other response & $0.35(0.68)$ & $0.93(1.40)$ & $1.34(1.80)$ \\
\hline Same event & $0.23(0.58)$ & $0.14(0.52)$ & $0.32(0.67)$ \\
\hline Overgeneral memories & $3.50(2.12)$ & $4.64(2.13)$ & $4.05(2.32)$ \\
\hline$B D I$ & $8.52(8.99)$ & $13.63(7.91)$ & $14.31(12.41)$ \\
\hline PSS-SR & $N A$ & $18.51(12.49)$ & $14.71(12.68)$ \\
\hline
\end{tabular}

Notes. BDI, Beck Depression Inventory; PSS-SR, Post Traumatic Stress Disorder Symptom Scale, N.A. = not assessed. 
Response latency

An ANOVA performed on latency data (i.e., reaction times) yielded a main effect of Valence $F(1,109)=6.25, p<0.05, \eta_{p}{ }^{2}=0.06$. Overall, participants tended to respond slower to positive cues than to negative cues, $t(111)=1.77, p=0.07$. However, no main effect of Group was apparent, $F(2,109)=0.14, p=0.87$. Moreover and critically, no significant interaction effect between Valence and Group could be observed, $F(2$, 109) $=0.24, p=0.79$.

\section{Depressive and PTSD symptoms}

Table 1 also shows mean BDI and PSS-SR scores for each group. A one-way ANOVA revealed a borderline significant difference between the three groups for depressive symptoms, $F(2,104)=2.8, p=0.06$. Post-hoc analyses (LSD) indicated that the control group reported less depressive symptoms than did the continuous $(p=0.05)$ and recovered memory groups $(p<0.05)$. No differences were observed between the continuous and the recovered memory group in terms of depressive symptom reporting ( $p$ $=0.76)$. Similarly, no differences were observed between the continuous and the recovered memory group in terms of PTSD symptom reporting $(p=0.15)$.

\section{Correlational analyses}

For the continuous and recovered memory group together, the Pearson correlation between BDI scores and PSS-SR score was significant, $r(81)=0.67, p<0.001$. Given that five participants (three belonging to the continuous and two belonging to the recovered memory group) failed to complete both questionnaires, the current analysis pertained to a subsample of 81 participants (instead of 86).

For each group, Pearson correlation coefficients were computed between the number of specific memories to positive and negative cue words and PSS-SR and BDI scores. All correlations failed to reach conventional levels of significance (all $r s<0.34$; ps $>0.09$ ). In the subsample of people reporting recovered CSA memories, Pearson correlations between negative specific autobiographical memories, on the one hand, and depressive symptoms and PTSD symptoms, on the other hand, were $r(43)=0.26, p$ $=0.09$ and $r(43)=0.16, p=0.31$, respectively. With respect to positive specific autobiographical memories recalled by this group, Pearson correlations with depressive symptoms and PTSD symptoms were $r(43)=0.05, p=0.73$ and $r(43)=0.06, p=0.71$, respectively.

\section{Additional explorative analyses}

Explorative analyses were conducted in which we took the two different types of recovered memories into account: people with spontaneously recovered memories of abuse $(n=28)$ and people who recovered their abuse memories within a therapeutic context $(n=16)$. Thus, AMT scores were subjected to 4 (group: continuous memory, spontaneously recovered memory, therapy induced recovered memory, control) $\times 2$ 
(cue valence: positive, negative) ANOVAs, with repeated measurement on the second factor.

Table 2 shows mean AMT and questionnaire scores for each group. With respect to autobiographical memory specificity, we found, again, main effects of Group, $F(3$, $108)=2.72, p=0.05, \eta_{p}^{2}=0.07$, and Valence, $F(1,108)=3.93, p=0.05, \eta_{p}^{2}=0.04$. Importantly, no significant interaction between Group and Valence emerged $F(3,108)$ $=2.13, p=0.10$. Post-hoc analyses (LSD) revealed that the control group retrieved more specific memories than did the continuous memory group ( $p<0.05$, Cohen's $d=$ $0.73)$, the spontaneously recovered memory group $(p<0.05$, Cohen's $d=0.54)$, and the in therapy recovered memory group ( $p<0.05$, Cohen's $d=0.59$ ). The three CSA groups did not differ in terms of specificity (all $p s>0.50$ ).

A main effect of Group was observed for 'other responses' $F(3,108)=2.69, p=$ $0.05, \eta_{p}{ }^{2}=0.07$ and same event responses $F(3,108)=2.95, p=0.04, \eta_{p}{ }^{2}=0.08$. Posthoc analyses (LSD) of group differences for each of the two measures revealed that the spontaneously recovered memory group reported more 'other responses' than the controls ( $p<0.05$, Cohen's $d=0.81)$, the continuous memory group $(p<0.05$, Cohen's $d=0.34)$, and the in therapy recovered memory group ( $p<0.05$, Cohen's $d=0.25$ ). Also, people reporting in therapy recovered memories retrieved more same event memory responses relative to controls ( $p<0.05$, Cohen's $d=0.54)$, people with continuous memories ( $p<0.05$, Cohen's $d=0.68$ ), and people with spontaneously recovered memories ( $p<0.05$, Cohen's $d=0.70)$.

A main effect of Valence was found with respect to overgeneral memories, $F(1$, $108)=22.92, p<0.001, \eta_{p}{ }^{2}=0.18$. Again, overgeneral memories were more common in response to negative cue words than in response to positive ones $(p<0.05)$. No other main effects were apparent. Furthermore, no significant interaction effects could be observed.

Additional explorative analyses with respect to the content of the specific AMT responses yielded no significant group differences. That is, with respect to the mean percentage of specific memories related to childhood experiences, no significant group differences were found, $F(2,83)=0.36, p=0.70, \eta_{p}{ }^{2}=0.01$. Moreover, no significant group differences were found with respect to the mean percentage of specific trauma (CSA) related memories reported, $F(2,83)=0.30, p=0.74, \eta_{p}^{2}=0.01$. 
TABLE 2

Mean AMT scores and mean questionnaire scores for people reporting spontaneously recovered memories and people who recovered their memories during the course of therapy. Standard deviations are given between parentheses.

\begin{tabular}{lcc}
\hline & $\begin{array}{l}\text { Spontaneously recovered group } \\
(n=28)\end{array}$ & $\begin{array}{l}\text { Recovered in therapy group } \\
(n=16)\end{array}$ \\
\hline Specific memories total & $4.14(2.82)$ & $3.94(3.02)$ \\
\multicolumn{1}{c}{ Positive specific memories } & $1.96(1.29)$ & $2.19(1.60)$ \\
$\quad$ Negative specific memories & $2.18(1.76)$ & $1.75(1.65)$ \\
Omissions & $0.25(.64)$ & $0.38(0.72)$ \\
Other response & $1.50(1.90)$ & $1.06(1.65)$ \\
Same event & $0.14(0.45)$ & $0.63(0.88)$ \\
Overgeneral memories & $4.07(2.45)$ & $4.00(2.16)$ \\
BDI & $14.96(13.66)$ & $13.00(9.80)$ \\
PSS-SR & $13.89(12.30)$ & $16.36(13.74)$ \\
\hline
\end{tabular}

Notes. BDI, Beck Depression Inventory; PSS-SR, Post Traumatic Stress Disorder Symptom Scale.

\section{DISCUSSION}

We tested whether people who recovered CSA memories exhibit a less specific retrieval style compared to people who never forgot their abuse experiences (continuous memory group) and people without a history of abuse (controls). Based on the speculation that a lack of memory specificity underlies the subjective experience of amnesia typically reported by recovered memory patients, we hypothesized that people with recovered memories would show reduced autobiographical memory specificity relative to people with continuous memories and controls.

The main results can be summarized as follows. To begin with, people reporting CSA memories - whether continuous or recovered - showed reduced autobiographical memory specificity relative to controls. No significant differences were observed in terms of autobiographical memory specificity between people reporting continuous memories of abuse and people with recovered abuse memories. Thus, the present findings suggest that reduced autobiographical memory specificity is not by itself characteristic for people with recovered memories of CSA. We also examined whether autobiographical memory specificity differed between people who recovered memories within a therapeutic context and those who recovered memories outside a therapeutic context (i.e., spontaneously recovered memories). Our data, however, indicate that this was not the case. 
We failed to observe a significant difference in memory specificity between the continuous memory group and the recovered memory group, which opposes the idea that recovered memories in general are more likely to occur when an individual has great difficulty retrieving specific autobiographical memories. Some authors (Dalenberg, 1996; Rassin et al., 2000) have speculated that lack of memory specificity underlies the subjective experience of amnesia that is typical for recovered memory patients in general and those who recovered memory in therapy in particular. We therefore expected that particularly people with CSA memories recovered in therapy would exhibit a less specific retrieval style relative to the other three groups. Yet, our data clearly show that reduced memory specificity is not a unique characteristic for this particular group. That is, all three groups reporting a history of CSA showed significantly reduced memory specificity rates compared to controls.

By and large, our data replicate previous findings of McNally et al. (2006), who showed that controls provide more specific autobiographical memories than do the continuous, the repressed, and recovered memory groups. Furthermore, our results support recent findings showing that people reporting a history of CSA are less specific than non-abused controls in response to general (but not concrete) retrieval cues (Hauer, Wessel, Geraerts, Merckelbach, \& Dalgleish, 2008).

It is tempting to interpret the results of the current study along the lines of the socalled affect regulation hypothesis (Williams, Stiles, \& Shapiro, 1999; Raes et al., 2003; Kleim \& Ehlers, 2008). According to this hypothesis, individuals with a trauma history attempt to avoid remembering specific details of their childhood in order to reduce trauma-related distress. This avoidance behavior is thought to exert its influence not only on the recollection of trauma memories, but also on other, non-traumatic autobiographical memories, resulting in an overall reduced autobiographical memory specificity (for an overview see Williams et al., 2007). Note, however, that the current study did not seek to systematically parse out the presence of psychopathology from trauma exposure. Therefore, the interpretation that a history of trauma exposure alone is critical for poor autobiographical memory specificity remains speculative.

The finding that our groups with CSA memories showed a less specific retrieval style seems consistent with the emphasis that some scholars place on trauma history as an antecedent of reduced autobiographical memory specificity. Since Williams' (1996) initial theory highlighting trauma history as the dominant path to reduced specificity, his view has been echoed by many researchers (e.g., Hermans et al., 2004; Kuyken \& Brewin, 1995). Even though our data at first sight seem to support this view, it is vital to note that reporting a history of CSA does not necessarily imply that the trauma really did happen. The point here is, of course, that the accuracy of recovered memories has been fiercely debated in the literature (e.g., Loftus \& Davis, 2006; McNally, 2003a; McNally \& Geraerts, 2009). Thus, the possibility that at least some people in our therapy group - and perhaps also in our other CSA groups - claim to have experienced CSA, while in fact they did not have such background, should be taken 
into account. These people might nevertheless ruminate about their CSA memories and this may deplete resources needed to retrieve specific autobiographical memories (e.g., Watkins \& Teasdale, 2001; Williams, 1996; Williams et al., 2007). Thus, although traumatic memories may be incorrect, they may be very real in their consequences, a point also nicely illustrated by a study of McNally and co-workers (McNally et al., 2004), who showed that the traumatic memories of people who claim to have been abducted by UFO's are accompanied by a psychophysiological reaction pattern than is typical for patients with PTSD.

The question remains how the impression of amnesia that is almost by definition part of memory recovery can be understood. One possibility is that this impression is not so much carried by a less specific retrieval style, but paradoxically by highly successful retrieval of a series of childhood events. For example, during therapy, patients are often asked to recall various childhood events. Some might attribute the difficulty related to successful retrieval to amnesia. Ultimately, the more events they recall, the more often poorer memory will be inferred. There is indeed some experimental evidence that repetitively talking and thinking about one's past might induce an impression of amnesia (Merckelbach, Wiers, Horselenberg, \& Wessel, 2001; Winkielman, Schwarz, \& Belli, 1998). Clearly, this issue warrants further research within the context of recovered memories.

As to the limitations of the current study, it should be mentioned that no corroboration for the current trauma reports was sought, making it impossible to report on the authenticity of these experiences. Also, our in therapy recovered memory subgroup was smaller than the other groups. There are several reasons for this asymmetry. For example, participants who recovered their abuse memories during the course of therapy might be more reluctant to apply for studies on recovered memories because of the increasing knowledge about suggestive therapeutic routes to recovery and the scepticism it arouses. Fortunately, memory recovery due to suggestive therapeutic influences is apparently on the decline (e.g., McHugh, Lief, Freyd, \& Fetkewicz, 2004). Hence, memory recovery in a therapeutic context might be occurring less frequently than spontaneous memory recovery. Additionally, we only focussed on the presence of a history of childhood sexual abuse in our experimental groups and thus did not explicitly check for the presence of all other forms of trauma exposure. One might also speculate whether the use of direct instead of general retrieval cues may have eliminated the differences in specificity between our controls and CSA groups. That is, Hauer et al. (2008) showed that while people reporting a history of CSA were less specific than non-abused controls in response to generative retrieval cues (i.e., retrieval process relying on iterative retrieval cycles through a hierarchical memory system; example of a cue word is 'hurt'), this difference disappeared when using direct retrieval cues (i.e., retrieval process relying on close associations between retrieval cues and specific memory representations; example of a cue word is 'funeral'). Thus, whereas the standard version of the AMT uses words that are believed to elicit rela- 
tively generative memory retrieval, a concrete word-version of the AMT specifically designed to promote relatively direct retrieval of memories (e.g., Conway \& PleydellPearce, 2000) eliminates the difference in memory specificity between CSA patients and controls. In addition, while a recent study by Crane and Duggan (2009) showed that an earlier age of CSA onset is associated with lowered memory specificity, age of CSA onset was only asked in a global manner in the present study, making it difficult to systematically look at the link between early CSA onset and memory specificity. Also, the exact time range for the period of amnesia reported by our recovered memory participants was not recorded. It is well-known that autobiographical memories of events that happened before the age of three are almost never recalled, a phenomenon known as childhood amnesia (e.g., Eacott \& Crawley, 1998). Thus, amnesia for CSA occurring at very young age would be expected. Future studies should take these considerations into account when investigating memory specificity in samples who report CSA by, for example, excluding participants whose claims of recovered memories may have been related to childhood amnesia and/or examining whether the time range of the reported amnesia is related to the later recovery of CSA memories.

In sum, the present study demonstrates that people reporting a history of CSA show reduced autobiographical memory specificity compared to people reporting no history of abuse, but we found no evidence that reduced memory specificity is particularly pronounced in people with (in therapy) recovered memories. Our data thus seem to be at odds with the idea that reduced memory specificity is likely to explain the impression of amnesia that frequently occurs within this group. However, large systematic studies are needed to replicate this. Examining what might account for the subjective impression of amnesia experienced by people reporting recovered memories of abuse still remains a promising though challenging avenue for future research. 



\section{CHAPTER 3}

UNDERESTIMATION OF PRIOR REMEMBERING AND

SUSCEPTIBILITY TO FALSE MEMORIES

This chapter is an adapted version of:

Raymaekers, L., Peters, M.J.V., Smeets, T., Abidi, L., \& Merckelbach, H. (2011). Underestimation of prior remembering and susceptibility to false memories: Two sides of the same coin? Consciousness and Cognition, 20, 1144-1153. doi: 10.1016/j.concog. 2010.12.010. 


\section{SUMMARY}

In two studies, we explored whether susceptibility to false memories and the underestimation of prior memories (i.e., Forgot-lt-All-Along effect) tap overlapping memory phenomena. Study 1 investigated this issue by administering the Deese-RoedigerMcDermott task (DRM) and the Forgot-It-All-Along (FIA) task to an undergraduate sample $(N=110)$. It was furthermore explored how performances on these tasks correlate with clinically relevant traits such as fantasy proneness, dissociative experiences, and cognitive efficiency. Results show that FIA and DRM performances are relatively independent from each other, suggesting that these measures empirically refer to separate dimensions. However, they do not seem to define different profiles in terms of dissociation, fantasy proneness, and cognitive efficiency. Study 2 replicated the finding of relative independence between false memory propensity (as measured with the DRM task) and the underestimation of prior memories (as measured with an autobiographical memory dating task) in people with a history of childhood sexual abuse ( $N$ $=35$ ).

\section{INTRODUCTION}

Significant life experiences tend to be well remembered. Some people, however, report that they have had the experience of forgetting and subsequently recovering memories of aversive life events. Since the 1980's, many studies have focused on mechanisms that may underlie such recovery of autobiographical memories. Recovered memories refer to autobiographical recollections that are perceived as having been unavailable or inaccessible for some period of time (Sivers, Schooler, \& Freyd, 2002). According to Schooler (1999; p. 205), "An individual who reports recovering a memory for trauma is really indicating two sentiments: (a) that the abuse occurred and (b) that there was a period of time in which the memory was not available."

Schooler and colleagues were among the first to publish systematic case studies of individuals reporting to have experienced the discovery of long-forgotten memories of abuse (Schooler, Ambadar, \& Bendiksen, 1997a; Schooler, 2001; Shobe \& Schooler, 2001). They observed that some people reporting recovered trauma memories had mentioned these experiences to their partner, family or friends before the "recovery" of the abuse episodes (Schooler et al., 1997a). It appeared that these individuals forgot having remembered the traumatic event, producing an "illusion of amnesia". Schooler (1999) hypothesized that this underestimation of prior remembering could explain how people may come to believe that they previously forgot an important episode, a phenomenon that he termed the "Forgot-It-All-Along" (FIA) effect.

With this in mind, Merckelbach et al. (2006) examined the existence of this effect for autobiographical details in different samples (see also a recent study by Abenavoli \& Henkel, 2009, for a similar procedure). Merckelbach and colleagues instructed undergraduate participants and women with childhood sexual abuse (CSA) experiences 
to recall vivid memories of certain childhood events. After a delay of one hour or two days, participants were asked whether they had recently thought about any of these events and several others. Despite having recalled the events either an hour or two days before, many participants claimed not to have thought about these events for years. Relative to individuals reporting continuous CSA memories, those who reported having recovered CSA memories were more likely to forget remembering the recent events during the laboratory tasks. This finding provides indirect support for Schooler's (1999) idea that the FIA bias is typical for at least some individuals reporting recovered memories of CSA.

Another line of research examining memory performance of people reporting recovered CSA memories demonstrates that this group exhibits a heightened vulnerability to develop false memories. A case in point is a study by Clancy, Schacter, McNally, and Pitman (2000) that relied on the Deese-Roediger-McDermott (DRM) task (Deese, 1959; Roediger \& McDermott, 1995). Basically, this task has been shown to be effective in eliciting laboratory induced false memories for semantically related words by requiring participants to study a list of words, all of which are strong associates of a non-presented critical lure. For example, participants are instructed to study words such as injection, sharp, pain, thread, words that are all associated with the nonpresented critical item needle. Typically, many participants falsely recall and recognize the non-presented lures on later tests (Roediger, Watson, McDermott, \& Gallo, 2001). Clancy, Schacter, McNally, and Pitman (2000) found that individuals reporting recovered CSA memories more often falsely recognize the non-presented critical lures relative to individuals with continuous CSA memories and control participants with no history of sexual abuse.

The pronounced false memory effects on the DRM and the enhanced forgetting of prior remembering in people reporting recovered memories seem to indicate different routes to recovered memory reports. Clinical vignettes are also suggestive of distinct types of recovered memory experiences (Schooler et al., 1997a; see also McNally \& Geraerts, 2009). Thus, on the one hand, there are persons who gradually came to believe that they are abuse survivors. They typically attribute current problems to their repressed memories of abuse. The abuse events were mostly recovered step by step, often promoted by suggestive therapeutic techniques such as hypnosis, dream interpretation or guided imagery. It is tempting to assume that these people exhibit a heightened susceptibility to false memories. Another pathway seems evident in people who are suddenly reminded of events and mistakenly believe they have not thought about the events for many years. They experience their recollection as shocking and often describe it as an "Aha-Erlebnis". Here, it is plausible that individuals have a tendency to overlook prior remembering, i.e., are susceptible to the FIA effect rather than to false memories (see for example McNally \& Geraerts, 2009).

Geraerts et al. (2009) suggest that the FIA account offers a mechanism to explain recovered memory experiences involving events that actually did occur, whereas the 
DRM account offers a mechanism to explain false recovered memories. However, whether susceptibility to false memories and the FIA effect reflect two different and unrelated pathways has not yet been firmly established. Furthermore, the question arises whether susceptibility to false memories and FIA effect go along with different personality characteristics. If it could be shown that susceptibility to false memories and FIA are unrelated phenomena that have their own distinct personality correlates, this would underpin the clinical impression that there are two different pathways to "recovering" memories.

A number of studies have looked at whether certain personality traits contribute to susceptibility to false memories. Many of them examined the links between fantasy proneness (i.e., an extensive involvement in fantasy, vivid imagery, and daydreaming), dissociative symptoms, (e.g., derealisation, depersonalization, identity confusion), and false memories in undergraduate samples. For example, Jelicic and co-workers (2006) found a link between the creation of memories of a non-existent film and fantasy proneness as measured by the Creative Experiences Questionnaire (CEQ; Merckelbach, Horselenberg, \& Muris, 2001). That is, participants who reported false details (i.e., memories of the non-existent film) scored significantly higher on the CEQ relative to those who did not report such details. Furthermore, positive associations between false memories and traits closely related to fantasy proneness (e.g., absorption and creative imagination) have been observed with other paradigms (Drivdahl \& Zaragoza, 2001; Hyman \& Billings, 1998).

In addition to studies focussing on the link between false memories and fantasy proneness, researchers have attempted to relate false memories to dissociative symptoms. For example, Clancy and co-workers (2000) found a significant correlation between performance on the DES and DRM false recognition in people reporting continuous and recovered memories of CSA. Similarly, Dehon, Bastin, and Larøi (2008) reported that scores on the Dissociative Experiences Scale (DES questionnaire; Bernstein \& Putnam, 1986) were positively associated with increased DRM false recall rates in undergraduates. In another study using a misinformation paradigm in undergraduate students, Hyman and Billings (1998) reported a positive association between false memories and dissociative experiences, and suggested that habitual dissociation may facilitate the acceptance of external information as self-defining, thereby increasing the likelihood to accept falsely suggested events as autobiographical memories. Using a variety of stimulus materials (e.g., video footage, slides), work of Giesbrecht and colleagues (Giesbrecht, Geraerts, \& Merckelbach, 2007; Merckelbach, Zeles, van Bergen, \& Giesbrecht, 2007; see also Candel, Merckelbach, \& Kuijpers, 2003) also showed that there is a robust connection between dissociative symptoms and false memories (i.e., memory commission errors) in undergraduates. A link between false memory development and certain individual differences has also been documented in clinical samples. For example, Peters, Horselenberg, Jelicic, and Merckelbach (2007) showed 
that people with previous-life memories (i.e., memories of highly unlikely events) report elevated levels of dissociation.

Like dissociation, poor cognitive efficiency (i.e., reporting many cognitive failures) has been associated with memory dysfunctions (Merckelbach, Muris, Nijman, \& De Jong, 1996). Though research on individual differences and the FIA effect is rather scarce, one could speculate that people showing a large FIA effect will also score high on measures of cognitive failures (i.e., everyday lapses in attention, memory and perception, e.g., Broadbent, Cooper, Fitzgerald, \& Parkes, 1982). One widely used measure of cognitive efficiency is the Cognitive Failures Questionnaire (CFQ; Broadbent et al., 1982) in which cognitive efficiency is approached in terms of susceptibility to cognitive failures. Wilhelm, Witthöft, and Schipolowski (2010) identified three factors underlying CFQ scores that were labeled 'retrieval' (e.g., "Are you unable to remember something that you had been told some time ago?"), 'intention forgotten' (e.g., "Do you find you forget what you came to the shops to buy?"), and 'clumsiness' (e.g., 'Do you bump into objects?'). Given that the overall content of the CFQ seems to have much in common with the type of failure that occurs in the FIA effect, one would predict them to covary.

We investigated (a) whether the FIA effect (i.e., the underestimation of prior remembering) and susceptibility to false memories are relatively independent from each other. We investigated this issue in an undergraduate sample (Study 1) and in a sample consisting of people with a history of childhood sexual abuse (Study 2). Moreover, we examined (b) whether these memory illusions are related to different individual difference measures (Study 1). We hypothesized that the FIA and DRM effects would be unrelated to each other in the student as well as in the trauma sample. We also expected that these measures would be related to different individual difference measures. Specifically, we tested whether the susceptibility to false memories is particularly related to heightened levels of self-reported dissociation and fantasy proneness. On the other hand, susceptibility to underestimate prior memories was predicted to be particularly related to cognitive failures (Study 2 ).

To avoid potential confounding factors (e.g., depression, motivational variables), we started with a non-clinical undergraduate sample to examine the relation between false memory propensity and the susceptibility to underestimate prior memories. One might argue, though, that results found in an undergraduate sample cannot be generalized to results in people with a trauma history. Particularly, differences in mean education level, mean age, and potential psychopathology between student samples and trauma samples could lower the generalizability of the findings. In study 2, we therefore examined the relation between false memory propensity and susceptibility to the FIA effect in people with a history of childhood sexual abuse. To increase ecological validity, we used an autobiographical memory dating task which can be viewed as an autobiographical version of the FIA task described above (Parks, 1999). 


\section{METHOD}

\section{Participants}

One hundred and ten psychology undergraduates (92 women) with a mean age of 19.8 years $(S D=2.76)$ participated in exchange for course credit. All participants were first year students at Maastricht University. The study was approved by the Standing Ethical Committee of the Faculty of Psychology and Neuroscience, Maastricht University.

\section{Materials}

Forgot-It-All-Along (FIA) task

During an initial study phase, participants studied a list of 100 homographic target words, each accompanied by a context word that "biased" the interpretation of the target (e.g., hand-palm; see Arnold \& Lindsay, 2002; 2005). Both context and target word appeared on a computer screen for two seconds and participants were instructed to repeat the word pairs out loud in order to prepare themselves for an upcoming memory test. Immediately after the presentation of each word pair, a study sentence appeared on the screen to ensure that people fully understood the context of each target item. The study sentence contained the context word and a row of asterisks representing the target word (e.g., "She was holding the pen in the **** of her hand"). The study sentences appeared on the screen for three and a half seconds during which participants were required to read them aloud.

In Test 1 (immediately following the study phase), participants were tested for a subset (approximately two thirds) of the words presented during the study phase, with some of the target items being cued with the same context word as initially studied (i.e., "studied-context" words; e.g., hand-p**m), while the remaining items were cued with a new context word that was different from the one studied during the study phase and selected to bias the interpretation of the target item towards its other meaning (i.e., "other-context" words; e.g., tree-p**m). Context words were always presented together with the first and the last letter of the target words, and participants were instructed to fill in the missing letters and verbalize the words so that the experimenter could write down their responses. Participants were instructed that on half of the trials they would receive the same context word as originally studied during the study phase, while on the other half of the trials they would receive a context word different from the one initially studied but one that was nevertheless related to the targets. Participants were told they should only respond with targets that they remembered studying during the study phase. The purpose of introducing other context items is to imitate a situation in which a person recollects a past experience in a quali- 
tatively different context from that in which it was originally encoded (for a detailed description, see Arnold \& Lindsay, 2002; 2005).

During Test 2 (immediately following Test 1), participants were subjected to a final memory test in which they were tested for all items studied during the initial study phase. Importantly, participants' memory for the original target words was always tested with the original studied-context cues, directing their recall efforts back to the original encoding experience at study, and not to the intervening test phase (Test 1). In order to measure people's susceptibility to forgetting prior instances of remembering, participants had to make a judgment immediately after recalling each of the target items on the final test (Test 2). Specifically, they were asked the crucial question: "Did you or did you not correctly recall this particular target item during Test 1 , irrespective of being primed with a studied or another context word?" The basic finding with this paradigm is that people more often forget/underestimate their prior recollection of the words on Test 1 when cued with an "other-context" word than when cued with a "studied-context" word. Thus, when people remember the experience in a different context on the previous test, they are more likely to believe that the recall on the final test is completely new and that they had not previously recalled it.

\section{Deese-Roediger-McDermott (DRM) paradigm}

In this paradigm, participants are asked to study lists of words, all of which are strong associates of a non-presented item termed 'the critical lure'. Individual differences in false recall and/or recognition of the critical lures on later memory tests are thought to reflect variability in proneness to false memories (Roediger \& McDermott, 1995). In the current study, 10 neutral word lists containing 15 words each derived from a larger set of lists previously employed in our lab (Peters, Jelicic, Haas, \& Merckelbach, 2006) were used. Participants were instructed to study each orally presented word list after which they were given two minutes to recall as many words as possible from the study phase. Finally, a recognition task was administered that included 30 studied words (i.e., these words were obtained by selecting the $1^{\text {st }}, 8^{\text {th }}$, and $10^{\text {th }}$ word of each studied list) and the 10 critical lures.

\section{The Dissociative Experiences Scale (DES)}

The DES (Bernstein \& Putnam, 1986) is a 28-item self-report measure (Cronbach's alpha $=0.81$ ) that asks respondents how often they experience dissociative symptoms like derealization or depersonalization. Items are scored on $100 \mathrm{~mm}$ Visual Analogue Scales (VASs) representing the degree to which they apply to them (anchors: $0=$ not at all; $100=$ very much). A total DES score (range: $0-100$ ) is obtained by averaging across individual items, with higher scores indicating stronger dissociative tendencies. 
The Creative Experiences Questionnaire (CEQ)

The CEQ (Merckelbach et al., 2001) is a measure (Cronbach's alpha $=0.69$ ) based on Wilson and Barber's (1983) listing of fantasy proneness characteristics. It includes 25 dichotomous (yes/no) items that cover experiences related to daydreaming, imagination, and fantasy. The number of yes-answers is summed to obtain a total CEQ score (range: 0-25), with higher total CEQ scores indicating higher levels of fantasy proneness.

The Cognitive Failures Questionnaire (CFQ)

The CFQ (Broadbent et al., 1982) is a 25-item self-report instrument (Cronbach's alpha $=0.84$ ) measuring the frequency of everyday cognitive failures and minor lapses (e.g., "Do you sometimes forget what you just read?"). Participants indicate on a 5-point scale (anchors: $0=$ never; 4 = very often) how often they have experienced each cognitive failure in the past couple of months. Scores are summed to obtain a total CFQ score (range: 0-100) with higher scores indicating poorer cognitive efficiency.

\section{Procedure}

After having provided informed consent, participants were given instructions and stimulus materials. Presentation order of the DRM and FIA task were counterbalanced such that half of the participants performed the DRM task, completed the three questionnaires, and then carried out the FIA task, while the other half started with the FIA task, then completed the questionnaires, and ended with the DRM task.

\section{RESULTS}

\section{FIA performance}

Recall performance. The proportion of correctly recalled words on Test 1 was significantly higher for items cued with studied-context words $(M=0.69)$ than for items cued with other-context words $(M=0.52), t(109)=37.77, p<0.001$. An ANOVA was performed on the proportion correctly recalled items on Test 2 , with context during Test 1 (studied-context, other-context and studied but non-tested context) as repeated measure. There was a significant difference in proportion of items recalled for the studied-context $(M=0.88)$, other-context $(M=0.82)$, and non-tested $(M=0.84)$ conditions, $F(2,218)=38.94, p<0.001, \eta_{p}{ }^{2}=0.26$. The recall rate was relatively high regardless of whether participants had previously recalled the target from a studied- or an other-context cue on Test 1.

Judgment of previous recollection. The proportion of items judged on Test 2 as recalled on Test 1 is shown in Table 1. An ANOVA was performed on the proportion correct judgments, with context as the repeated measure. Overall, participants were significantly more likely to forget that they had recalled an item on Test 1 when they had been cued with the other-context word on Test 1 than when it had been cued with 
the studied-context word, $F(1,109)=208.26, p<0.001, \eta_{p}{ }^{2}=0.66$. Thus, context did affect whether or not participants correctly reported that they had recalled the item on Test 1 . More specifically, participants were significantly less likely to correctly judge that they had recalled the item before in the other-context condition than in the studied-context condition. Replicating prior work (e.g., Arnold \& Lindsay, 2002, 2005), our findings demonstrate an increased tendency to forget prior incidents of remembering when retrieval contexts change between retrieval attempts (i.e., the FIA effect).

TABLE 1

Mean number of items and mean proportion of items judged as "recalled" as a function of recall status on Test 1 and Test 2 in an undergraduate sample (Study 1). Standard deviations are given between parentheses.

\begin{tabular}{lcc}
\hline Test1/Test 2 recall status & No. of items & $\begin{array}{c}\text { Proportion judged as } \\
\text { "recalled" on Test } 1\end{array}$ \\
\hline Not recalled/not recalled & Studied-context & \\
Not recalled/recalled & $3.69(3.16)$ & $0.05(0.19)$ \\
Recalled/recalled & $6.78(2.53)$ & $0.09(0.20)$ \\
Recalled/not recalled & $\mathbf{2 3 . 1 1 ( 4 . 3 9 )}$ & $\mathbf{0 . 8 7}(0.12)$ \\
\hline & $0.41(0.63)$ & $0.10(0.29)$ \\
Not recalled/not recalled & Other-context & $0.06(0.15)$ \\
Not recalled/recalled & $4.55(2.89)$ & $0.13(0.16)$ \\
Recalled/recalled & $11.82(2.82)$ & $\mathbf{0 . 6 0}(\mathbf{0 . 1 9})$ \\
Recalled/not recalled & $\mathbf{1 6 . 0 7 ( 3 . 5 4 )}$ & $0.33(0.41)$ \\
\hline NA/not recalled & $1.55(1.20)$ & $0.14(0.13)$ \\
\hline
\end{tabular}

\section{$D R M$ recall and recognition performance}

Table 2 shows the means for correct recall and recognition (i.e., proportion recalled/recognized studied words), and false recall and recognition of critical lures (i.e., proportion recalled/recognized critical lures). On average, participants correctly recalled $0.66(S D=0.09)$ of the studied words and falsely recalled $0.38(S D=0.22)$ of the non-studied critical lures. For the recognition memory, on average, participants correctly recognised $0.81(S D=0.13)$ of the studied words and falsely recognised 0.77 (SD $=0.22$ ) of the non-studied critical lures. These results are in line with the robust false recall and recognition effects typically found with the DRM paradigm (Roediger \& McDermott, 1995). 


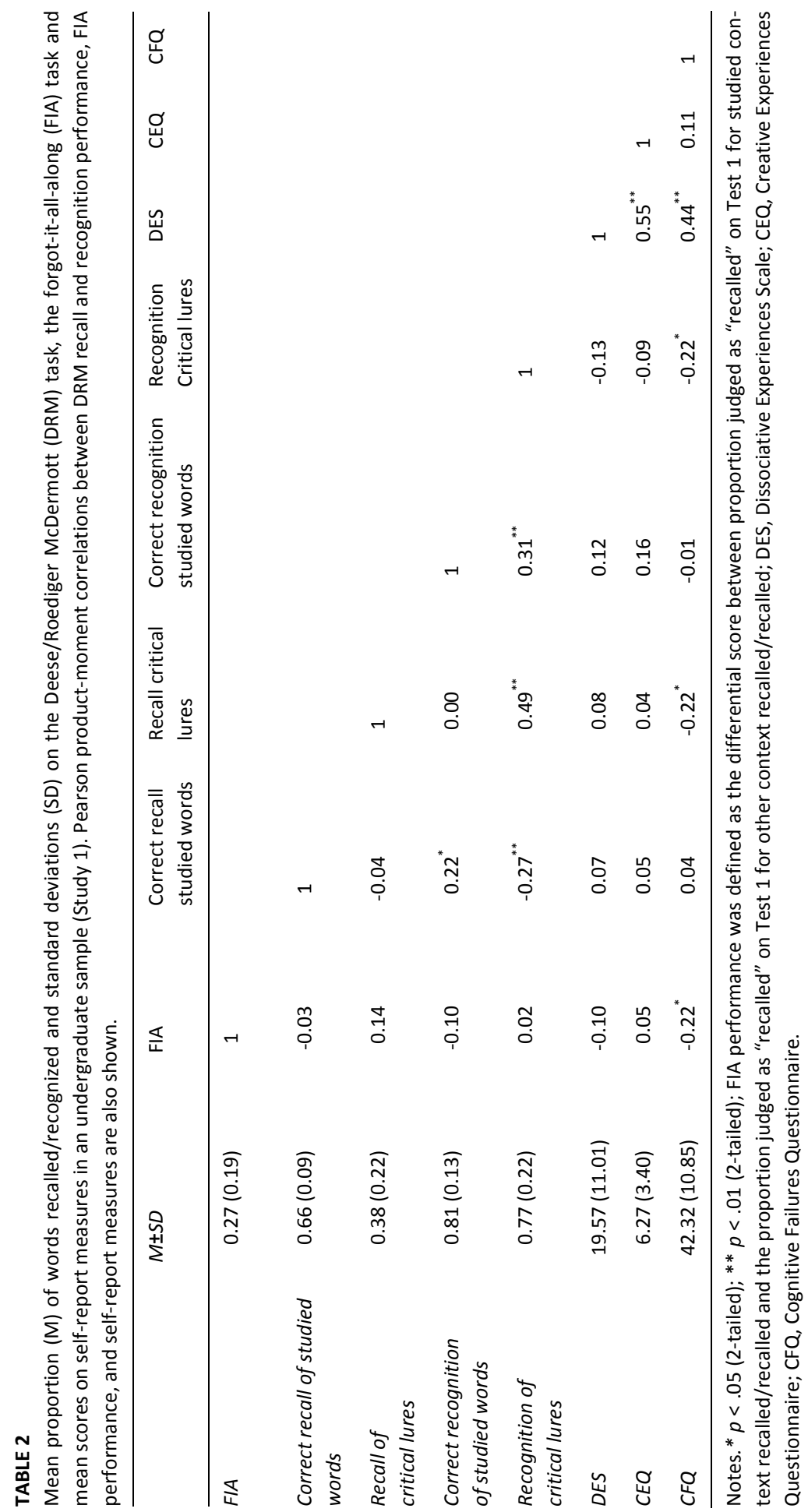




\section{Correlational analyses}

Table 2 shows mean scores and standard deviations on the DES, the CEQ, and the CFQ. As can be seen, mean scores of participants on self-report measures were similar to those found in previous studies (e.g., Merckelbach et al., 1996; Merckelbach, Muris, \& Rassin, 1999). Table 2 also shows Pearson product-moment correlations between the FIA effect, DRM recall and recognition performance, dissociative experiences, fantasy proneness, and cognitive efficiency. FIA performance was defined as the differential score between correct recall during Test 2 when previously being cued with a studied context word (T1) versus when previously being cued with an other-context word (T1; see Arnold \& Lindsay 2002, 2005). We found no significant correlation between FIA effect and DRM false recall ( $r=0.14, p=0.16)$. Nor did the correlation between FIA and DRM false recognition attain significance $(r=0.02, p=0.86)$. Though unrelated to one another, both DRM false recall as well as FIA correlated significantly with CFQ scores. More specifically, significant correlations between CFQ scores and both false recall and false recognition ( $r=-0.21, p<0.05$ and $r=-0.22, p<0.05$, respectively) and between CFQ scores and FIA effect $(r=-0.22, p<0.05)$ were found. Thus, in contrast to what we predicted, high levels of cognitive failures were associated with reduced susceptibility to false memories and weaker FIA effects, although the correlations were by all standards modest.

Not surprisingly, DRM false recall was significantly associated with false recognition performance $(r=0.49, p<0.001)$. DES scores were significantly correlated with CEQ $(r=0.55, p<0.001)$ and CFQ $(r=0.44, p<0.001)$ scores. All other correlations failed to reach conventional levels of significance.

We furthermore looked at the correlations between the FIA effect, DRM correct recall, DRM correct recognition, DES, CEQ, and CFQ scores (Table 2). As is to be expected, correct recall on the DRM task correlated significantly with correct recognition on the DRM task $r=0.22, p<0.05$. Moreover, DRM correct recall was negatively correlated with false recognition of the critical lures $(r=-0.27, p<0.01)$, while, correct recognition on the DRM task was significantly correlated with false recognition of the critical lures $(r=0.31, p<0.01)$. All other correlations failed to reach conventional levels of significance (see Table 2 ).

\section{STUDY 2}

Study 1 showed that the FIA effect was unrelated to DRM false recall and false recognition performance in an undergraduate sample. In study 2 , we sought to replicate the relative independence between the FIA effect and false memory propensity for words by administering an autobiographical memory dating task (Parks, 1999) and DRM task to a sample consisting of people with a history of CSA. We chose to use an autobiographical memory dating task (see also Merckelbach et al., 2006) instead of the standard FIA task (Arnold \& Lindsay, 2002) to increase ecological validity. 


\section{METHOD}

\section{Participants}

Thirty-five (30 women) individuals with a mean age of 44.14 years $(S D=9.15$ ) participated in exchange for a small financial reimbursement. As part of an ongoing research project, participants were recruited by means of advertisements in local newspapers. The advertisements invited people to participate in our research when they had a history of childhood sexual abuse (CSA) that was never forgotten (i.e., people with continuous memories of CSA). CSA was defined as the presence of "hand/mouth to genital" and "genital to genital" contact imposed upon a victim before the age of 18 . To check whether participants had experienced their CSA history as traumatic, we asked them to rate the traumatic impact of their CSA on an 8-point Likert scale with 1 referring to a very low traumatic impact and 8 referring to a very high traumatic impact. On average, participants rated the traumatic impact of their CSA history as 7.21 $(S D=1.41)$. Eighteen $(51 \%)$ participants reported no other history of abuse, $6(17 \%)$ participants reported a history of CSA in addition to emotional abuse, 1 (3\%) reported a history of CSA in addition to physical abuse/violence, 4 (11\%) participants reported a history of CSA in addition to emotional and physical abuse/violence, 3 (9\%) participants reported a history of CSA in addition to emotional abuse and neglect, and 3 (9\%) reported a history of CSA in addition to emotional and physical abuse/violence and neglect. In order to control for issues such as childhood sexual curiosity, only individuals who reported a reasonable age gap between themselves and the perpetrator(s) at time of the events, were included. The study was approved by the Standing Ethical Committee of the Faculty of Psychology and Neuroscience, Maastricht University.

\section{Materials}

\section{Autobiographical memory dating task}

To examine participants' ability to recall prior remembering, we used an autobiographical memory dating task that was originally developed by Parks (1999). In this task, participants first completed a 23-item 'yes-no' questionnaire about specific childhood events or facts (questionnaire 1). The items were either drawn from the Parks task (1999) or formulated along the lines of his items (e.g., "Do you have vivid memories of the first time you went to a funeral?"; see Merckelbach et al., 2006). Participants were instructed to think for 3 seconds about each item, before indicating whether they had or had no vivid memories about these events. Hereafter, they filled out some unrelated questionnaires that served as a filler task. After an interval of one hour, participants completed a second autobiographical questionnaire (questionnaire 2). This questionnaire consisted of 18 items of which nine were drawn from the first questionnaire (i.e., target items) and nine items pertained to not previously mentioned items (i.e., control items). The target items were described in exactly the same way as 
in the first questionnaire though listed in a different order. For target as well as control items, participants were instructed to indicate 'to their best estimate' the time they recalled 'even if it was only briefly' the events or facts described by the items. The following response scale was presented to the participants: $0=$ one hour or less ago; 1 = several days ago; 2 = several weeks ago; 3 = several months ago; 4 = about a year ago; 5 = several years ago. They were instructed to give an estimate even when they felt an item did not apply to them (but see below).

DRM paradigm

As in study 1, the DRM paradigm was used to measure susceptibility to false memories for words. Participants were instructed to study 5 orally presented word lists consisting of 10 words each. After presentation of each list, they were given one minute to recall as many words as possible. Participants were presented with 5 neutral word lists derived from a larger set of lists previously employed in our lab (Peters et al., 2006). Finally, a recognition task was administered that included 15 studied words (i.e., these words were obtained by selecting the $1^{\text {st }}, 8^{\text {th }}$, and $10^{\text {th }}$ word of each studied list) and the 5 critical lures.

\section{Procedure}

After having provided informed consent, participants were given instructions and stimulus materials. Presentation order of the DRM and autobiographical FIA task was counterbalanced.

\section{Design and analyses}

Analyses were restricted to those target items for which the participants claimed to have vivid memories (i.e., yes-responses on questionnaire 1). In other words, items referring to events that did not happen to participants or for which participants did not have vivid memories were excluded from the analyses.

One way to evaluate memory dating performance is to calculate mean dating estimates that participants gave to their vivid memories. Another way to look at the data is to focus on participants who gave at least one correct estimate (i.e., response = 0 ), but also made dating errors for other vivid memories (see for a similar approach, Parks, 1999 and Merckelbach et al., 2006).

\section{RESULTS}

\section{Autobiographical memory dating performance}

We analyzed the number of vivid memories, the proportion correct recall in time for vivid target items, the mean time estimate of the vivid target items, and how often participants gave at least one correct recall and had one or more dating errors (this 
latter variable indicates that participants followed the instructions but nevertheless made errors).

Overall, participants said to have vivid memories for $5.17(S D=1.64)$ of the 9 target items. The proportion of vivid memories that were correctly dated (i.e., items that were given a rating of 0$)$ was $0.36(S D=0.39)$. Mean dating estimate ${ }^{2}$ was $2.14(S D=$ 1.73). Note that correct dating performance corresponds to a 0 on the $0-5$ scale (see materials). A mean dating estimate of 2.14 reflects a mean response of "around several weeks ago", illustrating that participants underestimated their prior memories. Seven participants (20\%) had a mean estimate of "about a year ago" or longer. Twenty-one (60\%) participants had at least one accurate estimate in combination with one or more dating errors.

\section{$D R M$ recall and recognition performance}

Table 3 shows the mean proportion recalled/recognized studied words, and the mean proportion falsely recalled/recognized critical lures. On average, participants correctly recalled $0.55(S D=0.14)$ of the studied words and falsely recalled $0.86(S D=0.15)$ of the non-studied critical lures. With regard to DRM recognition performance, participants on average correctly recognised $0.83(S D=0.14)$ of the studied words and falsely recognised $0.90(S D=0.15)$ of the non-studied critical lures.

\section{Correlational analyses}

Table 3 shows Pearson product-moment correlations between the autobiographical FIA effect and DRM recall and recognition performance. With regard to the autobiographical FIA effect, we examined performance on the autobiographical memory dating task focussing on the mean dating estimates. DRM parameters were defined in the same way as in study 1 . We found no significant correlation between mean dating estimate (FIA) and DRM false recall ( $r=0.21, p=0.25)$, nor did the correlation between mean dating estimate (FIA) and DRM false recognition attain significance $(r=0.06, p=$ $0.73)$.

We furthermore calculated the correlations between the autobiographical FIA effect, DRM correct recall and DRM correct recognition (see also Table 3). As is to be expected, correct recall on the DRM task correlated significantly with correct recognition on the DRM task $(r=0.55, p<0.01)$. Moreover, DRM correct recall was negatively correlated with false recognition of the critical lures $(r=-0.50, p<0.01)$. All other correlations were non-significant.

\footnotetext{
${ }^{2}$ We also looked at performance on the autobiographical memory dating task (Parks, 1999) in a small number $(n=12$ ) of people reporting recovered memories of CSA (see chapter 4 ).
} 
TABLE 3

Mean (M) proportion of words recalled/recognized and standard deviations (SD) on the Deese/Roediger McDermott (DRM) task and an autobiographical forgot-it-all-along (FIA) task (Parks, 1999) in a sample of people with a history of childhood sexual abuse (Study 2). Pearson product-moment correlations between DRM recall performance, DRM recognition performance, and autobiographical FIA performance are also shown.

\begin{tabular}{lllllll}
\hline & $M(S D)$ & $\begin{array}{l}\text { FIA } \\
\text { mean } \\
\text { dating } \\
\text { estimate }\end{array}$ & $\begin{array}{l}\text { Correct } \\
\text { recall } \\
\text { studied } \\
\text { words }\end{array}$ & $\begin{array}{l}\text { Recall } \\
\text { critical } \\
\text { lures }\end{array}$ & $\begin{array}{l}\text { Correct } \\
\text { recognition } \\
\text { studied } \\
\text { words }\end{array}$ & $\begin{array}{l}\text { Recognition } \\
\text { critical } \\
\text { lures }\end{array}$ \\
\hline FIA mean dating estimate & $2.14(1.73)$ & 1 & & & \\
Correct recall of studied words & $0.53(0.12)$ & -0.11 & 1 & & \\
Recall of critical lures & $0.88(0.15)$ & 0.21 & 0.33 & 1 & \\
Correct recognition of studied words & $0.81(0.16)$ & -0.17 & $0.55^{* *}$ & 0.15 & 1 \\
Recognition of critical lures & $0.94(0.11)$ & 0.06 & $-0.50^{* *}$ & -0.01 & -0.25 & 1 \\
\hline
\end{tabular}

Notes. $^{*} p<.05$ (2-tailed); ${ }^{* *} p<.01$ (2-tailed); FIA performance was defined as the differential score between proportion judged as "recalled" on Test 1 for studied context recalled/recalled and the proportion judged as "recalled" on Test 1 for other context recalled/recalled.

\section{GENERAL DISCUSSION}

The aim of the current studies was to examine to what extent susceptibility to false memories is related to the tendency to underestimate prior remembering in an undergraduate sample (Study 1) and a sample of people with a history of childhood sexual abuse (Study 2). We also wanted to explore whether these memory illusions were differentially associated with dissociative experiences, fantasy proneness, and cognitive efficiency (Study 1 ).

The main findings of the current studies can be summarized as follows. Firstly, in studies 1 and 2, the standard DRM false recall and recognition effects and the FIA effect were found. That is, participants showed a tendency to falsely recall and recognize the non-presented critical lure words. They also were less likely to correctly judge that they had recalled an item in the other-context condition than in the studied-context condition (as measured with the FIA task, see Arnold \& Lindsay, 2002, 2005; Study 1) or came up with inaccurate estimates when they were asked to date recent recalls of vivid childhood memories (as measured with an autobiographical memory dating task, see Parks, 1999; Study 2). Secondly, these FIA effects were unrelated to DRM false recall and false recognition performance (Study 1 and 2). Thus, FIA and DRM measures seem to index relatively independent memory illusions. Thirdly, study 1 showed that both FIA and DRM measures correlated significantly with cognitive efficiency: the less cognitive failures participants reported, the stronger they exhibited FIA and DRM effects, although the associations were by all standards modest. Fourthly, no correlations between FIA and DRM on the one hand, and dissociative symptoms (i.e., DES) 
and fantasy proneness (i.e., CEQ) on the other, were found. With respect to the interrelations between the personality traits, DES was found to correlate significantly with CEQ and CFQ scores, a pattern that has also been found in previous studies (see for example Merckelbach et al., 1999).

Clinical case vignettes suggest that qualitatively different memory illusions may underlie recovered memory reports. Thus, in the literature, recovered memory cases have been interpreted in terms of a heightened susceptibility to false memories but also in terms of a tendency to underestimate prior recall (e.g., Clancy et al., 2000; Loftus \& Davis, 2006; Merckelbach et al., 2006; Schooler, 1999). We found that, whether a participant shows a strong or subtle false memory effect is largely independent of the size of the FIA effect in that participant. Thus, our data indicate that we are, indeed, dealing with two different constructs. Meanwhile, they also imply that the two memory illusions are not orthogonal. There is no reason to assume that those who are susceptible to false memories as indexed by DRM parameters are less susceptible to underestimation of prior recall (as indexed by the FIA effect). The implication of this would seem to be that there must be cases in which people exhibit both: a tendency to develop false memories and a tendency to underestimate prior remembering. A thorough examination of how and under which circumstances these memory illusions covary in clinical groups, among which people with recovered memories, seems warranted.

Unlike previous studies that often relied on special samples (e.g., people with recovered memories; Clancy et al., 2000; see also Drivdahl \& Zaragoza, 2001; Jelicic et al., 2006), we did not find fantasy proneness and dissociative experiences to be related to the size of the false memory effect in our sample consisting of non-clinical undergraduates (Study 1). Our failure to find correlations between these traits and false memory susceptibility may have to do with our reliance on intelligent, young adults (i.e., undergraduates). On the other hand, finding a correlation between false memory susceptibility and dissociation or fantasy proneness in a clinical sample introduces the interpretational problem of the possibility of a third underlying (mediating) variable (e.g., post traumatic stress symptoms). Therefore, we believe that the non-significant zero-order correlations that we found are informative: they strongly suggest that the idea that susceptibility to false memories and underestimation of prior recall have distinct profiles in terms of symptoms and traits has little empirical basis. Unexpectedly, we found that cognitive efficiency (as indexed by self-reported cognitive failures) was linked to both the FIA phenomenon and the DRM effect. The direction of the correlations suggests that a relative lack of cognitive efficiency to some degree immunizes against false memories and a tendency to overlook previous instances of remembering although, of course, the correlational nature of our findings precludes a causal interpretation of this relationship. Nevertheless, one possible explanation of the negative associations between self-reported cognitive efficiency, false memories, and the FIA effect is that self-reported cognitive efficiency reflects optimism and reliance on liberal 
criteria for evaluating the accuracy of self-reported memory reports. By this view, heightened levels of cognitive failures would imply that people are critical and use strict standards (see for a similar line of argumentation Hekkanen \& McEvoy, 2002). In more general terms, the significant correlations between self-reported cognitive efficiency and memory illusions illustrate that this might be a fruitful area for further research. So far, studies in this domain have traditionally focused on characteristics that superficially seem to be more interesting (e.g., dissociative symptoms; fantasy proneness) than lack of cognitive efficiency (e.g., Hyman \& Billings, 1998; Winograd, Peluso, \& Glover, 1998; Jelicic et al., 2006). A more systematic analysis of how cognitive efficiency relates to memory illusions would be interesting because this cognitive efficiency can be related to other phenomena, for example, mind wandering (e.g., Smallwood, Fishman, \& Schooler, 2007; on the link between attention lapses and cognitive failures, see Carriere, Cheyne, \& Smilek, 2007; Cheyne, Carriere, \& Smilek, 2006).

With respect to the interrelations between the various self-report measures (study 1 ), we found positive and significant correlations between dissociative experiences, on the one hand, and everyday cognitive failures and fantasy proneness, on the other. Though cognitive failures and fantasy proneness appear to be predictors of dissociative experiences in the current student sample, these measures were found to be unrelated to each other. This pattern of fantasy proneness and cognitive failures as independent correlates of dissociation replicates previous work (e.g., Horselenberg, Merckelbach, \& Josephs, 2003; Merckelbach et al., 1999).

As to the limitations of the current study, it should be mentioned that no corroboration for the current trauma reports was sought, making it impossible to report on the authenticity of these experiences. Another limitation of the current studies is the way in which pertinent memory illusions were measured. Using lab tasks, both underestimation of prior recall and susceptibility to false memories have been documented in clinical samples, e.g., women who reported recovered memories of CSA (Clancy et al., 2000; Merckelbach et al., 2006). However, it might well be the case that we would have found a different pattern of correlations had we used false memory paradigms that involved episodic rather than semantic memories. Clearly, this possibility needs to be addressed in future studies. In order to increase ecological validity, we, in study 2 , investigated the relation between false memory propensity (as measured with the DRM task) and susceptibility to the FIA effect as measured with an autobiographical memory dating task (see Parks, 1999) in a sample of people reporting a history of childhood sexual abuse (CSA). As said above, we replicated the finding of relative independence between DRM performance and the FIA effect.

In sum, the current studies showed the FIA effect to be unrelated to DRM false recall and false recognition performance. This indicates that FIA and DRM tap different memory illusions that are independent of one another. However, at the level of personality characteristics, both aberrations did not have distinct profiles. Thus, from a clinical perspective, the existence of two different types of memory illusions seems to 
have limited relevance. Both types are related to cognitive efficiency, a link that merits further research. 


\section{CHAPTER 4}

SOURCE MONITORING AND THE UNDERESTIMATION OF PRIOR REMEMBERING

Raymaekers, L., Smeets, T., \& Peters, M.J.V. (submitted for publication). Source monitoring errors are related to the underestimation of prior remembering in individuals reporting continuous and recovered memories of childhood sexual abuse. 


\section{SUMMARY}

Previous studies showed that people reporting recovered memories of childhood sexual abuse (CSA) exhibit a stronger tendency to underestimate their prior rememberings relative to people with continuous CSA memories and controls. The present study investigated whether a heightened susceptibility to source monitoring errors could account for these findings. People with recovered $(n=12)$ or continuous $(n=35)$ CSA memories and non-traumatized controls $(n=27)$ were compared with regard to their performance on an autobiographical version of the Forgot-It-All-Along (FIA) task and their source monitoring abilities. People with recovered memories were slightly better in dating their recent recalls of vivid memories (i.e., less underestimation of prior remembering) than people reporting continuous memories of abuse and controls. A significant association between the FIA effect and source monitoring abilities was found, indicating that better source monitoring abilities went along with a diminished tendency to underestimate prior remembering.

\section{INTRODUCTION}

Can people forget traumatic memories of childhood sexual abuse (CSA) and accurately recover these memories later in life? This question has led to a heated debate in psychology, psychiatry, and the law (Loftus \& Davis, 2006; McNally, 2003a). For decades, two views dominated the debate: the repression view versus the false memory view. Proponents of the repression view argue that people with recovered memories may have no access to traumatic memories for often a long period of time. This inaccessibility is thought to result from special mechanisms such as repression and dissociation that serve a defensive role. That is, such mechanisms supposedly block traumatic memories from awareness rendering a person temporarily incapable of retrieving his/her memories (Brown, Scheflin, \& Hammond, 1998; Van der Kolk, 1994; Van der Kolk \& Fisler, 1995). Advocates of the false memory view, on the other hand, claim that traumatic memories are rarely - if ever - truly forgotten. By this view, recovered memories are thought to be the result of suggestive therapeutic interventions. The most important feature of this view is that the idea of repression is quite implausible (McNally, 2003a; McNally \& Geraerts, 2009).

The repression account has not received much (if any) credit over the past few years, as direct empirical evidence for repression or dissociation as the drivers of amnesia is generally lacking (Brewin \& Andrews, 1998; Giesbrecht, Lynn, Lilienfeld, \& Merckelbach, 2008; Loftus \& Ketcham, 1994; McNally, 2003a, 2004a; Merckelbach \& Muris, 2001; Piper, Lillevik, \& Kritzer, 2008). Notwithstanding the lack of scientific support for the underlying mechanisms postulated by the repression account, a significant portion of abuse victims report that there was a period in their lives in which they had no memories of the abuse (Briere \& Conte, 1993; Loftus, Polonsky, \& Fullilove, 1994). More importantly, recent research suggests that a subset of these recovered 
memory experiences (i.e., spontaneously recovered memories) often contains elements that can be corroborated by family members, friends, etc. (McNally \& Geraerts, 2009; but see also Raymaekers, Smeets, Peters, Otgaar, \& Merckelbach, 2012). Taken together, recovered memory reports with authentic elements seem to exist, but repression or dissociative amnesia are not considered likely candidates to explain the subjective impression of forgetting characterizing these reports. How then can we explain the alleged period of forgetting in people reporting recovered memories of CSA?

Schooler and colleagues observed that some people reporting recovered memories of CSA had mentioned their experiences to their partner, family or friends before the recovery of the abuse episodes (Schooler, Ambadar, \& Bendiksen, 1997). They hypothesized that in these cases, individuals 'forgot' having remembered a traumatic event before the moment of its 'recovery', thereby creating an illusion of amnesia. Thus, the authors argued that the underestimation of prior remembering could explain how people may come to believe that they previously forgot an important episode, a phenomenon that was later termed the "Forgot-It-All-Along" (FIA) effect (Schooler, 1999).

Merckelbach et al. (2006) experimentally tested the FIA effect for autobiographical details in undergraduate participants (study 1 and 2) and women with continuous (i.e., always accessible) or recovered memories of childhood sexual abuse (study 3 ). Participants were asked to recall vivid memories of certain childhood events (i.e., first time they went to a funeral). After a delay of one hour or two days, they were asked whether they had recently thought about any of the target events and several others. Despite recalling the target events either an hour or two days before, many participants claimed not to have thought about these events for several weeks, months or even years. Importantly, participants who reported recovered CSA memories were more likely to forget remembering the recent events during the laboratory task than people who reported continuous memories of CSA (see also Arnold \& Lindsay, 2002, 2005). These findings support Schooler's (1999) idea that the FIA bias is typical for at least some individuals reporting recovered memories of CSA.

Taken together, previous data seem to support the idea that at least a subset of recovered memory reports refers to memories that are basically accurate but of which the accessibility was underestimated due to the FIA mechanism. An important issue is whether the FIA effect observed in people with recovered memories is a distinct phenomenon or whether it reflects a lack of metamemory functioning, notably source monitoring, in this group (see also Benner \& Lindsay, 2007 who interpreted their FIA effect found for pictorial stimuli within the source monitoring framework). Source monitoring refers to "cognitive processes that are involved in making attributions about the origins of memories, knowledge, and beliefs" (Johnson, Hashtroudi, \& Lindsay, 1993, p. 3). So, one could speculate that when people lack these metamemory skills, they also will tend to underestimate prior recall attempts. Alternatively, one 
could argue that there are two types of recovered memories, those recovered spontaneously and those recovered in therapy and that FIA effects are typical for the former, while source monitoring deficits - and the susceptibility to suggestive therapy influences that they imply - is typical for the latter category (see Raymaekers, Peters, Smeets, Abidi, \& Merckelbach, 2011; Roediger, Watson, McDermott, \& Gallo, 2001).

The present study was designed to extend the findings of Merckelbach et al. (2006) by examining the role of source monitoring in relation to the FIA effect. Overall, we expected that good source monitoring abilities would be related to a smaller FIA effect. We also hypothesized that people reporting recovered memory experiences would exhibit a significantly greater FIA effect relative to people reporting continuous memories of CSA. Furthermore, on an exploratory basis, we investigated whether people reporting different types of recovered memory experiences (i.e., in therapy recovered vs. spontaneous) also differ with respect to the magnitude of the FIA effect.

\section{METHOD}

\section{Participants}

We recruited CSA participants through advertisements in local newspapers as part of an ongoing research project on continuous and discontinuous memories of CSA (see also Raymaekers et al., 2011). The advertisements invited people to participate in our research when they had a history of CSA that had either never been forgotten or was recovered after initially having 'forgotten' the CSA (i.e., the CSA was believed to be inaccessible or unavailable for some period of time). Childhood sexual abuse was defined as presence of "hand/mouth to genital" and "genital to genital" contact with adults occurring before the age of 18 . Controls were recruited by means of internet advertisements and flyers distributed in several public places. The study was approved by the standing ethical committee of the Faculty of Psychology and Neuroscience, Maastricht University.

Based on a semi-structured memory interview (see for a similar methodology, Raymaekers, Smeets, Peters, \& Merckelbach, 2010), participants were assigned to one of the following groups: (a) the continuous memory group consisting of participants who stated that they had never forgotten about their abuse; (b) the recovered memory group consisting of people who claimed there was a period in their life in which CSA memories were inaccessible or unavailable. This group entailed participants who maintained that they had recovered CSA memories outside a therapeutic context (i.e., spontaneously) or, in contrast, had recovered their CSA memories within a therapeutic context (i.e., in therapy recovered); and finally (c) the control group consisting of participants without a lifetime history of abuse. Participants who showed mixed memory profiles (see Raymaekers et al., 2010; Raymaekers et al., 2012) were excluded from the study $(n=5)$. Also, one person was excluded due to a lack of actual memories about 
the CSA (i.e., the participant presented herself with repressed - not yet recovered memories of CSA, see for example McNally et al., 2006).

The final sample consisted of 74 participants: 35 (30 women) in the continuous memory group (mean age $=44.14$ years, $S D=9.15), 12$ (10 women) in the recovered memory group (mean age $=45.92$ years, $S D=14.08$ ), and 27 (18 women) in the control group (mean age $=36.15$ years, $S D=12.41)$. Seven of the $12(58 \%)$ participants reported CSA memories that were recovered during the course of (suggestive) therapy. There were significant age $[F(2,71)=4.92, p<0.05]$ and level of education $[F(2,71)=$ $3.33, p<0.05$ ] differences between the groups. Control participants were significantly younger and had a significantly higher level of education than people reporting continuous and recovered memories of CSA. Finally, there were no gender distribution differences between the groups, $\chi^{2}(2)=3.47, p=0.18$.

\section{Materials}

\section{Autobiographical memory dating task}

Participants' ability to recall prior attempts at remembering was examined by means of an autobiographical memory dating task that was originally developed by Parks (1999; see also Merckelbach et al., 2006). The current task consisted of two questionnaires, administered with a one-hour interval in between. Participants first completed a 23item 'yes-no' questionnaire about specific childhood events or facts (questionnaire 1). The items were drawn from the Parks task (1999) or formulated along the lines of his items (e.g., "Do you have vivid memories of the first time you went to a funeral?"). Participants were instructed to think for 3 seconds about each item before indicating whether they did or did not have vivid memories about these events. After one hour, participants completed the second questionnaire consisting of 18 items, of which nine were drawn from the first questionnaire (i.e., target items) and nine items pertained to not previously mentioned items (i.e., control items). The target items were described in exactly the same way as in the first questionnaire though listed in a different order. For target as well as control items, participants were instructed to indicate to their best estimate' the last time they recalled 'even if it was only briefly' the events or facts described by the items. The following response scale was used: $0=$ one hour or less ago; 1 = several days ago; 2 = several weeks ago; 3 = several months ago; 4 = about $a$ year ago; 5 = several years ago. Participants were instructed to give a dating estimate even when they felt an item did not apply to them (but see below).

\section{Source monitoring test (SMT)}

The SMT used in the present study was derived from the study of Parks (1997; see also Henquet, Krabbendam, Dautzenberg, Jolles, \& Merckelbach, 2005; Smeets et al., 2006). It was developed to determine participants' ability to differentiate between internally generated and actually verbalized (i.e., external) thoughts. It consisted of two parts: (1) a source monitoring acquisition phase (SMA) and (2) a surprise recogni- 
tion + source monitoring task $(\mathrm{R}+\mathrm{SMT})$. The SMA consisted of 24 questions concerning personal history (e.g., "At what age did you learn to swim?") and preferences (e.g., "What is your favourite colour?"). The questions were presented on a computer screen, with a computer program specifically developed for this purpose. It contained 16 trials: Half of the trials involved single questions while the other half of the trials concerned dual questions. Dual question trials consisted of a question presented the top and one at the bottom half of the screen. Presentation of the questions was followed by a $3 \mathrm{sec}$ blank screen. Participants were instructed to prepare an answer to the presented questions. On single question trials, the word "answer" appeared $1 \mathrm{sec}$ after presentation of the blank screen. On dual question trials, either the words "answer top" or "answer bottom" appeared. Thus, people had to prepare an answer to both questions, but they verbalized the answer to only one question. This resulted in verbalizing answers to 16 questions and covertly preparing - but not verbalizing answers to 8 questions. Single and dual question trials were presented in a quasirandom order. An experimenter was present to check whether participants actually verbalized the answers. All participants were capable of answering the questions, which can be considered indicative of the simple and direct nature of the questions. After a delay of approximately $15 \mathrm{~min}$, participants received the R+SMT. During this paper-and-pencil test, participants were presented with the 24 original questions, each paired with a new question of the same content and form. For example, the old item "At what age did you learn to swim?" was presented along with the new item "At what age did you learn to ride a bike?" Participants were asked to identify, for each of the 24 pairs of old and new items, the questions they had seen before (i.e., the recognition memory aspect of the test). In addition, they had to indicate whether they had verbalized answers to the old items or only thought about an answer (i.e., the source memory aspect of the test).

\section{Procedure and analyses}

After having provided informed consent, participants first filled out questionnaire 1 of the autobiographical memory dating task. Next, during a one-hour interval, participants performed several unrelated non-verbal filler tasks. Then, the second questionnaire of the autobiographical memory dating task was completed. Following this, participants were presented with the SMA. After a delay of approximately $15 \mathrm{~min}$, participants performed the R+SMT.

With respect to the autobiographical memory dating task, we analyzed the number of vivid memories, the proportion correct dating estimates for vivid target items (i.e., proportion of participants indicating to have thought about the target an hour or less ago), the mean dating (i.e., time) estimate for the vivid target items, and how often participants gave at least one correct response and had one or more dating errors (this latter variable indicates that participants followed the instructions but nevertheless made errors; cf. Merckelbach et al., 2006). The dating estimate is a reflection of 
the FIA effect: the longer ago the dating estimate, the more one underestimates prior memories or recollections. Analyses were restricted to those target items for which the participants claimed to have vivid memories (i.e., yes-responses on questionnaire 1). Thus, items referring to events that did not happen to participants or for which participants did not have vivid memories were excluded from the analyses (cf., Merckelbach et al., 2006). Memory dating performance was indexed by calculating the mean dating estimates that participants gave to their vivid memories (see for a similar approach, Parks, 1999 and Merckelbach et al., 2006). The proportion correct dating recall in time of vivid target items was evaluated by looking at the proportion of items that were given a rating of 0 . These dating estimate parameters were subjected to univariate analyses of variance.

With respect to the monitoring task, performance on the R+SMT was analyzed as follows (see also Smeets et al., 2006). Firstly, a recognition memory score was calculated by summing the number of correctly identified old items divided by the total number of items (i.e., proportion of correct recognition of memory items presented during the SMA). Secondly, a proportion correct source hits was calculated, conditioned on the correct memory recognition of the items. That is, a source hit was scored as correct if the matching stimulus sentence was correctly recognized. Correspondingly, source false-alarm rates (i.e., the number of erroneous claims of having verbalized an answer that in fact was covertly prepared) were calculated conditioned on correct memory recognition of the items (cf. Smeets et al., 2006). Finally, measures of accurate and biased discrimination between internal and external thoughts (i.e., discrimination index $[\mathrm{Pr}]$ and bias index $[\mathrm{Br}]$, respectively) were determined on the basis of the two-high threshold theory (Snodgrass \& Corwin, 1998; see also Corwin, 1994). Thus, the discrimination index was defined as $\operatorname{Pr}=[$ (number of source hits + $0.5) /($ number of source targets +1$)]-[$ (number of source false alarms +0.5$) /($ number of source distracters+1)]. The bias index was defined as $\mathrm{Br}=[$ (number of source false alarms +0.5$) /($ number of source distracters +1$)] /(1-P r)$. For each of the R+SMT parameters (i.e., recognition memory score, proportion of correct source hits, and source false-alarm rates, discrimination index, bias index), univariate analyses of variance (group: controls versus continuous memory group versus recovered memory group) were conducted. To evaluate the link between source monitoring performance and the FIA effect, Pearson product-moment correlations (two-tailed test) between SMT parameters and FIA performance were calculated across groups.

\section{RESULTS}

\section{Autobiographical memory dating}

Mean number of vivid memories, proportion correct recall, mean dating estimates, and the number of people giving at least one correct dating estimate and one or more dating errors for each group can be found in Table 1. To control for group differences 
with respect to age and education, an analysis of covariance (ANCOVA) was conducted in which both factors were entered as covariates. Recovered memory, continuous memory, and control participants did not differ with regard to the mean number of target items for which they said to have vivid memories (see Table 1 ), $F(2,71)=0.65, p$ $=0.53, \eta_{p}^{2}=0.02$. Furthermore, people with recovered memories, people with continuous memories, and controls did not differ with respect to the proportion correct estimates (i.e., 0) for vivid target items (see Table 1), $F(2,71)=0.15, p=0.87, \eta_{p}{ }^{2}=$ 0.01 . When evaluating group differences in mean dating estimates for vivid target items, a borderline significant difference emerged between the groups, $F(2,71)=2.83$, $p=0.07, \eta_{p}{ }^{2}=0.08$. The mean dating estimate of the recovered memory group corresponded to $0.92(S D=0.90)$ which differed significantly from the mean dating estimate of 2.14 reported by people with continuous memories of CSA, $t(45)=3.11, p<0.01$ and the mean dating estimate of 2.04 reported by controls, $t(37)=-2.44, p=0.02$. The mean dating estimate of the recovered memory group for their vivid memories was in the "some days ago" range. The mean dating estimate of the continuous memory group for their vivid memories corresponded to "some weeks ago". Likewise, for control participants, the mean dating estimate for their vivid memories corresponded to "some weeks ago".

\section{TABLE 1}

Mean number of vivid memories, proportion correct recall, mean dating estimates and the number of people giving at least one correct dating estimate and one or more dating errors for each group. Standard deviations are presented between parentheses.

\begin{tabular}{llll}
\hline & $\begin{array}{l}\text { Controls } \\
(n=27)\end{array}$ & $\begin{array}{l}\text { Continuous } \\
(n=35)\end{array}$ & $\begin{array}{l}\text { Recovered } \\
(n=12)\end{array}$ \\
\hline Mean number of vivid memories & $4.89(1.67)$ & $5.17(1.64)$ & $4.75(1.82)$ \\
Proportion correct recall & $0.41(0.45)$ & $0.36(0.39)$ & $0.52(0.41)$ \\
Mean dating estimate & $\mathbf{2 . 0 4 ( 1 . 9 6 )}$ & $\mathbf{2 . 1 4 ( 1 . 7 3 )}$ & $\mathbf{0 . 9 2 ( 0 . 9 0 )}$ \\
At least 1 correct + errors & 13 & 21 & 9 \\
\hline
\end{tabular}

Dating estimates of people reporting different types of recovered memory experiences Exploratory analyses were performed to investigate the autobiographical FIA effect in people reporting memories recovered in therapy versus outside of therapy (i.e., spontaneously recovered). The spontaneously recovered memory group consisted of 5 participants ( 5 women; mean age $=49.6$; $S D=10.1$ ), reporting they had previously forgotten memories of CSA and then spontaneously recalled them outside of therapy, without being prompted by anyone else or consciously seeking such memories. The in therapy recovered memory group consisted of 7 participants (5 women; mean age $=$ 43.3; $S D=16.6$ ), who gradually recovered their memories of CSA during therapy, often 
prompted by suggestive therapeutic techniques such as hypnosis, guided imagery or dream interpretation. In order to determine the differences between the spontaneously recovered memory group and the in therapy recovered memory group, four nonparametric Mann-Whitney $U$ tests were conducted, in which each of the above mentioned variables served as dependent variable.

The spontaneously recovered memory group and in therapy recovered memory group differed significantly in the number of vivid memories that they reported, $z=-$ $1.98, p<0.05$. The spontaneously recovered memories group had an average rank of 4.10 and the in therapy recovered memories group had an average rank of 8.21 vivid targets.

There was also a significant difference between groups in the proportion correct recall, $z=-2.89, p<0.05$. The spontaneously recovered memory group had an average rank of 10.00 and the in therapy recovered memory group had an average rank of 4.00 , which indicates that the spontaneously recovered memory group was better in correctly estimating the last time they had thought about the vivid target items than the in therapy recovered memory group.

Moreover, there was a significant difference between groups in the mean dating estimate for vivid target items, $z=-2.21, p<0.05$. The spontaneously recovered memory group had an average rank of 3.80 and the in therapy recovered memory group had an average rank of 8.43 . This suggests that the in therapy recovered memory group overestimated the last time they thought about the vivid target items (in other words, underestimated prior remembering) compared to the spontaneously recovered memory group.

Finally, the spontaneously recovered memory group and in therapy recovered memory group did not differ significantly in making at least one correct recall and one or more dating errors, $z=-1.62, p=0.11$. The spontaneously recovered memory group had an average rank of 5.00 and the in therapy recovered memory group had an average rank of 7.57, which indicates that the groups were similar in understanding and following the instructions.

\section{Source monitoring performance}

Mean scores derived from the SMT for the controls, the continuous memory, and the recovered memory group can be found in Table 2. To control for group differences with respect to age and education, an analysis of covariance (ANCOVA) was conducted in which both factors were entered as covariates. Recovered memory, continuous memory, and control participants did not differ with regard to recognition memory (see Table 2), $F(2,71)=1.77, p=0.18, \eta_{p}{ }^{2}=0.05$. Furthermore, people with recovered memories, people with continuous memories, and controls did not differ with respect to source hits, $F(2,71)=1.79, p=0.17, \eta_{p}{ }^{2}=0.05$. Also, groups did not differ in terms of source false-alarm rate, $F(2,71)=0.05, p=0.96, \eta_{p}{ }^{2}=0.01$, discrimination index, $F(2,71)=0.35, p=0.70, \eta_{p}{ }^{2}=0.01$, or bias index $F(2,71)=0.56, p=0.57, \eta_{p}{ }^{2}=0.02$. 
TABLE 2

Source monitoring performance of control participants, continuous and recovered memories of childhood sexual abuse participants. Standard deviations are presented between parentheses.

\begin{tabular}{llll}
\hline & $\begin{array}{l}\text { Controls } \\
(n=27)\end{array}$ & $\begin{array}{l}\text { Continuous } \\
(n=35)\end{array}$ & $\begin{array}{l}\text { Recovered } \\
(n=12)\end{array}$ \\
\hline Recognition memory $^{a}$ & $0.99(0.02)$ & $0.96(0.06)$ & $0.95(0.06)$ \\
Source hits $^{b}$ & $0.90(0.08)$ & $0.83(0.13)$ & $0.81(0.13)$ \\
Source false-alarm rate $^{c}$ & $0.11(0.23)$ & $0.19(0.29)$ & $0.16(0.29)$ \\
Discrimination index $^{d}$ & $0.73(0.27)$ & $0.60(0.35)$ & $0.60(0.33)$ \\
Biasindex $^{e}$ & $0.50(0.18)$ & $0.50(0.20)$ & $0.43(0.23)$ \\
\hline
\end{tabular}

${ }^{a}$ Proportion of correctly recognized old memory items. ${ }^{b}$ Proportion of total correct source attributions conditioned on correct memory recognition of the items. ${ }^{c}$ Proportion of false positives conditioned on correct memory recognition of the items. ${ }^{d}$ Measure of accurate discrimination (two-high threshold). ${ }^{e}$ Measure of biased responding (two-high threshold).

\section{Correlational analyses}

Bivariate correlations between SMT parameters and FIA performance (i.e. mean dating estimate) across our groups can be found in Table 3. The significant negative relation between the discrimination index of the SMT (i.e., measure of accurate discrimination between internal and external thoughts) and the mean dating estimate (i.e., FIA performance) indicates that good source monitoring abilities are related to superior autobiographical dating performance (FIA performance). In other words, the better the source monitoring ability (i.e., increased discrimination index), the lower the mean dating estimate and thus the smaller the FIA effect (i.e., reduced underestimation of prior remembering). The significant positive connection between false alarms and dating estimates points in the same direction: the more false alarms (i.e., source monitoring problems), the larger the mean dating estimate error (i.e., the more underestimation of prior remembering). 


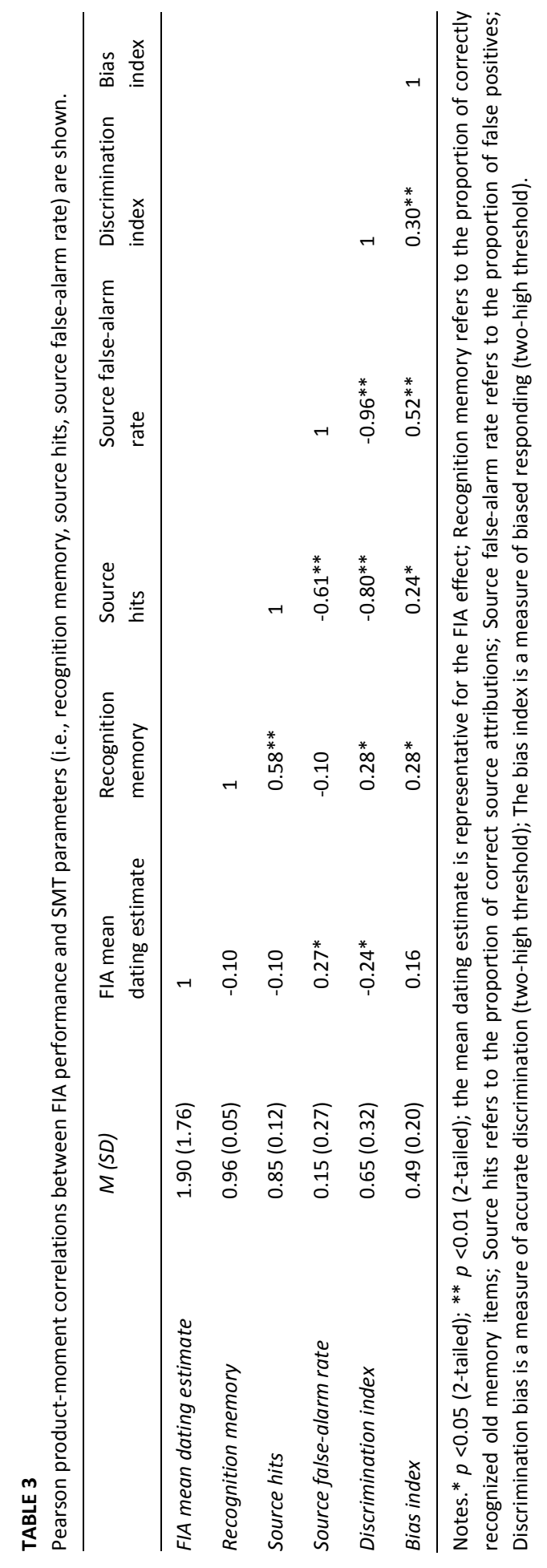




\section{DISCUSSION}

Previous studies showed that people reporting recovered memories of childhood sexual abuse (CSA) exhibit a larger tendency to underestimate their prior rememberings relative to people with continuous CSA memories and controls (e.g., Merckelbach et al., 2006). The present study investigated whether a heightened susceptibility to source monitoring errors among recovered memory patients could account for these findings. Individuals with recovered or continuous CSA memories and non-traumatized controls were compared with regard to their performance on an autobiographical version of the FIA task and their source monitoring abilities. The main results can be summarized as follows. First, those individuals claiming to have recovered memories were marginally better at dating their recent recalls of vivid memories than people reporting continuous memories of abuse and controls. Moreover, source monitoring skills were found to be related to the FIA effect. Thus, in line with our expectations, it was found that a good source monitoring ability (i.e., ability to discriminate between internally generated thoughts versus externally verbalized thoughts) was related to less underestimation of prior remembering (i.e., superior correct autobiographical dating performance).

The fact that the present study did not provide evidence for a larger FIA effect in people reporting recovered memories of CSA is at odds with previous data reported by Merckelbach et al. (2006). When looking at the descriptive data, controls on all parameters (mean dating estimate for the vivid target items, number of vivid memories, the proportion correct recall in time for the vivid target items and making at least one correct recall and one or more dating errors) performed similar to the data reported by Merckelbach et al. (2006). People reporting recovered CSA memories, on the other hand, performed especially deviant compared to earlier results; for example, their mean dating estimate in the current study was found to be $0.92(S D=0.90)$, whereas the mean dating estimate for this group reported by Merckelbach et al. (2006) was $4.14(S D=0.85)$. One possible explanation for these divergent findings could be that the present study specifically selected for people who were absolutely certain that they had previously forgotten their memories about their abusive past. More specifically, all participants answered affirmatively to the question "if someone would have asked me, during the period in which the memories were unavailable or inaccessible, whether I was sexually abused as a child, I would say definitely not". So, people who were uncertain about whether they had forgotten their CSA memories prior to recovery were not invited to participate in the current study. It could be hypothesized that when people state that they are absolutely certain that the memories were temporarily inaccessible or unavailable, susceptibility to the effect of underestimation of prior remembering is mitigated. Research has shown that when people are uncertain about their own memory (i.e., memory distrust; see Van Bergen, 2011), they are more likely to depend on suggestions or cues administered by others potentially resulting in an increased susceptibility to source-monitoring errors (Gudjonsson, 2003). As the pre- 
sent study showed that underestimation of prior remembering is related to source monitoring problems, it is reasonable to assume that recovered memory people distrusting their own memory might be especially susceptible to the FIA effect. Future research is, however, needed to investigate the role of self-reported degree of forgetting and memory distrust in dating recent recalls of vivid memories.

It has been argued that at least two different types of recovered memories can be identified: memories recovered during the course of suggestive therapy versus memories recovered spontaneously, outside the course of suggestive therapy (e.g., Clancy et al., 2000; Loftus \& Davis, 2006; Merckelbach et al., 2006; Schooler, 1999). These recovered memory types are thought to represent different cognitive profiles generated by differing cognitive mechanisms. A study that provided evidence for this view showed that people with spontaneously recovered memories exhibited a stronger tendency to underestimate their prior memories relative to people reporting memories recovered during the course of therapy, people with continuous memories, and controls (Geraerts et al., 2009). However, exploratory analyses on the current data showed that the spontaneously recovered group was better in correctly estimating the last time they had thought about the vivid target items than the in therapy recovered group. Thus, especially people with in therapy recovered memories overestimated the last time they thought about the vivid target items (i.e., underestimated prior remembering) compared to people with spontaneously recovered memories. This conclusion however remains tentative as its reliability is likely limited by low statistical power.

Several limitations of the current study deserve some comment. First and foremost, due to the very strict criteria for enrollment, few people reporting recovered memories of CSA participated in this study. That is, the interview used in this study to classify the participants into the different groups was more in-depth and strict than the interviews used in prior studies from our lab (e.g., Merckelbach et al., 2006). Additionally, prior to the study, a screening took place by telephone in which several questions were asked regarding the degree of forgetting. For example, only participants who were sure that they had forgotten their memories of CSA and in which no reinterpretation of memories took place evoking an illusion of forgetting (see McNally \& Geraerts, 2009; see also Raymaekers et al., 2012) were recruited for the study. Furthermore, people with mixed memory profiles were excluded from our recovered memory sample (see e.g., Raymaekers et al., 2010). Finally, a consensus model based on 3 independent raters was used to obtain a reliable classification. As recent study (Raymaekers et al., 2012) shows that the process of classifying recovered memory reports is difficult and open to subjective interpretation. For this reason, using an expert panel as consensus model is recommended for future research on recovered memories. The current sample size of the recovered memory group illustrates that the way in which recovered memories are defined and classified influences the influx of participants into a study. 
In conclusion, contrary to previous findings (Geraerts et al., 2006, 2009; Merckelbach et al., 2006), people reporting recovered memories of CSA did not show a specific tendency to overlook recent recalls of autobiographical events relative to people with continuous CSA memories and controls. If anything, those individuals claiming to have recovered memories were marginally better at dating their recent recalls of vivid memories than people reporting continuous memories of abuse and controls. Moreover, people reporting spontaneously recovered memories of CSA were not more likely to underestimate their prior rememberings relative to people reporting in therapy recovered memories. To our knowledge, this study is the first to show that the FIA effect is related to source monitoring ability: the better the source monitoring ability, the less one tends to underestimate prior rememberings. 


\section{PART II \\ CLASSIFICATION \& \\ BELIEFS ABOUT MEMORY}





\section{CHAPTER 5}

UNDERGRADUATES' RECOVERED MEMORY EXPERIENCES AND

BELIEFS ABOUT MEMORY 


\section{SUMMARY}

Previous surveys showed that many people tend to hold unrealistic beliefs about memory functioning. Such improbable beliefs are suggested to contribute to the emergence of recovered memories. The question arises whether the recent accumulation of sceptical research about recovered memory claims has affected the beliefs that individuals hold about memory. The present study addressed this issue in an undergraduate sample and furthermore surveyed these individuals about personal recovered memory experiences. About one fourth of the current undergraduate sample (28\%) reported recovered memory experiences. Moreover, we found that undergraduates (still) tend to hold unrealistic beliefs about memory. It can be concluded that years of spreading of knowledge did not result in debunking faulty assumptions about recovered memories and in reducing endorsement rates of recovered memory experiences among undergraduates.

\section{INTRODUCTION}

The debate regarding the authenticity of recovered memory experiences has traditionally been characterized by two opposing viewpoints (Lindsay \& Read, 2001; McNally \& Geraerts, 2009). According to one perspective, defensive mechanisms like repression or dissociation can impede traumatic memories from entering consciousness, thereby serving as a safeguard against conscious recollection by the individual for prolonged periods of time. The other perspective, supported by many scholars, argues that recovered memories in most if not all cases may be the result of an iatrogenic process in which certain psychotherapeutic techniques (e.g., hypnosis, guided imagery) may foster false beliefs and/or memories that are experienced as genuine autobiographical memories (e.g., McNally, 2003a).

It has been argued that unrealistic assumptions about memory functioning that are not derived from a consensus among memory researchers (Zola, 1997) may contribute to the emergence of recovered memories (Lindsay \& Read, 1994; Loftus, 1993). Several studies investigating subjective memory beliefs have shown that people have unrealistic views about memory functioning (e.g., Magnussen et al., 2006; Magnussen \& Melinder, 2012). For example, these studies have indicated that many people believe that repression of distressing memories is a common reaction to traumatic events. Merckelbach and Wessel (1998) also noted that both psychotherapists and undergraduates hold strong misbeliefs about memory in general and repression more specifically, with $39 \%$ of the student sample believing that it is possible to have memories of the first two years of their life. Furthermore, $94 \%$ of them believed in repression, and $90 \%$ stated that it is possible to develop psychological complaints because of harboring repressed memories. In a similar vein, Naka and Maki (2006) explored whether unrealistic beliefs about memory are associated with daily experiences of forgetting and remembering among undergraduates. They found that $71 \%$ of the stu- 
dents believed that it was possible to completely forget and later accurately recover memories. In addition, $70 \%$ of them reported that they had actually experienced such recovered memories. However, when questioned in more detail about the alleged recovered memory experiences, participants mainly described episodes that reflected normal forgetting in everyday life. This latter point demonstrates that people have a hard time distinguishing the notion of repression from mere forgetting. Put differently, people tend to confuse not thinking about something for a long time with being unable to do so (McNally, 2005; McNally \& Geraerts, 2009; Yapko, 1994). Finally, Rubin and Berntsen (2007) found that people believe that it is possible to have forgotten memories of childhood sexual abuse. In their study, $67 \%$ of the people from the general population who were asked how plausible it would be for a person with longstanding emotional problems and a need for psychotherapy to be a victim of childhood sexual abuse (CSA) even though the person could not remember the abuse, indicated that such an occurrence was (very) plausible.

The aforementioned studies illustrate a widespread belief amongst laypeople, undergraduates and even psychotherapists that memorable (i.e. traumatic) events can be forgotten but nevertheless have profound effects on current behavior (Magnussen et al., 2006; Magnussen \& Melinder, 2012; Merckelbach \& Wessel, 1998; Naka \& Maki, 2006; Rubin \& Berntsen, 2007; see also Garry, Loftus, \& Brown, 1994). However, from an academic point of view, a more nuanced picture emerges. The advent of new empirical research has brought both sides of the recovered memory controversy (cf. supra) closer to one another (e.g., McNally \& Geraerts, 2009), and consequently the intensity of the debate has decreased. Points of consensus between both sides have been reached, such as that false memories recovered during therapy exist and that memories that have long not been thought about may be experienced as recovered memories (e.g., Lindsay \& Read, 1995; McNally \& Geraerts, 2009). Of course, one of the subsidiary aims of scientific research in this domain is the dissemination of knowledge to governmental agencies, health professionals, and society in general. Thus, one would anticipate that the accumulating scientific knowledge and the growing consensus in the field of recovered memories could have led to debunking faulty assumptions about recovered memory and a decrease in the endorsement of recovered memory experiences in the general population. The present survey therefore explored recovered memory reports in a sample of first-year psychology undergraduates of which it is believed that they would have benefited from the widespread dissemination of knowledge on how human memory generally functions.

\section{METHOD}

\section{Participants}

Our sample consisted of 135 first year psychology students (104 women, $M_{\mathrm{age}}=19.7$, $S D=1.4)$ recruited at Maastricht University, The Netherlands. The survey was approved 
by the Ethical Committee of the Faculty of Psychology and Neuroscience, Maastricht University.

\section{Materials}

Questionnaire regarding personal memory experiences

Participants completed a 17-item questionnaire concerning personal memory experiences. They were asked to read the questions carefully and select the response option that most closely reflected their opinion. To encourage honest responding, participants were reassured that there were no 'right' or 'wrong' answers.

Participants were informed that the survey involved questions about "occasions in which one remembered a specific event that was believed to have been previously forgotten". They were specifically informed that such experiences designate "memories that were once unavailable or inaccessible for a long period of time", and were asked whether they had ever experienced such memory recovery. Only when participants indicated to have experienced at least one such remembering of a previously forgotten memory, they were instructed to complete the remaining 16 questions. In case they had more than one experience that qualified, only the most prominent (i.e., noteworthy) had to be described and kept in mind while answering the questions.

The follow-up questions (see 'results' for details) first addressed the nature and content of the memory involving the specific event that was previously forgotten ( 6 questions). Next, questions about the period in which they had forgotten about the event ( 3 questions) and about the first time they remembered the event after the period of forgetting ( 7 questions) were addressed. All questions were derived and adapted from the semi-structured memory interview that is currently used in our lab to interview people reporting continuous and recovered memories of childhood trauma (e.g., Raymaekers, Smeets, Peters, \& Merckelbach, 2010; see also further on in this dissertation).

\section{Questionnaire regarding personal opinion about memory functioning}

This 10-item questionnaire addressed participants' personal opinions regarding the functioning of human memory (e.g., whether repression exists; see Table 1 for all 10 items). Questions were similar to those used in previous surveys by Merckelbach and Wessel (1998) and Naka and Maki (2006). Response options were "yes", "no", or "don't know". Note that all participants were required to fill out this questionnaire.

\section{Procedure}

Questionnaires were administered in an Introductory Psychology lecture. Participants first read and signed an informed consent form. On an individual basis, they then started with answering questions regarding personal memory experiences, followed by those regarding personal opinions about human memory. Participants were informed that the questionnaire was not intended as a test of their knowledge, but as an explo- 
ration of their opinion about certain memory issues. Completing the questionnaires took about 10 minutes.

\section{RESULTS}

\section{Questionnaire regarding personal memory experiences}

Twenty-eight percent of the participants $(n=38)$ indicated that they remembered an event of which they believed they had previously forgotten (Q1). The first of the follow-up questions asked respondents to describe the nature and content of this specific memory (Q2; open-ended). Responses most often (i.e., in $58 \%$ of the 38 cases) pertained to events involving family, friends or school, such as celebrating Christmas Eve, going on a family holiday, having an argument with a friend, etc. Other responses were rather diverse. For example, one respondent referred to his/her memory of a certain soccer player scoring the winning goal. Four responses related to instances in which the locations of objects or persons' names were forgotten. Another four respondents remained equivocal about the nature and content of the memory (e.g. referring to "an event that came back to mind after seeing a picture", "the memory refers to an experience in my early childhood"). Also, one respondent refrained from answering the question and another respondent explicitly stated that he/she did not want to talk about it.

Noteworthy is the fact that none of the descriptions explicitly referred to childhood sexual abuse experiences. However, five potentially traumatic events were mentioned by the respondents. These referred to the recovery of memories about almost choking on a candy, a car accident, being locked up in a dark room and feeling scared, witnessing a serious verbally aggressive dispute between parents, and being forced into receiving hospitalized treatment for kidney and bladder problems. On the subsequent question (Q3), 35\% of the respondents indicated that it concerned a negative experience, $27 \%$ said it referred to a positive experience, and $38 \%$ found the event to be neutral. Moreover, $33 \%$ of the respondents described their memory as referring to a traumatic childhood experience (Q4). Respondents were, on average, 10 years old $(S D=5.6$ ) when the event occurred (Q5). In $44 \%$ of the cases, respondents believed that they considered the event to be important at the time it occurred (Q6). The final question about the nature and content of the memory (Q7) probed whether the event was something that happened only once or more than once, with $31 \%$ of the respondents indicating that the forgotten memory referred to an event that happened more than once.

The following three questions dealt with the period in which respondents had forgotten about the event. In $24 \%$ of the cases, respondents indicated that they had talked about the event during the alleged period of forgetting (Q8). Thirty-nine percent of the respondents indicated that they felt they had completely forgotten about the event (i.e., not just parts or only details of the event, but the entire event itself; Q9). 
Respondents were then asked whether, during the alleged time of forgetting, they would have responded that the event had not occurred had they been directly asked about it (Q10). Nineteen percent retrospectively believed they would, while $81 \%$ felt that such a direct question would probably have cued the forgotten memories.

The other seven questions related to the moment respondents' remembered the event for the first time after the period of forgetting. We inquired what had triggered the return of the memories (Q11). Responses included triggering (1) by talking to another person about a related topic or having been asked about the specific event (47\%); (2) by experiencing a similar event (13\%); (3) spontaneously, without specific retrieval cues being present (13\%); (4) after seeing a particular picture (11\%); (5) by music (5\%); and (6) by reading about a similar event (5\%). Participants were, on average, 17.3 years old $(S D=2.6)$ when remembering the event after the period of forgetting (Q12). Fifty-one percent of the respondents indicated to have been surprised about the content of the memory (Q13). When the memory returned, $68 \%$ of the respondents were surprised that they had forgotten about that particular event (Q14). Moreover, $73 \%$ of the respondents were convinced that the recovered memory was essentially accurate (Q15), and the event was considered to be important at time of occurrence by $43 \%$ of the respondents (Q16). Finally, participants were asked to speculate about the reasons why they had forgotten about the event (Q17). The stated reasons included the unimportance of the event (35\%), the traumatic or stressful nature of the event $(20 \%)$, the passage of time $(11 \%)$, the absence of proper reminders $(8 \%)$, alcohol (5\%), not thinking about it (5\%), and repression (3\%). One respondent did not answer the question while the remaining respondents ( $13 \%$ of the sample) indicated to have no idea about what caused them to forget about the event.

\section{Questionnaire regarding personal opinion about memory functioning}

Table 1 provides an overview of undergraduates' personal opinions on 10 forcedchoice questions about memory functioning ${ }^{3}$. With respect to repression and forgetting, $81 \%$ of the participants indicated that they believed in the concept of repression, $67 \%$ believed repression to cause psychological problems, $54 \%$ thought that repressed memories should be reactivated in order to reduce psychological symptoms, $86 \%$ was convinced that some memories tend to stay unconscious, $36 \%$ thought that traumatic memories can be completely forgotten, and $64 \%$ stated that a memory can be recovered even after it had been completely forgotten. Regarding early childhood memories, $33 \%$ of the sample believed that it was possible to have memories about the first two years of life whereas $17 \%$ of the participants reported to personally have had such early memories. Twelve percent of the participants thought that memories accurately

\footnotetext{
${ }^{3}$ Note that there are minor differences in the $n$ 's with respect to the forced-choice questions. As the questionnaire was handed out during a lecture, it was impossible to check whether every subject had filled out all questions.
} 
reflected reality and $95 \%$ of the students believed that false memories could be successfully implanted in memory.

TABLE 1

Overview of the responses of 135 first year psychology students to 10 forced-choice questions involving personal opinions about memory functioning.

\begin{tabular}{|c|c|c|c|}
\hline \multirow[t]{2}{*}{ Item } & \multirow[t]{2}{*}{ Response } & \multicolumn{2}{|c|}{ Undergraduates $(N=135)$} \\
\hline & & $\%$ & $n$ \\
\hline \multirow[t]{3}{*}{ 1. Repression exists } & Yes & 81 & 108 \\
\hline & No & 4 & 5 \\
\hline & Don't know & 15 & 20 \\
\hline \multirow[t]{3}{*}{ 2. Repressed memories cause psychological problems } & Yes & 67 & 89 \\
\hline & No & 5 & 6 \\
\hline & Don't know & 28 & 37 \\
\hline \multirow{3}{*}{$\begin{array}{l}\text { 3. Repressed memories should be reactivated in order to } \\
\text { reduce psychological symptoms }\end{array}$} & Yes & 54 & 72 \\
\hline & No & 12 & 16 \\
\hline & Don't know & 34 & 45 \\
\hline \multirow[t]{3}{*}{ 4. I have memories about the first two years of my life } & Yes & 17 & 22 \\
\hline & No & 70 & 93 \\
\hline & Don't know & 13 & 18 \\
\hline \multirow[t]{3}{*}{ 5. Having memories of the first two years of life is possible } & Yes & 33 & 43 \\
\hline & No & 23 & 31 \\
\hline & Don't know & 44 & 58 \\
\hline \multirow[t]{3}{*}{ 6. Memory accurately reflects reality } & Yes & 12 & 16 \\
\hline & No & 77 & 101 \\
\hline & Don't know & 11 & 15 \\
\hline \multirow[t]{3}{*}{ 7. Implanting false memories in someone's head is possible } & Yes & 95 & 126 \\
\hline & No & 3 & 4 \\
\hline & Don't know & 2 & 3 \\
\hline \multirow[t]{3}{*}{ 8. Some memories remain in the unconsciousness } & Yes & 86 & 114 \\
\hline & No & 2 & 3 \\
\hline & Don't know & 12 & 16 \\
\hline \multirow[t]{3}{*}{ 9. Traumatic memories can be completely forgotten } & Yes & 36 & 48 \\
\hline & No & 44 & 59 \\
\hline & Don't know & 20 & 26 \\
\hline \multirow{3}{*}{$\begin{array}{l}\text { 10. A memory can be recovered even if it had been } \\
\text { completely forgotten }\end{array}$} & Yes & 64 & 85 \\
\hline & No & 8 & 10 \\
\hline & Don't know & 28 & 37 \\
\hline
\end{tabular}


Personal opinions about memory functioning: Comparing current results with previous findings reported by Merckelbach and Wessel (1998)

To explore whether the accumulation of scientific knowledge about memory functioning over the past decade has led to debunking faulty beliefs about memory, a comparison was drawn between the present findings and data reported by Merckelbach and Wessel (1998). Specifically, chi-square analyses were performed with respect to 6 items that were posed in both the present investigation and the Merckelbach and Wessel's (1998) study.

The number of subjects answering "Yes", "No" and "I don't know" on the 6 identical forced-choice questions about memory functioning in the Merckelbach and Wessel (1998; $N=50)$ sample and in the present sample $(N=135)$ are presented in Table 2. $3 \times 2$ Chi-Square analyses show that the present sample appeared to be quite similar to the Merckelbach and Wessel sample with respect to their responses on at least five of the 6 questions; all $\chi^{2}(2)<5.0$, all $p^{\prime}$ s $>0.09$ (see Table 2). Only with respect to the question whether repressed memories cause psychological problems (Q2), the two samples differed significantly from one another: $\chi^{2}(2)=9.58, p=0.008$. Even if we were to restrict answers to "yes" vs. "I don't know" on a post-hoc basis, $2 \times 2$ chi-square analyses revealed a significant difference in responding between the two samples: $\chi^{2}$ (1) $=8.84, p=0.003$. In the present sample, respondents more often responded with "I don't know", whereas in the Merckelbach and Wessel sample, respondents more often endorsed the "yes" option. 


\section{TABLE 2}

Overview of the responses of 50 undergraduate students in Health Sciences (sample Merckelbach \& Wessel, 1998) and 135 first year psychology students (present chapter) to 6 forced-choice questions involving personal opinions about memory functioning. Standard deviations are presented between parentheses.

\begin{tabular}{|c|c|c|c|c|c|}
\hline Item & Response & $\begin{array}{l}\text { Merckelbach \& } \\
\text { Wessel, } 1998 \\
(N=50) \\
\%(n)\end{array}$ & $\begin{array}{l}\text { Current } \\
\text { sample } \\
(N=135) \\
\%(n)\end{array}$ & Statistics & Significance \\
\hline 1. Repression exists (Q1) & $\begin{array}{l}\text { Yes } \\
\text { No } \\
\text { Don't know }\end{array}$ & $\begin{array}{l}94(47) \\
2(1) \\
4(2)\end{array}$ & $\begin{array}{l}81 \text { (108) } \\
4(5) \\
15(20)\end{array}$ & $\chi^{2}(2)=4.73$ & 0.09 \\
\hline $\begin{array}{l}\text { 2. Repressed memories cause } \\
\text { psychological problems (Q2) }\end{array}$ & $\begin{array}{l}\text { Yes } \\
\text { No } \\
\text { Don't know }\end{array}$ & $\begin{array}{l}90(45) \\
2(1) \\
8(4)\end{array}$ & $\begin{array}{l}67(89) \\
5(6) \\
28(37)\end{array}$ & $\chi^{2}(2)=9.58^{*}$ & $0.01^{*}$ \\
\hline $\begin{array}{l}\text { 3. Repressed memories should be } \\
\text { reactivated in order to reduce } \\
\text { psychological symptoms (Q3) }\end{array}$ & $\begin{array}{l}\text { Yes } \\
\text { No } \\
\text { Don't know }\end{array}$ & $\begin{array}{l}60(27) \\
18(8) \\
22(10)\end{array}$ & $\begin{array}{l}54(72) \\
12(16) \\
34(45)\end{array}$ & $\chi^{2}(2)=2.50$ & 0.29 \\
\hline $\begin{array}{l}\text { 4. I have memories about the } \\
\text { first two years of my life (Q4) }\end{array}$ & $\begin{array}{l}\text { Yes } \\
\text { No } \\
\text { Don't know }\end{array}$ & $\begin{array}{l}16(8) \\
60(30) \\
24(12)\end{array}$ & $\begin{array}{l}17(22) \\
70(93) \\
13(18)\end{array}$ & $\chi^{2}(2)=2.97$ & 0.23 \\
\hline $\begin{array}{l}\text { 5. Having memories of the first } \\
\text { two years of life is possible (Q5) }\end{array}$ & $\begin{array}{l}\text { Yes } \\
\text { No } \\
\text { Don't know }\end{array}$ & $\begin{array}{l}39(16) \\
25(11) \\
36(15)\end{array}$ & $\begin{array}{l}33(43) \\
23(31) \\
44(58)\end{array}$ & $\chi^{2}(2)=0.89$ & 0.64 \\
\hline $\begin{array}{l}\text { 6. Memory accurately reflects } \\
\text { reality (Q6) }\end{array}$ & $\begin{array}{l}\text { Yes } \\
\text { No } \\
\text { Don't know }\end{array}$ & $\begin{array}{c}8(4) \\
84(41) \\
8(4)\end{array}$ & $\begin{array}{l}12 \text { (16) } \\
77(101) \\
11(15)\end{array}$ & $\chi^{2}(2)=1.09$ & 0.58 \\
\hline
\end{tabular}

Notes. Q1 (Merckelbach \& Wessel, 1998; $n=45$; current sample $n=133$ ); Q2 (current sample $n=132$ ); Q3 (Merckelbach \& Wessel, 1998; $n=42$; current sample $n=133$ ); Q4 (current sample $n=133$ ); Q5 (Merckelbach \& Wessel, 1998; $n=42$; current sample $n=131$ ); Q6 (Merckelbach \& Wessel, 1998; $n=49$; current sample $\mathrm{n}=132){ }^{*} p<0.05$

\section{DISCUSSION}

The aim of the present study was to explore whether the accumulation of empirical knowledge about recovered memories has led to different rates of recovered memory experiences and adjusted assumptions about our memory functioning throughout the years.

The main conclusions can be summarized as follows. In $28 \%(n=38)$ of the cases, undergraduates reported recovered memory experiences. This rate is much lower than recovered memory rates reported by, for example, Naka and Maki (2006). In their sample, $70 \%$ of the undergraduates reported recovered memory experiences. Apart from cultural factors - the Naka and Maki (2006) study relied on a Japanese sample, while ours was a European sample - the framing of the question(s) may have contrib- 
uted to this difference. As authors have argued that people have a hard time characterizing the differences between repression and mere forgetting (e.g., Yapko, 1994) and often tend to misinterpret the definition of recovered memories (McNally, 2003a), we asked undergraduates about experiences in which memories were previously inaccessible or unavailable (e.g. Schooler, Ambadar, \& Bendiksen, 1997; Schooler, 2001; Shobe \& Schooler, 2001). So, contrary to Naka and Maki (2006), we did not ask undergraduates about episodes that were previously completely forgotten and later recovered. We followed this strict definition as to avoid conceptual confusion. After all, merely not thinking about an event or ordinary forgetting is different from recovered memory experiences (McNally, 2005). This "framing" difference in itself may have contributed to the relatively low rate (i.e., 28\%) of recovered memory reporting in our study (see, for forgetting rates for various types of abuse and trauma, Elliot, 1997; Epstein \& Bottoms, 1998; Epstein \& Bottoms, 2002; Melchert, 1996; Melchert \& Parker, 1997).

With respect to beliefs about memory functioning, chi-square analyses revealed that undergraduates still tend to hold unrealistic beliefs about memory. Thus, there were no significant differences in response rates between the Merckelbach and Wessel (1998) sample and the present sample, apart from the question whether repressed memories may cause psychological problems. In fact, $81 \%$ of the respondents indicated that they believed in the concept of repression. Moreover, $67 \%$ believed that repressed memories cause psychological problems, and 54\% supposed that repressed memories should be reactivated in order to reduce psychological symptoms. In addition, $86 \%$ of the respondents assumed that some memories remain unconscious and $36 \%$ believed that traumatic memories can be completely forgotten. The statement that a memory can be recovered even when it has been forgotten completely was judged to be true by $64 \%$ of the respondents. While the aforementioned rates seem lower than rates previously reported by Merckelbach and Wessel (1998), they do not significantly differ from each other. Apparently, many undergraduates still hold unrealistic beliefs about memory functioning, despite the vast collection of critical literature, some of which is in the form of popular science books (e.g., McNally, 2003a).

Older surveys concluded that many laypersons believe in repression claims (e.g., "repression exists"). For example, Golding, Sanchez, and Sego (1996) showed that 89\% of their undergraduate sample $(N=613)$ claimed to have some experience with repressed memories, and most respondents had expressed their belief in memory repression and felt like repressed memories should be admitted as evidence in court. Things have hardly changed. The present data show that memory repression is still considered to be a credible phenomenon. When thinking about what might have contributed to the persistence of believing in repression, the media seem to have played an important role. Over the past decade, it has saturated lay culture with information about repression and recovered memories (e.g., Bottoms \& Davis, 1997; Lindsay \& Read, 1995). Straightforward examples are movies like "The butterfly effect" (2004) 
and "Repressions" (2007) in which repressed memories of traumatic events seem to be merely ordinary incidences.

In addition to believing in repression, $17 \%$ of our respondents indicated to have memories about events occurring in early childhood (i.e., before the age of 2) whereas, even though they did not claim to have such memories, $33 \%$ believed in the existence of early childhood memories. Only $12 \%$ of the respondents believed that memory accurately reflects reality, and as much as $95 \%$ thought it was possible to implant false memories in peoples' minds.

Taken together, the current data show that about one fourth of the current undergraduate sample reported recovered memory experiences. In addition, in line with previous findings (Merckelbach \& Wessel, 1998; Naka \& Maki, 2006; Rubin \& Berntsen, 2007), our results suggest that undergraduates (still) tend to hold unrealistic beliefs about memory. Importantly and relevant for the present findings is the fact that most police officers, counsels, prosecutors, triers of fact - judges and jurors - and even journalists are laypeople when it comes to memory. It is worrisome when they believe that repression and recovered memories are unproblematic phenomena, which may enter the legal arena as evidence (e.g., Howe, 2012). Educating people who hold such naive opinions should be one of the primary goals of researchers in the domain of recovered memories. 



\section{CHAPTER 6}

CLASSIFYING RECOVERED MEMORY REPORTS

This chapter is an adapted version of:

Raymaekers, L., Smeets, T., Peters, M.J.V., Otgaar, H., \& Merckelbach, H. (2012). The classification of recovered memories: A cautionary note. Consciousness and Cognition, 21, 1640-1643. doi: 10.1016/j.concog.2012.09.002. 


\section{SUMMARY}

Traditionally, recovered memories of childhood sexual abuse (CSA) have been classified as those emerging spontaneously versus those surfacing during the course of suggestive therapy. Thus, recovered memories do not form a homogeneous category. Nevertheless, the conceptual distinctions between the various types of recovered memories remain difficult for researchers and clinicians. With this in mind, the current study explored whether recovered memories can be reliably classified. We found that classification can be rather problematic in a subset of cases. To reduce potential bias, we urge for the development and subsequent use of a more reliable classification system and multiple expert raters in research on recovered memories.

\section{INTRODUCTION}

Recovered memories of childhood sexual abuse (CSA) do not form a unitary category, with at least two types of recovered memory experiences having been identified (Schooler, Bendiksen, \& Ambadar, 1997). In the recovered in therapy type, people gradually become to believe that they experienced CSA and think they must have forgotten about it for a long time. These memories are often recovered due to suggestive therapeutic practices (e.g., hypnosis). The second, spontaneously recovered memory type concerns suddenly recalled CSA memories outside a therapeutic context that are usually accompanied with feelings of shock and surprise.

Recent research (e.g., Geraerts et al., 2009; Raymaekers, Smeets, Peters, \& Merckelbach, 2010) has relied on these relatively general descriptions rather than detailed decision trees for differentiating continuous memories (i.e., memories characterized as having been continuously accessible to the individual) from spontaneous and in therapy recovered memories about CSA. This way, categorizing recovered memory reports becomes an inherently subjective process. Its reliability may be especially jeopardized by cases that are ambiguous. For example, one could distinguish spontaneously from in therapy recovered memories based on whether they surfaced in versus outside therapy. However, one could also focus on whether memories were prompted by another person. Consider an individual reporting recovered memories after having talked to a "paranormally gifted" woman. One could classify them as spontaneously recovered (outside of therapy) or, given the suggestive nature of the situation, as in therapy recovered.

Another interpretational problem concerns persons who reinterpret memories that have always been accessible. For example, victims might reinterpret CSA memories that were always accessible to them as traumatic only after they come to understand the abusive nature of these experiences. This experience can evoke a feeling of forgetting and may result in people reporting to have recovered CSA memories. Nevertheless, as argued by McNally and Geraerts (2009), reinterpreting continuous memories should not be confused with retrieving CSA memories after a period of amnesia. 
Also, the degree of forgetting is evaluated on the basis of retrospective self-reports, which might result in fuzzy demarcation lines between recovered memories that were previously forgotten and continuous memories people did not think about for years (Loftus, Joslyn, \& Polage, 1998). Finally, some individuals have mixed memory profiles, reporting, for example, continuous memories of abuse by person $A$ along with recovered memories of abuse by person B (see Raymaekers et al., 2010).

With these considerations in mind, we tested how reliably memory reports are classified when evaluators rely on general descriptions of (recovered) memory experiences. As recovered memory reports are only seldom straightforward and uncomplicated (Alison, Kebbell, \& Lewis, 2006), we expected that making such categorizations is a process rife with subjective judgments. While general descriptions may be intuitively compelling, they may fall short of the type of precision that is needed for research purposes, thereby creating room for observer effects (Rosenthal \& Rubin, 1978).

\section{METHOD}

\section{Participants}

Participants were recruited through advertisements in local newspapers. The advertisements specifically invited people to participate in our research when they had alleged recovered memories (i.e., defined as previously inaccessible or unavailable memories; Sivers, Schooler, \& Freyd, 2002) of being sexually abused as a child. Inclusion criteria were that participants had to be 18 years or older and reported memories of having been a victim of CSA. Only people reporting memories of the abuse were included, meaning that individuals with repressed memories of abuse (i.e., the belief of having been a victim of CSA without having memories or images about the events) were not included in this sample. CSA was defined as sexual behaviour ranging from fondling to penetration imposed upon the victim before the age of 18 or forced sexual activity between a child prior to age 18 and a person who was at least 5 years older. Following an additional screening in which individuals were asked questions about their memory for the abuse (e.g., "Were the memories of the abuse always accessible or was there a period in your life in which the memories were inaccessible or unavailable?"), eligible participants were invited to come to our lab. The final sample consisted of 52 participants ( 36 women) with a mean age of 48.02 years ( $S D=10.62$ ). All 52 memory reports included elements of recovered memories. The study was approved by the standing Ethical Committee of the Faculty of Psychology and Neuroscience, Maastricht University. 


\section{Materials}

Recovered Memory Interview

Participants completed a semi-structured memory interview (see for example Raymaekers et al., 2010) in which they provided information about the nature and duration of the abuse, information on the perpetrator, the nature and context of recovering memories about the abuse, etc.

\section{Classification System}

The classification system consisted of the following five categories: (1) spontaneously recovered memories, (2) memories recovered during the course of therapy, (3) memory experiences which could easily be confused with recovered memories but are more likely referring to a reinterpretation account, (4) mixed memory profile, and (5) suggestive - outside of therapy - category. The different categories were conceptualized as follows: (1) People with spontaneously recovered memories usually report that they had previously forgotten and then spontaneously recalled memories of CSA outside of therapy, without prompting from anyone else, or even a conscious attempt to seek such memories; (2) people with in therapy recovered memories usually state that they had gradually recovered their memories of abuse during therapy, prompted by suggestive therapeutic techniques (such as dream interpretation, hypnosis, guided imagery, etc.), during an active effort to reconstruct their missing pasts; (3) people who, at first glance, seem to report recovered memory experiences but are not clear or unsure about their prior degree of forgetting and are, therefore, likely to be considered having continuous memories that were reinterpreted; (4) a mixed memory profile can be viewed as a memory report involving different types of (recovered) memory experiences (e.g., continuous memories for event $A$ in combination with recovered memories for event B); and (5) The suggestive - outside of therapy - category includes reports based on memories which were (presumably) prompted by a third person though occurring outside the course of therapy (e.g., memories suggested by a paranormally gifted person or a Reiki master).

\section{Procedure and data analysis}

We examined how four independent expert raters who were instructed about the five categories (cf. supra) interpreted the 52 recovered memory reports. The raters (T.S./M.P./H.O./H.M.) were memory researchers with a $\mathrm{PhD}$ in psychology. They were familiar with the literature on recovered memories and had acted as expert witnesses in court cases that involved CSA. Memory reports were verbatim descriptions of CSA memories provided by women who volunteered to participate in a research project on recovered CSA memories (i.e. new, not previously published, sample of memory reports). Raters evaluated each memory report according to the above-mentioned heuristic descriptions (see "classification system"). 


\section{RESULTS}

Inter-rater reliability was assessed by calculating the intra-class correlation coefficient (ICCs; Shrout \& Fleis, 1979), using the two-way random effects model and absolute agreement type (McGraw \& Wong, 1996). A single measure ICC of 0.78 was obtained which corresponds to "excellent" agreement (Fleiss, 1986). However, in only 63\% (33/52 memory reports) of the cases, there was unanimous agreement between all raters. In 29\% (15/52 memory reports) of the cases, agreement between three out of four raters was observed. An example of disagreement is that four reports were classified by two experts as spontaneously recovered, whereas the other experts classified these reports as reinterpreted continuous memories. This suggests that reinterpreting memories that were never forgotten can be confused with spontaneously recovered memories or vice versa, even by experts in the field (McNally \& Geraerts, 2009).

Taken together, while an overall high level of agreement was reached (ICC of 0.78 ), all 4 raters agreed upon the classification category in only 33 out of 52 reports. Moreover, in only $28 / 52$ cases all four raters agreed upon either a spontaneously or in therapy recovered memory classification.

\section{DISCUSSION}

Our data indicate that expert raters can achieve a good level of agreement when classifying recovered memory reports in 5 categories, yet fail to agree in no less than $37 \%$ of the cases. It thus seems that the current guidelines used to classify recovered memory experiences are sensitive to disagreement. In fact, in only $54 \%$ of the cases, all raters agreed upon either a spontaneously or in therapy recovered memory classification. This illustrates that, according to the opinion of the present raters, 24 cases (46\%) fell outside the commonly used classification categories.

Importantly, some researchers have argued that the type of recovered memory is related to the extent to which memories refer to authentic elements (see e.g., Geraerts et al., 2007). That is, memories recovered during the course of suggestive therapy were significantly less often corroborated by collateral evidence than continuous memories and memories recovered in the absence of a therapeutic context. This research finding seems to indicate that the distinction between recovered during suggestive therapy versus spontaneously recovered might be helpful for discriminating between "false" and "true" recovered memories. Our data, however, imply that the distinction is not unproblematic and that it carries the risk that researchers tend to classify memories according to their superficial profile rather than looking at the context in which the claims were made. In addition, deciding whether a therapy is suggestive is feasible for clear-cut cases, but there are also many instances where the suggestiveness of the therapy remains unclear. Furthermore, a patient who undergoes radical recovered memory therapy may still recall a genuine CSA memory, whereas another person may develop false memories of abuse via other routes (e.g., watching a movie 
about incest; dreaming about CSA) in spite of receiving conventional therapy. All in all, the dimensions of suggestive versus non-suggestive therapy and true versus false memory are unlikely to be identical. Assuming that memories recovered during suggestive therapy are necessarily proxies for false memories, whereas spontaneously recovered memories always reflect authentic recovered memories would be overly simplistic. Moreover, the potential misunderstanding that is created by the term spontaneously recovered memory deserves special consideration. Even though the term suggests that the process of recovery occurred suddenly and unexpectedly, spontaneous memory recovery does not imply the absence of identifiable retrieval cues (e.g., a movie fragment, a certain smell).

Some suggestions for future research are in order. First, the belief that one has previously (temporarily) 'forgotten' about the abuse is a vital aspect in deciding whether a memory is classified as continuous or recovered, yet people are often poor at recalling prior attempts of remembering (e.g., Merckelbach et al., 2006). Given that we cannot validate individuals' judgments of prior forgetting, the diagnostic interviews used to evaluate memory reports should be optimized. Ideally, multiple questions should assess prior memory states in deciding upon classification as a recovered memory. In doing so, alternative explanations for a mere illusion of forgetting (e.g., for examples, see McNally \& Geraerts, 2009) can be systematically ruled out. Second, previous data suggest that a fair number of people have mixed memory profiles (see e.g., Raymaekers et al., 2010). These individuals should ideally be excluded from studies on recovered memory experiences. Third, memories recovered outside the context of therapy, but prompted by someone other than a registered therapist should not be treated as spontaneously recovered memories, but preferably be classified separately or excluded from the analyses. Fourth, reinterpreting memories that were never forgotten should not be confused with spontaneously recovered memories. Finally, previous papers on spontaneous versus in therapy recovered memories - including those of our lab (e.g., Geraerts et al., 2009; Raymaekers et al., 2010) - that were based on the classification of a single expert should be interpreted with caution. We propose that a better approach would be one in which independent expert raters classify cases. By only including cases on which independent raters converge or at least by reporting on consistency and (reasons for) variability among the raters in future research, the risk of obtaining biased outcomes is reduced. A welcome side effect of such an endeavor would be that findings from different laboratories could be compared more reliably.

In sum, to reduce potential bias, we urge for the development and subsequent use of a more reliable classification system in research on recovered memories. When evaluating recovered memory reports, we advise to use an expert panel to check the reliability of the classifications or as a consensus model to yield a consistent classification. In order to classify recovered memory reports, one has to collect specific information about circumstances under which memory recovery took place. Hence, a first 
attempt at adapting the formerly used semi-structured memory interview (e.g., Raymaekers et al., 2010) was made in the upcoming chapter (revised semi-structured memory interview; see appendix). 



\section{CHAPTER 7}

GENERAL DISCUSSION 


\section{AIMS OF THE PRESENT DISSERTATION}

The current dissertation aimed at (a) enhancing our understanding of the cognitive mechanisms underlying recovered memories of CSA experiences (PART I), and (b) examining whether the currently applied recovered memory classification procedure is reliable or in need of revisions (PART II). Subsidiary, the present thesis looked at the base rate of recovered memory reporting in undergraduates and evaluated their beliefs about general memory functioning. In answer to the questions posed in Part I, we first examined whether reduced autobiographical memory specificity may explain the illusion of amnesia typically reported by people claiming to have recovered memories of CSA (chapter 2). Furthermore, we explored whether susceptibility to false memories and the underestimation of prior remembering (i.e., Forgot-It-All-Along or FIA effect) tap overlapping memory phenomena and how performance on these tasks correlates with clinically relevant traits such as fantasy proneness, dissociative experiences, and cognitive efficiency (chapter 3). Moreover, we explored the FIA effect and investigated its relationship with source monitoring abilities in people reporting continuous memories of CSA, recovered CSA memories, and controls (chapter 4). In part II of this thesis, we looked at the occurrence of spontaneously recovered memory experiences in an undergraduate sample. Also, we explored whether the accumulation of scientific knowledge on trauma and memory has affected the beliefs that laypeople (i.e., undergraduates) hold about these concepts (chapter 5). Moreover, we examined whether the classification of recovered memory claims on the basis of the presently available rather general type descriptions, can be considered reliable (chapter 6). Finally, the present thesis includes a (revised) semi-structured interview for the assessment of recovered memory experiences (appendix). This interview involves a more elaborate questioning approach than the one previously used in our lab. Basically, it increasingly focuses on the nature and degree of forgetting in people reporting recovered memory experiences. This increased profundity is expected to facilitate the classification process in recovered memory research.

The main findings of the research described in this dissertation will be discussed below. We also address some general conceptual and methodological issues. Furthermore, implications of the present findings are outlined and suggestions for future research are provided. Finally, some concluding remarks are put forward.

\section{SUMMARY AND DISCUSSION OF THE RESEARCH FINDINGS}

\section{Autobiographical specificity and amnesia}

In the past decade, Richard McNally has invested much energy in debunking myths about trauma and memory (e.g., McNally, 2003a, 2004a, 2004c, 2005). He argues that many myths originate from the conceptual confusion surrounding the label of traumatic dissociative amnesia (e.g., McNally, 2004a). For instance, whereas traumatic 
amnesia constitutes a memory failure following exposure to a traumatic event and is specific for the trauma itself, it is sometimes used as a synonym for psychogenic amnesia, a memory malfunction involving a sudden retrograde autobiographical memory loss constituting a failure to remember anything from one's past, including a loss of personal identity (for a review, see McNally, 2003a, pp. 186-189). Another misconception stems from misinterpreting data illustrating non-disclosure; a failure to acknowledge having been abused does not ultimately imply repression or dissociation of abuse memories (e.g., McNally, 2004c). Yet, one of the most common misconceptions, according to McNally, relates to the misinterpretation of not thinking about something as an inability to remember it. That is, even if memories would fail to enter awareness for many years, then this in itself would not mean that they were actively blocked from awareness by special mechanisms such as repression (McNally, 2005).

Many victims report having remembered being sexually abused during childhood after not thinking about it for a long time. This much is incontestable. What remains questionable, however, is the assumption that people can recall a previously repressed memory of a traumatic event. Indeed, researchers have challenged the repression account by showing that one does not need to invoke special mechanisms such as massive repression to explain recovered memory experiences (e.g., McNally, 2005). For example, Schooler and colleagues (1997a) observed that, despite reporting an alleged period of forgetting, some people with recovered trauma memories had mentioned these experiences to others before the "recovery" of the abuse episodes. Thus, at least some recovered memory individuals forgot having remembered the traumatic event prior to recovery. This underestimation of prior remembering is believed to contribute to a mere impression of having been amnesic for often an extensive period of time.

Another interesting research avenue endeavouring to explain the impression of amnesia involves the exploration of autobiographical memory specificity. Specifically, some authors (Dalenberg, 1996; Rassin et al., 2000) have speculated that a lack of memory specificity underlies the subjective experience of amnesia typically reported by people with alleged recovered memories. Therefore, the study presented in chapter 2 tested whether people who recovered CSA memories exhibit a less specific retrieval style compared to people reporting continuous memories of CSA (i.e., people who never forgot their abuse experiences) and controls (i.e., people without a history of abuse). Results indicated that people reporting CSA memories - whether continuous or recovered - showed reduced autobiographical memory specificity relative to controls. No significant differences were observed in terms of autobiographical memory specificity between people reporting continuous memories of abuse and people with recovered abuse memories. Thus, these results suggest that reduced autobiographical memory specificity is not by itself characteristic for people with recovered memories of CSA. In a more explorative fashion, we also examined whether autobiographical memory specificity of people who recovered memories within a therapeutic context 
differed from those who recovered memories outside a therapeutic context (i.e., spontaneously recovered memories). Our data, however, indicated that this was not the case.

From the results outlined above, it can be concluded that the impression of amnesia typically reported by individuals with recovered memories cannot be explained by reduced autobiographical memory specificity (see also McNally et al., 2006). But what then can account for the phenomenon of individuals failing to remember their CSA until many years later? One account was already mentioned and involves the underestimation of prior remembering (Schooler et al., 1997a). An additional explanation involves the way in which the abuse was experienced. That is, research shows that some CSA victims do not experience their abuse as traumatic at time of occurrence, for example due to a failure to fully understand what was happening (Clancy, 2010; McNally, 2005). It makes sense that when instances of sexual abuse are initially misunderstood (e.g., merely confusing), they are perfectly "forgettable". Furthermore, absence of proper retrieval cues can possibly also assist in managing not to think about the abuse. Yet another explanation for the impression of amnesia might come from literature suggesting that a disturbed sleeping pattern (e.g., sleep deprivation) can lead to symptoms similar to those of dissociative disorders, including amnesia (see, for an overview, Van der Kloet, Merckelbach, Giesbrecht, \& Lynn, 2012). For example, research by Giesbrecht and Merckelbach (2004) has suggested that individual differences in sleeping behavior might underlie dissociative experiences, thereby challenging the view that dissociation results from exposure to traumatic events and may serve as a defense mechanism (see also Watson, 2001, 2003). Relatedly, in a recent review on the role of sleep in dissociative symptoms, van der Kloet and colleagues (2012) argue that "dissociative symptoms are associated with a labile sleep-wake cycle, in which dreamlike mentation invades the waking state, produces memory failures, and fuels dissociative experiences" (p. 159). The point here is that sleep and especially so-called REM sleep is known to contribute to the encoding and elaboration of episodic memory (Llewellyn, in press). Thus, a disturbed sleep-wake cycle might produce encoding failure, and in its wake, amnesia and other dissociative symptoms. That this research lead is promising is shown by the work of McNally and Clancy (2005) who found that sleep paralysis (i.e., temporarily experiencing an inability to move when falling asleep or upon awakening) is more prevalent among those who report CSA experiences. The phenomenon of sleep paralysis may easily be misinterpreted as a manifestation of repressed memories and may fuel the idea that one misses parts of one's autobiography. Thus, studying self-reported amnesia in people reporting recovered memories could benefit from exploring general dissociative experiences in relation to sleeping behaviour.

Yet another research line that may shed light on the amnesia claims of people with recovered memories is provided by studies that found daydreaming to have memory-undermining properties (Delaney, Sahakyan, Kelley, \& Zimmerman, 2010). For example, Delaney and co-workers instructed undergraduates to learn word lists and 
then to engage in daydreaming. Compared to a control condition, the daydreamers forgot more words than the controls. One wonders whether the amnesic effects of daydreaming are particularly pronounced in people who engage in maladaptive daydreaming and also whether maladaptive daydreaming might be related to so-called spontaneous recovered memories (see also Bigelsen \& Schupak, 2011). These questions deserve systematic research attention.

\section{Underestimation of prior remembering and false memories}

Previous research documented pronounced false memory effects on the Deese/Roediger-McDermott (DRM) task and enhanced forgetting of prior remembering (i.e., Forgot-It-All-Along effect; FIA account) in people reporting recovered memories (Clancy et al., 2000; Schooler et al., 1997a; Schooler, 1999, 2001; Shobe \& Schooler, 2001). Geraerts et al. (2009) suggest that the FIA effect represented a mechanism to explain recovered memory experiences involving events that actually did occur, whereas the DRM effect taps into the propensity to develop false recovered memories. However, whether susceptibility to false memories and the FIA effect reflect two different and unrelated pathways had not yet been fully established. Furthermore, the question arose whether susceptibility to false memories and the FIA effect go along with different personality characteristics. Hence, the two studies described in chapter 3 explored whether the susceptibility to false memories and the underestimation of prior remembering tap distinct memory phenomena. Study 1 investigated this issue by administering the DRM and the FIA task in an undergraduate sample. Results indicated that FIA and DRM performances were relatively independent of each other, suggesting that these measures may, indeed, refer to separate dimensions. However, that study also found that these dimensions did not seem to define different profiles in terms of dissociation, fantasy proneness, and cognitive efficiency. Study 2 replicated the finding of relative independence between false memory propensity (as measured with the DRM task) and the underestimation of prior remembering (as measured with an autobiographical memory dating task) in people with a CSA history.

\section{Underestimation of prior remembering and source monitoring}

Past studies showed that people reporting recovered memories of CSA exhibit a greater tendency to underestimate their prior rememberings (i.e., FIA effect) relative to people with continuous CSA memories and controls (e.g., Merckelbach et al., 2006). An important issue is whether the FIA effect observed in people with recovered memories reflects a distinct phenomenon or whether it reflects a general lack of metamemory functioning, most notably source monitoring. Source monitoring refers to "cognitive processes that are involved in making attributions about the origins of memories, knowledge, and beliefs" (Johnson et al., 1993, pp. 3). So, one could speculate that when people lack these metamemory skills (i.e., exhibit source monitoring difficulties), they also will tend to underestimate prior recall attempts. To investigate 
this issue, the study described in chapter 4 compared people reporting recovered or continuous CSA memories and non-traumatized controls with regard to their performance on an autobiographical version of the FIA task and their source monitoring abilities. Contrary to previous findings reported by, for example, Merckelbach and colleagues (2006), this study did not provide evidence for superior forgetting of prior remembering in people reporting recovered memories of CSA. As a matter of fact, the current findings revealed that people reporting recovered memories tended to be more accurate in their estimates than controls. Importantly, this study confirmed an association between the FIA effect and source monitoring abilities in that better source monitoring abilities went along with a diminished tendency to underestimate prior remembering.

By not replicating a heightened proneness to the FIA illusion in recovered memory patients, the current findings contradict earlier data reported by Merckelbach et al. (2006) and Geraerts et al. (2009). One possible explanation for these conflicting findings may have to do with the inclusion criteria that were presently employed. In the current study, the inclusion criteria were somewhat strict. That is, the current study specifically selected for people who were absolutely certain that they had previously forgotten about their memories of their abusive past. Specifically, we excluded participants who indicated that if they, during the alleged time of forgetting, would have been directly asked about the event they probably would have remembered it. One could speculate that when people state that they are absolutely certain that the memories were temporarily inaccessible or unavailable, susceptibility to the effect of underestimation of prior remembering is mitigated. Note, however, that people tend to confuse not thinking about something for a long time with being unable to do so (McNally, 2003a; McNally \& Geraerts, 2009; Yapko, 1994). So, although our participants claimed that memories were truly forgotten, this does not necessarily mean that they actually were. Prior accessibility of a memory is after all difficult to determine, as a continuum of possible prior memory states can be distinguished ranging from a mere impression of unavailability of memories to complete incapability of recalling the event(s) (Schooler, 1994). But at least we made an attempt to exclude people who were uncertain about whether they had forgotten their CSA memories prior to recovery, an endeavor that had not been undertaken before (e.g., by Merckelbach et al., 2006 and Geraerts et al., 2009).

Relatedly, research shows that when people are uncertain about their own memory (i.e., memory distrust; see Van Bergen, 2011) they are more likely to depend on suggestions or cues administered by others, potentially resulting in an enhanced susceptibility to source-monitoring errors (Gudjonsson, 2003). As our data illustrate a positive relationship between the underestimation of prior remembering and source monitoring problems, one might hypothesize that people with recovered memories who can distinguish between their own memories and external influences are the ones being especially susceptible to the FIA effect. Because the current study excluded ex- 
actly these people, one could hypothesize that this strict selection procedure has contributed to the conflicting findings. Future research is, however, needed to investigate the role of self-reported degree of forgetting and memory distrust in dating recent recalls of vivid memories.

One might argue that the findings from chapters 3 and 4 are difficult to reconcile. More specifically, chapter 3 illustrates a relative independence between susceptibility to false memory development, on the one hand, and underestimation of prior remembering, on the other. Yet, chapter 4 shows that underestimating prior remembering is related to poor source monitoring abilities (i.e., source monitoring errors), which in turn is believed to be involved in the development of false memories (e.g., Johnson, 1997; Lindsay \& Johnson, 2000). Although false memories have often been explained in terms of source monitoring errors (e.g., Lindsay \& Johnson, 1989; Zaragoza \& Lane, 1994), it is important to note that only suggestion-based false memories (e.g., using a misinformation paradigm) seem to be related to source monitoring abilities whereas the development of spontaneous false memories (i.e., false memories arising without external suggestive pressure) has mainly been described by theoretical accounts such as Fuzzy-trace Theory (FTT; Brainerd, Reyna, \& Ceci, 2008) and Associative-Activation Theory (AAT; Howe, 2008; Otgaar, Howe, Peters, Smeets, \& Moritz, 2012). Specifically, the FTT framework posits the existence of two separate, parallel representations of an experience in memory: a verbatim trace and a gist trace. Whereas the verbatim trace refers to the item-specific (e.g., word-to-word) remembrance of information, the gist trace refers to remembering the general (i.e., non-specific) meaning of information (e.g., fuzzy, imprecise information such as semantic or relational information). According to the FTT framework, spontaneous false memories arise from individuals' tendency to connect items across distinct events that share meaning (e.g., Brainerd \& Reyna, 1998). As such, the DRM paradigm promotes the creation of gist-based memories of semantic relatedness (i.e., 'theme') in the DRM lists. In other words, DRM effects (i.e., recalling the non-presented critical lure) are explained by assuming that the independent traces of words (e.g., bed, rest, awake, etc.) related to the critical lure (e.g., sleep) increase the likelihood of recalling the critical lure (e.g., sleep).

An alternative explanation, the ATT account, is based on spreading activation models (e.g., Collins \& Loftus, 1975) suggesting that the processing of one word activates a corresponding concept in our knowledge base that spreads out to other concepts. Thus, with respect to the DRM effect, it is believed that "the activation of one word activates another whereby some of these activated concepts are items that have not been presented yet have been incorrectly activated due to their connection with presented items in the knowledge base" (Howe, Wimmer, Gagnon, \& Plumpton, 2009, p. 230; see also Otgaar, Howe, Peters, Sauerland, \& Raymaekers, 2012). In chapters 3 and 4 , the DRM paradigm was used to study false memory development. This paradigm is argued to promote spontaneous, non-suggestion-based false memories (see Brainerd, Reyna, \& Ceci, 2008). As stated above, spontaneous false memory develop- 
ment has mainly been predicted by theoretical accounts other than the source monitoring explanation. Hence, the finding that the DRM task (measuring the development of spontaneous false memories) and the FIA task (which is related to source monitoring) are relatively independent measures is not at all surprising.

\section{Spontaneously recovered memory claims and beliefs about trauma and memory in undergraduates}

Older studies have demonstrated that people tend to hold unrealistic beliefs about memory functioning (Magnussen et al., 2006; Merckelbach \& Wessel, 1998; Naka \& Maki, 2006; Rubin \& Berntsen, 2007). Such views are suggested to contribute to the emergence of recovered memories (Lindsay \& Read, 1994; Loftus, 1993). One would, however, expect that the accumulating scientific knowledge and consensus in the field of recovered memories has led to debunking faulty assumptions about recovered memories and the endorsement of recovered memory experiences in the general population. To this end, the survey presented in chapter 5 explored recovered memory reporting in a sample of first-year psychology undergraduates of which it is believed that they would have benefited from the widespread dissemination of knowledge on how human memory generally functions. This study furthermore inquired undergraduates about personal recovered memory experiences.

We found that more than one fourth of the current undergraduate sample reported recovered memory experiences (28\%). Furthermore, in line with previous findings (Merckelbach \& Wessel, 1998; Naka \& Maki, 2006; Rubin \& Berntsen, 2007), our results showed that undergraduates (still) tend to hold unrealistic beliefs about memory. Although it was expected that the accumulation of scientific knowledge and consensus in the field of recovered memories would have led to a decrease in harboring faulty assumptions about recovered memory and the endorsement of recovered memory experiences in the general population, present data illustrate that this was, unfortunately, not the case.

What might have contributed to the persistence of believing in repression are the media. Over the past few decades, they frequently published and/or broadcasted an unfounded point of view on topics like repression and recovered memories (e.g., Bottoms \& Davis, 1997; Lindsay \& Read, 1995). Examples can be found in movies like "The butterfly effect" (2004) or "Repressions" (2007), in which repressed memories of traumatic events seem to come across as merely ordinary incidences. Another factor contributing to misunderstanding is related to what is commonly believed to be the meaning of the term repression. For example, research by Peskens (as described in Crombag \& Merckelbach, 1996) shows that a majority of people believe that not talking about a traumatic experience equals repression (see also Crombag \& Van Koppen, 1994).

In conclusion, the present data show that memory repression is (still) considered to be a credible phenomenon. This can have several consequences. Laypeople's im- 
plicit or intuitive theories about repressed memories guide society's thinking about this topic (Loftus, 1993). Moreover, on a more practical level, it can be expected that, if people believe in the concept of repression, they might be more likely to adopt false beliefs about harboring recovered memories.

\section{Classifying recovered memory claims}

In practice, it has proven to be difficult, for researchers and clinicians, to reliably classify claims of recovered memories solely on the basis of the available general descriptions of the different categories. Therefore, the study presented in chapter 6 explored how four expert raters independently interpreted and categorized verbatim transcripts of CSA memories. The Intra Class Correlation (ICC) was calculated for all the memory reports, using the panel's independent ratings as the measure of interest. Findings showed that, overall, a reasonable level of agreement was observed (i.e., ICC of 0.78). However, in only $63 \%$ of the cases all four raters agreed upon the classification category. Thus, it can be concluded that the classification of recovered memory claims is a process providing considerable room for category malleability.

Based on the present findings it can be concluded that the development and subsequent employment of a more reliable classification system is urgently needed. In order to classify recovered memory reports, one has to collect specific information about circumstances under which memory recovery took place. Hence, a first attempt at adapting the formerly used semi-structured memory interview (e.g., Raymaekers et al., 2010) was made (revised semi-structured memory interview; see appendix). By including questions about potential suggestive routes to recovery other than 'conventional' therapeutic practices, it is now possible to further separate "in therapy recovered memories" from "memories recovered in a therapy mimicking context" (e.g., alternative forms of "therapy" such as Reiki). Another improvement of the revised semi-structured memory interview involves the possibility to distinguish between "reinterpreting memories that were always remembered" versus "recovered memories that were allegedly forgotten" (see McNally \& Geraerts, 2009). Additionally, the revised interviewing procedure allows identifying people who have merely not thought about the abuse for a long period of time, so as to exclude them when conducting research on recovered memories. As not thinking about something is often misinterpreted as an inability to remember it, and is therefore known to be one of the most important misconceptions about trauma and memory, having the potential to exclude such cases can be considered a step forward in creating a database that is free of "noise". Finally, over the past few years, a potential misunderstanding was created by the term "spontaneously recovered memory". That is, although the term suggests that the process of recovery occurred suddenly and unexpectedly, spontaneous memory recovery does not imply the absence of identifiable retrieval cues (e.g., a movie fragment, a certain smell). Indeed, spontaneously recovered memory reports rarely involve complete absence of specific memory cues. By providing people with the option 
to choose between responses implying either a presence or absence of possible memory cues, researchers may gain more insight into the possible non-suggestive nature of memory recovery.

Although it is very much acknowledged that empirical investigation is necessary to evaluate the merits of the revised semi-structured memory interview and to test whether it does a better job in classifying recovered memory reports, it is believed to be an important first step for future research in the recovered memory field.

\section{CONCEPTUAL AND METHODOLOGICAL REMARKS}

Many mechanisms have been proposed to explain recovered memories of traumatic events. The two most commonly known mechanisms involve repression and dissociation. Repression was originally put forward by Freud (1957) who defined the concept as a defense mechanism of the ego that pushed traumatic memories out of consciousness. Dissociation, rather than repression, was propagated by Janet (1889) who believed that in case of traumatic events, the experience is compartmentalized and split from consciousness resulting in a disconnection from the person's awareness and thus an inability to talk about it (see Stoler, Quina, DePrince, \& Freyd, 2001).

Neither repression nor dissociation is backed up by solid scientific proof providing direct support for either of them being a driver of the amnesia experienced by people reporting recovered memories (Bonanno, 2006; Giesbrecht, Lynn, Lilienfeld, \& Merckelbach, 2008; Hayne, Garry, \& Loftus, 2006; Kihlstrom, 2006; McNally, 2003a, 2004a, 2006; Merckelbach \& Muris, 2001; Piper, Lillevik, \& Kritzer, 2008; Pope \& Hudson, 1995; Rofé, 2008). Nevertheless, the tendency to label unexplained or ordinary forgetting as repression appears to be deeply embedded in our cultural heritage (e.g., Lilienfeld, Lynn, Ruscio, \& Beyerstein, 2010, pp. 73-78; chapter 5 of present dissertation).

Recent insights seem to suggest that memories characterized as recovered are likely resulting from distortions in how some people understand their prior forgetting (i.e., these people tend to underestimate their prior rememberings; e.g., Merckelbach et al., 2006; but see Raymaekers et al., 2012). Consequently, alternative explanations for recovered memories have been proposed (e.g., not thinking about the abuse for a long time, delayed disclosure, etc., see McNally \& Geraerts, 2009) and cognitive explanations are now focussed on a lack of meta-awareness, amongst other things, instead of the initial emphasis on the idea that extreme emotional arousal interferes with normal memory integration processes (see Stoler et al., 2001). One can find this metamemory perspective also in recent research on Dissociative Identity Disorder (DID; formerly Multiple Personality Disorder) that is characterized by the core symptom of dissociative amnesia. For example, Huntjens, Verschuere, and McNally (2012) have recently explored the transfer of autobiographical information between identities in DID patients. They showed that although DID patients subjectively report amnesia for autobiographical details related to other alter states, they nevertheless recognize 
these details, indicating a transfer of information between alter identities. These results support the notion that memory performance and meta-memory beliefs do not necessarily correspond and might even diverge starkly.

Today, research is mainly exploring which mechanisms may underlie the impression of amnesia (i.e., alleged amnesia) typically reported by people with recovered memories (i.e., how the impression of having recovered memories occur). Importantly, the issue of cognitive mechanisms underlying recovered memory experiences should be separated from the question of whether or not it is possible to forget and then recover traumatic memories in the first place (Schooler, 1994). Nonetheless, the distinction between memories recovered during suggestive therapy versus spontaneously recovered memories seems to have become an analogy for distinguishing between "false" and "true" recovered memories, with researchers tending to classify memories according to their alleged authenticity instead of looking at, for example, the suggestive nature of the therapy that preceded the recollection of the memories.

A case in point is a recent review by Dalenberg et al. (2012). These authors summarized the data of Gerearts et al. (2007) to mean that spontaneously recovered memories are similarly likely to have corroboration (37\%) when compared with continuous memories (corroborated in 45\%). Dalenberg et al. (pp. 566-567) seem to conclude from this that recovered memories are just as authentic as continuous trauma memories. This position is problematic for a range of reasons. First, in only a minority of cases (37\%), corroborated evidence for the recovered trauma memory was found. Second, from a legal point of view, this evidence was far from solid (its main problem being the hearsay/solidarity character of the evidence). Third and most importantly, in the current context, the whole methodology for classifying recovered memories in the study can be seriously questioned. The point is that in the 2007 Geraerts et al. paper classification of memories was done before corroboration was systematically queried, but if the classification methodology is sensitive to bias, than it might incorporate corroboration evidence and the results become pretty circular.

The findings reported in chapter 6 bring home the point that definitional issues have to be sorted out first before proper research can be done on the cognitive and psychometric differences between various types of recovered memories. For example, what constitutes an in therapy recovered memory? Do we also include popular alternative "therapeutic" practices, such as chakra healing or Reiki therapy? And what counts as a "therapy-like" context? The same holds for spontaneously recovered memories. Do we include only memory experiences involving spontaneous recall without being prompted by anyone or anything, or do we include all memory reports in which memories did not surface during therapy or therapy-like sessions? Note that all these questions have implications for research as, for example, studies will likely be hindered by strict inclusion criteria (i.e., laborious recruitment resulting in small sample sizes). Ultimately, what seems to be important is whether the recollected memory surfaced in response to a deliberate attempt to recall it (e.g., was cued or not). So, one 
could consider adopting this "absence versus presence of cueing" distinction. Again, one has to be aware of the implications hereof as an absence of cueing is likely to result in very restricted samples sizes rendering research difficult and unattractive.

Given that recovered memories constitute a heterogeneous group and recent literature suggests that there are several etiological routes to recovered memory experiences (e.g., McNally \& Geraerts, 2009; see also chapter 6), it seems unlikely that each and every recovered memory experience can be explained in terms of either enhanced FIA or false memory propensity. Another likely candidate to explain recovered memory experiences, for example, involves relabeling (i.e., reprocessing experiences later in life; Epstein \& Bottoms, 2002; see also reinterpretation account postulated by McNally \& Gerearts, 2009).

In a recent chapter, McNally (2012) illustrates the conditions under which relabeling takes place with a prototypical case: "In the typical case (Clancy \& McNally, 2005/2006), the victim was about 7 years of age and failed to understand the experience as sexual or as abusive. The victim knew and trusted the perpetrator who neither threatened nor physically harmed the victim, who experienced confusion, disgust, or anxiety, but not terror. The abuse, often fondling, seldom occurred on more than one or a few occasions. The victim was able to avoid dwelling on this unpleasant, confusing experience precisely because it was not traumatic in the sense of being terrifying. He or she rarely disclosed it to other people, and hence did not discuss it with others. If the perpetrator died or moved away, the victim often lacked reminders of the experience to prompt recollection during the period when he or she did not think about the abuse. However, encounters with reminders in adulthood prompted recovery of the memory of CSA, and understanding it through the eyes of an adult often resulted in PTSD symptoms. For the first time, victims realized that someone, often someone they knew, loved, and trusted, had sexually exploited them."

\section{IMPLICATIONS OF THE PRESENT RESEARCH FINDINGS AND FUTURE DIRECTIONS}

Data described in chapter $\mathbf{2}$ show that reduced autobiographical memory specificity is not particularly pronounced in people with recovered memories of CSA. We conclude therefore that poor autobiographical memory specificity is unlikely to explain the impression of amnesia reported by this group. These data, by and large, replicate previous findings of McNally et al. (2006) showing that controls provided more specific autobiographical memories than did the continuous, the repressed, and the recovered memory groups. Furthermore, our results support recent findings showing that people reporting a history of CSA are less specific than non-abused controls in response to general (but not concrete) retrieval cues (Hauer, Wessel, Geraerts, Merckelbach, \& Dalgleish, 2008). Because this study did not seek to systematically parse out the presence of psychopathology from trauma exposure, the interpretation that a history of 
trauma exposure alone is critical for poor autobiographical memory specificity remains speculative. Nevertheless, the finding that our groups with CSA memories showed a less specific retrieval style seems consistent with the emphasis that some scholars place on trauma history as an antecedent of reduced autobiographical memory specificity (e.g., Williams, 1996).

The question remains how the impression of amnesia that is almost by definition part of memory recovery can be understood. One possibility is that this impression is not so much carried by a less specific retrieval style, but paradoxically by highly successful retrieval of a series of childhood events. For example, during therapy, patients are often asked to recall various childhood events. Some might attribute the difficulty related to successful retrieval to amnesia. Ultimately, the more events they recall, the more often poor memory will be inferred. There is indeed some experimental evidence that repetitively talking and thinking about one's past might induce an impression of amnesia (e.g., Merckelbach, Wiers, Horselenberg, \& Wessel, 2001; Winkielman, Schwarz, \& Belli, 1998). Clearly, this issue warrants further research within the context of recovered memories.

As described throughout this thesis, recovered memory cases have been interpreted in terms of a heightened susceptibility to false memories but also in terms of a tendency to underestimate prior recall (e.g., Clancy et al., 2000; Loftus \& Davis, 2006; Merckelbach et al., 2006; Schooler, 1999). Findings from the two studies outlined in chapter 3 show that the underestimation of prior remembering and the susceptibility to false memories apparently refer to separate memory phenomena although without defining different profiles in terms of dissociation, fantasy proneness, and cognitive efficiency. Thus, we found that whether participants show a strong or subtle false memory effect is largely independent of the size of their individual FIA effect, suggesting that we are indeed dealing with two different constructs. Meanwhile, the present data also imply that the two memory illusions are not orthogonal. So, there is no reason to assume that those who are susceptible to false memories as indexed by DRM parameters are less susceptible to underestimation of prior recall (as indexed by the FIA effect). The implication of this seems to be that there must be cases in which people exhibit both: a tendency to develop false memories and a tendency to underestimate prior remembering. A thorough examination of how these memory illusions covary in clinical groups, among which people with recovered memories, therefore seems warranted.

An additional rather unexpected result presented in chapter 3 was the finding that cognitive efficiency (as indexed by self-reported cognitive failures) was linked to both underestimation of prior remembering and the susceptibility to false memories. The direction of the correlations suggested that a relative lack of cognitive efficiency to some degree immunizes against false memories and a tendency to overlook previous instances of remembering although, of course, the correlational nature of our findings precludes a causal interpretation of this relationship. Nevertheless, one possible ex- 
planation for the negative association between self-reported cognitive efficiency, false memories, and the FIA effect is that self-reported cognitive efficiency reflects optimism and reliance on liberal criteria for evaluating the accuracy of self-reported memory reports. By this view, heightened levels of cognitive failures would imply that people are critical and use strict standards (see for a similar line of argumentation Hekkanen \& McEvoy, 2002). In more general terms, the significant correlations between self-reported cognitive efficiency and memory illusions illustrate that this might be a fruitful area for further research.

The findings presented in chapter 4 failed to show that individuals harboring recovered memories are worse at dating their recent recalls of vivid memories than people reporting continuous memories of abuse and controls. Importantly, however, source monitoring skills were found to be related to the FIA effect. The fact that the present study does not provide evidence for superior forgetting of prior remembering in people reporting recovered memories of CSA is at odds with previous data (Geraerts et al., 2006, 2009; Merckelbach et al., 2006). One possible explanation might be that the present study specifically selected people who were absolutely certain that they had previously forgotten their memories about their abusive past. One could hypothesize that when people state that they are absolutely certain that the memories were temporarily inaccessible or unavailable, susceptibility to the effect of underestimation of prior remembering is compromised. For example, research shows that when someone is uncertain about his/her own memory (i.e., memory distrust; see Van Bergen, 2011), he or she is more likely to depend on suggestions or cues provided by others potentially resulting in source-monitoring errors (Gudjonsson, 2003). Because chapter 4 shows that underestimation of prior remembering is related to source monitoring problems, it is reasonable to assume that those recovered memory patients who generally distrust their own memory might be especially susceptible to the FIA effect. Future research is, however, needed to investigate the role of self-reported degree of forgetting and memory distrust in dating recent recalls of vivid memories.

Data outlined in chapter 5 illustrate that undergraduates are relatively likely to report recovered memory experiences (i.e., more than one fourth of the present sample reported recovered memory experiences) and (still) tend to hold unrealistic beliefs about memory. Unrealistic assumptions about memory functioning may contribute to the emergence of recovered memories (Lindsay \& Read, 1994; Loftus, 1993), and so these findings are worrisome. For example, it is not too farfetched to believe that such unrealistic assumptions (e.g., "repression exists") about memory might render people increasingly susceptible to adopt false beliefs about harboring repressed memories.

Interestingly, when one enters the terms recovered memories in the Dutch legal database rechtspraak.nl, one obtains 32 hits. Many of these hits pertain to relatively recent cases $(19 \%>2010)$ and to cases that might fly under the radar of the LEBZ. One way to understand this type of recovered memory defense is that defendants and lawyers alike are convinced that there is a thing called repression. 
Findings described in chapter 6 indicate that classifying recovered memory reports produces ambiguous outcomes. Therefore, previous papers on spontaneous versus in therapy recovered memories - including those of our lab (e.g., Geraerts et al., 2009; Raymaekers et al., 2010) - that were based on the classification of a single expert should be interpreted with caution. We propose that a better approach would be one in which independent and multiple expert raters classify cases. By only including cases on which the raters agree or at least by reporting on consistency and variability among the raters in future research, the risk of obtaining biased outcomes is reduced. A beneficial side effect of such an endeavor would be that findings from different laboratories could be compared much more easily and reliably.

Based on data reported in chapter 6 , it can be concluded that the development and later use of a more reliable classification system is needed. In order to classify recovered memory reports, one has to collect specific information about circumstances under which memory recovery took place. Hence, a first attempt at adapting the formerly used semi-structured memory interview (e.g., Raymaekers et al., 2010) was made (see appendix). We admit, however, that empirical investigation is needed to evaluate the usefulness of this revised interviewing procedure.

\section{CONCLUDING REMARKS}

Research on recovered memories is an important area of investigation. In part because of its clear and substantial practical implications and in part because studying individuals reporting recovered memories has the potential to clarify certain fundamental issues regarding the nature of memory. The studies described in the present dissertation aimed at furthering our understanding of recovered memories- one of the most controversial topics in the history of psychology.

Taken together, the findings of the present dissertation have led to the following main conclusions:

- Reduced autobiographical memory specificity is unlikely to explain the impression of amnesia frequently reported by people with recovered memory experiences (chapter 2).

- Susceptibility to false memories and the underestimation of prior memories seem to tap distinct memory phenomena, however, they do not seem to define different profiles in terms of dissociation, fantasy proneness, and cognitive efficiency (chapter 3).

- Better source monitoring abilities go along with a diminished tendency to underestimate prior rememberings (chapter 4).

- A substantial minority of undergraduates report recovered memory experiences and (still) tend to hold unrealistic beliefs about memory (chapter 5).

- Classifying recovered memory claims is a process rife with subjective judgment (chapter 6). 



\section{APPENDIX}

ASSESSING MEMORIES OF CHILDHOOD SEXUAL ABUSE:

REVISED SEMI-STRUCTURED MEMORY INTERVIEW

The present semi-structured memory interview is partly based on the Abuse Recollection Questionnaire developed by Jonathan Schooler (2007, unpublished questionnaire). The Dutch version of this questionnaire was previously used in our lab to assess memories of childhood sexual abuse reported by the patients (e.g., Raymaekers et al., 2010, 2011, 2012). 


\section{SEMI-STRUCTURED MEMORY INTERVIEW ASSESSING MEMORIES OF CHILDHOOD SEXUAL ABUSE}

\section{PART I: PERSONAL INFORMATION}

Age:

Gender:

Level of education:

Current psychological/psychiatric complaints:

Current psychological/psychiatric diagnosis made by a professional:

Past psychological/psychiatric complaints:

Past psychological/psychiatric diagnosis made by a professional:

Current medication use:

Past drug use:

Current drug use:

Occurrence of other types of abuse during childhood (e.g., neglect, emotional abuse, other types of physical abuse):

Important remarks:

\section{PART II: NATURE OF THE CSA HISTORY}

Please describe the abuse event(s) that you remember (e.g., specific acts, context, etc. $)^{\circ}$ :

Approximately how old were you when the abuse started ${ }^{\circ}$ ?

Approximately how old were you when the abuse ended ${ }^{\circ}$ ?

Who was the perpetrator(s) ${ }^{\circ}$ ?

Did the abuse happen more than once ${ }^{\circ}$ ? Yes / No

Approximately how often did it occur ${ }^{\circ}$ ?

How significant did the abuse seem to you at that time (10 point scale) ${ }^{\circ}$ ?

Were the memories about the abuse events ever inaccessible or unavailable to you for a certain period of time? In other words, was there ever a time in which you forgot about the events? Yes / No

\footnotetext{
This question is either identical or very similar to the question addressed in the Abuse Recollection Questionnaire developed by Schooler (2007, unpublished questionnaire).
} 


\section{PART III}

The questions below are specifically about having remembered a specific event that you believe you had previously forgotten (i.e., memories that were once unavailable or inaccessible for a long period of time).

A) The best way to describe my experience of forgetting is as follows (encircle the most suitable option):

- I did not realise that it was sexual abuse at the time it occurred (e.g., I was too young to understand what was going on or events were not experienced as traumatic at that time). Memories were never truly forgotten, however, reinterpretation of the memories evoked the feeling that memories were temporarily gone.

- Reminders of the abuse were temporarily lacking which prevented me from thinking about the events. It felt as if memories were forgotten. However, if someone had asked me whether I was sexually abused as a child, I would have definitely known that I was an abuse victim.

- I actively avoided thinking about the events during that time. If someone had asked me whether I was sexually abused as a child, I would have definitely known that I was an abuse victim.

- Memories were truly inaccessible/unavailable during a certain time period. I am very sure that memories were completely forgotten at that time.

- $\quad$ Other, namely...

B) The following questions are about the period in which you had forgotten about the abuse event(s):

* $\quad$ Did you ever talk to anyone about the event during the period of forgetting ${ }^{\circ}$ ? Yes / No

* Do you think that, during that time, you had completely forgotten about the event (i.e., not just parts or only details of the event, but the entire event itself) ${ }^{\circ}$ ? Yes / No

* Do you think that if someone would have asked you about the event, during that time, you would say that it had never occurred/never happened to you ${ }^{\circ}$ ? Yes / No

\footnotetext{
This question is either identical or very similar to the question addressed in the Abuse Recollection Questionnaire developed by Schooler (2007, unpublished questionnaire).
} 
C) The following questions are about the first time that you remembered the event after the period of forgetting

* What triggered the return of the memories? In other words, what was the reason that you remembered the event again after you had forgotten about it? Encircle the option that reflects best your situation. Note that this question pertains to the first time you recovered the CSA memories after they were forgotten for a certain period of time. "The memories initially came back ... . :

- During therapy in which no special techniques were used to help me uncover the memories

- During therapy in which one of the following techniques was used to help me recover the memories: hypnosis, regression therapy, imagination therapy, inner child sessions, or a similar form of therapy (select the option that best reflects your situation);

- During an alternative form of therapy such as Reiki or chakra healing;

- After talking to someone about a related or similar event/experience outside a therapeutic context;

- After encountering a certain reminder or retrieval cue (e.g., seeing a movie, listening to a specific song, etc) outside a therapeutic context;

- Rather spontaneously, without a specific trigger or cause, outside a therapeutic context;

- During dreams outside a therapeutic context and without being in therapy during the period in which the memories came back;

- Other, namely:

* Approximately how old were you when you remembered the event after the period of forgetting ?

* Were you surprised by the content of the memory ${ }^{\circ}$ ?

Yes / No

* When the memory returned for the very first time, were you surprised that you had forgotten about the event ${ }^{\circ}$ ?

Yes / No

* When the memory returned for the very first time, were you certain about the accuracy of the memory? In other words, were you convinced that the event had

\footnotetext{
This question is either identical or very similar to the question addressed in the Abuse Recollection Questionnaire developed by Schooler (2007, unpublished questionnaire).
} 
actually occurred and could not be just a fantasy ?

Yes / No

* Do you consider this event to be important to you at this particular moment? Yes / No

* What do you believe to be the reason that you had forgotten about the event?

\footnotetext{
'This question is either identical or very similar to the question addressed in the Abuse Recollection Questionnaire developed by Schooler (2007, unpublished questionnaire).
} 

SUMMARY 
The present dissertation addresses the concept of recovered memories of childhood sexual abuse (CSA). Recovered memories involve: (a) reporting to have remembered traumatic childhood experiences after having been unable to recall these memories for a long period of time, (b) relating these past experiences to current psychological complaints (e.g., depressive symptoms), and (c) suggestive therapeutic practices (e.g., hypnosis) or other special circumstances (e.g., presence of suitable retrieval cues) that have contributed to remembering the events (Merckelbach et al., 2010). The debate about the veracity of recovered memories has been one of the most contentious and important controversies in the history of psychology, psychiatry, and the law (e.g., McNally, 2003a).

A fairly new, important and exciting approach to the recovered memory debate involves the application of cognitive paradigms to this field. This approach can inform us about mechanisms underlying alleged repression and recovery processes, as well as false memory development in people reporting recovered memories (McNally, 2003b). Following this line, an important aim of the current thesis is to enhance our understanding of the cognitive mechanisms underlying recovered memories of CSA experiences (PART I). Another exciting research avenue constitutes the taxonomy of various types of recovered memory, an agenda that has scarcely been taken up by researchers. As recovered memory reports are only seldom straightforward and uncomplicated, we expected that making clear-cut categorizations of such reports is a challenging and subjective process. Nevertheless, this issue had never been tested empirically. Hence, the present thesis explores whether the currently applied recovered memory classification procedure is reliable or in need of revisions (PART II).

Chapter 1 presents a case vignette of recovered memories in the legal arena, illustrating the potential devastating nature of the phenomenon. This chapter describes the onset and characteristics of the recovered memory debate and provides an overview of research on recovered memories. It outlines different types of recovered memory experiences and touches upon conceptual problems related to the concept of memory repression. It also addresses the validity of recovered memory reports and their role in the legal arena.

Some authors have speculated that a less specific retrieval style may underlie the subjective experience of amnesia typically reported by people who recover CSA memories (e.g., Dalenberg, 1996; Rassin et al., 2000). Chapter 2 describes a study that tested whether people who recovered CSA memories $(n=44)$ exhibit a less specific retrieval style compared to people reporting continuous memories of CSA (i.e., people who never forgot their abuse experiences; $n=42$ ) and controls (i.e., people without a history of abuse; $n=26$ ). We found no evidence for such a less specific retrieval style in people reporting recovered memories. That is, we observed that people reporting CSA memories - whether continuous or recovered - exhibited reduced autobiographical memory specificity relative to controls. This suggests that reduced autobiographical memory specificity is by itself not typical for people with recovered memories of CSA. 
Exploratively, we also examined whether autobiographical memory specificity differed between people who recovered memories within a therapeutic context and those who recovered memories outside a therapeutic context (i.e., spontaneously recovered memories). Our data, however, did not provide any clue for such a difference.

Memories recovered within a therapeutic context versus spontaneously recovered memories are believed to originate from different cognitive mechanisms. Specifically, previous research found indications that in therapy recovered memories are related to enhanced susceptibility to false memory development (DRM effect; e.g., Clancy et al., 2000), whereas spontaneously recovered memories are associated with underestimation of prior remembering (FIA effect; e.g., Merckelbach et al., 2006). However, whether the DRM and the FIA effect reflect two distinct and unrelated pathways, going along with their own set of personality features, has not yet been investigated. Hence, two studies described in chapter $\mathbf{3}$ explored whether the susceptibility to false memories and the underestimation of prior memories tap distinct underlying mechanisms. Results from study 1 (undergraduate sample, $N=110$ ) indicated that FIA and DRM performance are, indeed, relatively independent from each other, suggesting that these effects refer to separate dimensions. However, we also found that these constructs do not seem to be associated with different profiles in terms of dissociation, fantasy proneness, or cognitive efficiency. Study 2 replicated the finding of the relative independence between false memory propensity (as measured with the DRM task) and the underestimation of prior memories (as measured with an autobiographical memory dating task) in people with a CSA history $(N=35)$. So, false memory susceptibility and underestimation of prior retrieval are not related to each other, but this fact alone does not necessarily imply that there exist two distinct types of recovered memories.

As stated above, earlier research has shown that people reporting spontaneously recovered memories of CSA exhibit a stronger tendency to underestimate their prior rememberings relative to people with continuous CSA memories and controls (e.g., Merckelbach et al., 2006). An important issue is whether the FIA effects observed in people with recovered memories reflects a distinct phenomenon or whether it reflects a general lack of metamemory functioning, most notably source monitoring (i.e., cognitive processes involved in making attributions about the origins of memories, knowledge, and beliefs; Johnson et al., 1993, pp. 3). With this in mind, chapter 4 presents a study in which people reporting recovered $(n=12)$ or continuous CSA memories $(n=$ $35)$ and non-traumatized controls $(n=27)$ were compared with regard to their performance on an autobiographical version of the FIA task and their source monitoring abilities. Our data failed to show that individuals harboring recovered memories are worse at dating their recent recalls of vivid memories than people reporting continuous memories of abuse and controls. If anything, they tended to perform better than the other groups. Additionally, source monitoring skills were found to be related to the 
FIA effect. Thus, the idea that underestimation of prior memories is highly specific for and defines a specific subtype of recovered memories needs to be reconsidered.

The studies described in this dissertation and summarized above focused on cognitive mechanisms underlying recovered memory experiences. Given that we found little evidence for a specific cognitive architecture of various recovered memory types, we decided to focus on the phenomenology of recovered memories. Thus, the next two chapters and appendix were concerned with the occurrence of spontaneously recovered memory experiences and beliefs concerning trauma and memory in undergraduates (chapter 5 ) as well as the classification of recovered memory experiences (chapter 6 and appendix). One could say that the second part of this thesis mainly addresses definitional problems related to recovered memories. These problems are suggested to be inherent to the scientific study of recovered memories causing experimental pitfalls for research within the field and the judicial context. The inclusion of a revised interview procedure (appendix) constitutes an attempt to inform future research on recovered memories.

Chapter 5 describes a study in which undergraduates $(N=135)$ were inquired about personal recovered memory experiences and beliefs about memory functioning. Some authors believe that that unrealistic beliefs about memory contribute to the emergence of recovered memories (e.g., Lindsay \& Read, 1994). Older studies had demonstrated that people tended to hold unrealistic beliefs about memory functioning (e.g., Merckelbach \& Wessel, 1998). Over the past decade, however, much effort has been dedicated to debunking myths about trauma and memory (e.g., McNally, 2003a, 2004a, 2004c, 2005). Hence, we hypothesized that widespread dissemination of knowledge on how human memory generally functions would have led to relatively limited reporting of recovered memory experiences and a lowered rate of faulty assumptions about memory functioning. Contrary to this expectation, chapter 5's data illustrate that a non-trivial proportion of undergraduates report recovered memory experiences (i.e., more than one fourth of the present sample reported recovered memory experiences) and (still) tend to hold unrealistic beliefs about memory.

In practice it has proven to be difficult, for researchers and clinicians, to reliably classify claims of recovered memories solely on the basis of the available general descriptions of the different categories. Therefore, the study presented in chapter 6 explored how four expert raters independently interpreted and categorized verbatim descriptions of CSA memories $(N=52)$. A substantial disagreement was found between the expert raters (e.g., in only $63 \%$ of the cases all four raters agreed upon the classification category) illustrating that classifying recovered memory claims is a process potentially rife with subjective judgment.

Based on findings of the aforementioned chapter, we concluded that the development and subsequent employment of a more reliable classification system is needed. In order to classify recovered memory reports, one has to collect specific information about circumstances under which memory recovery took place. Hence, a 
first attempt at adapting the formerly used semi-structured memory interview (e.g., Raymaekers et al., 2010) was made (revised semi-structured memory interview; see appendix). 

SAMENVATTING 
Dit proefschrift gaat over hervonden herinneringen aan seksueel misbruik tijdens de kindertijd (SKM). Hervonden herinneringen omvatten: (a) het rapporteren van herinneringen aan traumatische ervaringen na een periode van amnesie, (b) het toeschrijven huidige psychische klachten (bijvoorbeeld depressieve symptomen) aan gebeurtenissen uit het verleden en, (c) de mogelijke aanwezigheid van therapeutische interventies (bijvoorbeeld hypnose) of andere bijzondere omstandigheden (bijvoorbeeld, de aanwezigheid van geschikte ophaal cues) die hebben bijgedragen aan het herinneren van de gebeurtenissen (Merckelbach et al., 2010). Hét debat betreffende hervonden herinneringen, namelijk de discussie over de juistheid van hervonden herinneringen, staat bekend als een van de meest omstreden en belangrijke controverses in de geschiedenis van de psychologie, psychiatrie, en de rechtspraktijk (bv., McNally, 2003a).

Een vrij nieuwe, belangrijke, en spectaculaire benadering van het debat over hervonden herinneringen heeft betrekking op de toepassing van methoden uit de cognitieve psychologie op dit gebied. Deze experimentele onderzoeken kunnen ons informeren over mechanismen die mogelijk ten grondslag liggen aan vermeende onderdrukking en herstel. Tevens kunnen ze bijdragen aan kennisvergaring met betrekking tot het ontwikkelen van valse herinneringen in mensen met hervonden herinneringen (McNally, 2003b). Daarom is een belangrijk doel van dit proefschrift meer te weten te komen over de cognitieve mechanismen die ten grondslag liggen aan hervonden herinneringen van SKM ervaringen (DEEL I). Een ander boeiend onderzoeksgebied betreft de identificatie van verschillende types van hervonden herinneringen. Vermits hervonden herinneringsrapportages slechts zelden eenvoudig en ongecompliceerd zijn, werd verondersteld dat het maken van indelingen van deze rapportages een uitdagend maar ook subjectief proces zou vormen. Deze aanname werd echter nooit eerder empirisch getoetst. Vandaar dat dit proefschrift onderzoekt of de huidige classificatieprocedure inzake hervonden herinneringen betrouwbaar is, of dat aanpassingen noodzakelijk zijn (DEEL II).

Hoofdstuk 1 beschrijft een casus over hervonden herinneringen in de juridische context, ter illustratie van de potentieel verwoestende aard van het verschijnsel. Dit hoofdstuk handelt over het ontstaan en de kenmerken van het debat omtrent hervonden herinneringen en geeft een overzicht van het onderzoek naar hervonden herinneringen. Het beschrijft verschillende typen van hervonden herinneringservaringen en brengt enkele conceptuele problemen in kaart die verband houden met geheugenrepressie. Ook wordt ingegaan op de betrouwbaarheid van hervonden herinneringsrapportages en hun rol in de rechtszaal.

Sommige auteurs hebben gesuggereerd dat het habitueel moeite hebben met het herinneren van specifieke gebeurtenissen kan bijdragen aan de subjectieve ervaring van amnesie die wordt gerapporteerd door mensen met hervonden herinneringen (bv., Dalenberg, 1996; Rassin et al., 2000). Daartoe beschrijft hoofdstuk 2 een studie naar of mensen met hervonden herinneringen aan SKM $(n=44)$ meer moeite vertonen in het ophalen van specifieke herinneringen in vergelijking met mensen die continue 
herinneringen aan SKM rapporteren (dat wil zeggen, mensen die nooit hun misbruik ervaringen vergaten, $n=42$ ) en controles (mensen zonder een misbruikgeschiedenis, $n$ = 26). Dat bleek niet het geval. Wel kon worden aangetoond dat mensen met SKM herinneringen - hetzij continu, hetzij hervonden - een verminderde autobiografische geheugenspecificiteit vertoonden ten opzichte van controles. Deze bevinding laat zien dat verminderde autobiografische geheugenspecificiteit op zichzelf niet kenmerkend is voor mensen met hervonden herinneringen aan SKM. Op exploratieve basis hebben we tevens onderzocht of autobiografische geheugenspecificiteit verschilde tussen mensen met in therapie hervonden herinneringen versus degenen met spontane (buiten therapie context) hervonden herinneringen. Onze gegevens wijzen erop dat dit niet het geval is.

$\mathrm{Er}$ is wel beweerd dat aan in therapie versus spontaan hervonden herinneringen verschillende cognitieve mechanismen ten grondslag liggen. In het bijzonder blijkt uit onderzoek dat in therapie hervonden herinneringen te maken hebben met een verhoogde vatbaarheid voor pseudoherinneringen (zoals het DRM effect; bv., Clancy et al., 2000), terwijl spontaan hervonden herinneringen geassocieerd worden met een algehele onderschatting van voorgaande herinneringen (FIA effect; bv., Merckelbach et al., 2006). Of DRM en FIA effecten daadwerkelijk twee verschillende en ongerelateerde fenomenen zijn, en tevens gepaard gaan met verschillende persoonlijkheidsprofielen, werd tot op heden nog niet onderzocht. Vandaar dat hoofdstuk 3 twee studies beschrijft waarin werd nagegaan of de vatbaarheid voor pseudoherinneringen en het onderschatten van eerdere herinneringen overlappende of onafhankelijke geheugenverschijnselen zijn. De resultaten van onderzoek 1 (studentensteekproef, $N=110$ ) tonen aan dat FIA en DRM effecten relatief onafhankelijk van elkaar zijn en als afzonderlijke dimensies kunnen worden beschouwd. Bovendien werd vastgesteld dat de vatbaarheid voor beide effecten niet lijkt samen te hangen met de persoonlijkheidskenmerken dissociatie, fantasierijkheid, en cognitieve efficiëntie. In studie 2 werden de data van studie 1 gerepliceerd met mensen met een SKM geschiedenis $(N=35)$.

Er wordt wel aangenomen dat mensen met spontaan hervonden herinneringen aan SKM zich kenmerken door een verhoogde neiging tot het onderschatten van voorgaande herinneringen (bv., Merckelbach et al., 2006). Een belangrijke vraag is of dit fenomeen een weerspiegeling vormt van een algemeen gebrekkig metageheugen, in het bijzonder bronverwarring (dit laatste verwijst naar cognitieve processen die betrokken zijn bij het oordelen over de oorsprong van herinneringen, kennis en overtuigingen; Johnson et al., 1993, pp. 3). Daarom beschrijft hoofdstuk 4 een studie waarin mensen met hervonden herinneringen aan SKM $(n=12)$, continue herinneringen aan SKM $(n=35)$ en niet-getraumatiseerde controles $(n=27)$ werden vergeleken met betrekking tot hun prestaties op een autobiografische versie van de FIA taak en hun brononderscheidende capaciteiten. In tegenstelling tot voorgaand onderzoek laten de huidige gegevens niet zien dat individuen met hervonden herinneringen minder goed zijn in het dateren van hun voorgaande herinneringen dan mensen die continue herin- 
neringen rapporteren of controles. Sterker nog, ze blijken zelfs iets beter te presteren dan de andere groepen. Belangrijk is de bevinding dat bronverwarring bijdraagt aan het FIA effect, in die zin dat meer bronverwarring samen gaat met een sterkere onderschatting van voorgaande herinneringen.

De studies die tot nog toe werden samengevat, richten zich allemaal op cognitieve mechanismen die ten grondslag liggen aan hervonden herinneringservaringen. De twee volgende hoofdstukken handelen over het optreden van spontaan hervonden herinneringservaringen en opvattingen over trauma en geheugen in studenten (hoofdstuk 5), evenals het classificeren van hervonden herinneringservaringen (hoofdstuk 6 en bijlage). Men zou kunnen stellen dat het tweede deel van dit proefschrift voornamelijk gaat over conceptuele en subjectieve problemen. Deze problemen zijn mogelijk inherent aan de definitie van en het onderzoek naar hervonden herinneringen en kunnen daardoor eventuele valkuilen veroorzaken in de wetenschappelijke en strafrechtelijke context. De opname van een herziene interview procedure (bijlage) dient te worden gezien als poging om toekomstig onderzoek naar hervonden herinneringen hierover te informeren.

Hoofdstuk 5 schetst een studie waarin studenten $(\mathrm{N}=135)$ worden bevraagd over hervonden herinneringservaringen en overtuigingen over het functioneren van het geheugen. Onderzoekers hebben gesuggereerd dat onrealistische opvattingen over het geheugen bijdragen aan het ontstaan van hervonden herinneringen (bv., Lindsay \& Read, 1994). Belangrijk is het gegeven dat oudere studies aantoonden dat mensen sterk geneigd zijn om vast te houden aan dergelijke onrealistische opvattingen over het geheugen (bv., Merckelbach \& Wessel, 1998). De afgelopen tien jaar is echter veel moeite geïnvesteerd in het ontkrachten van mythes over trauma en geheugen (bijv. McNally, 2003a, 2004a, 2004c, 2005). Daarom werd in de huidige studie verondersteld dat een brede verspreiding van kennis over de manier waarop het menselijk geheugen functioneert ertoe heeft geleid dat relatief weinig studenten hervonden herinneringservaringen rapporteren. Bovendien werd verwacht dat men er amper nog foutieve aannames over het functioneren van het geheugen op na zou houden. In tegenstelling tot wat werd verwacht, tonen de huidige gegevens aan dat meer dan een op vier studenten hervonden herinneringservaringen rapporteert en dat ze (nog steeds) onrealistische opvattingen over het geheugen hebben.

In de praktijk is het moeilijk gebleken om hervonden herinneringservaringen betrouwbaar in te delen op grond van de beschikbare, algemene beschrijving van de verschillende typologieën. Daarom werd in de studie die wordt beschreven in hoofdstuk 6 onderzocht hoe vier deskundige, onafhankelijke beoordelaars verbale rapportages van hervonden herinneringen interpreteerden en classificeerden $(N=52)$. De deskundige beoordelaars leken regelmatig te verschillen van mening (bijvoorbeeld in slechts $63 \%$ van de gevallen werd er tussen alle vier beoordelaars overeenstemming bereikt over de indeling van de rapportages) wat erop wijst dat het indelen van hervonden herinneringen een moeizaam, subjectief proces is. 
Op grond van bovengenoemde resultaten kan worden geconcludeerd dat de ontwikkeling en het latere gebruik van een betrouwbaarder classificatiesysteem noodzakelijk is. Om hervonden herinneringsrapportages te classificeren, moet men specifieke informatie verzamelen over de omstandigheden waaronder het hervinden van de herinneringen heeft plaatsgevonden. In dit proefschrift werd een eerste poging hiertoe ondernomen door een reeds bestaande semigestructureerde interviewprocedure (bv., Raymaekers et al., 2010) aan te passen (zie bijlage). 

REFERENCES 
Abenavoli, R., \& Henkel, L. A. (2009). Remembering when we last remembered our childhood experiences: Effects of age and context on retrospective memory judgments. Applied Cognitive Psychology, 23, 717732.

Alison, L., Kebbell, M., \& Lewis, P. (2006). Considerations for experts in assessing the credibility of recovered memories of child sexual abuse: The importance of maintaining a case-specific focus. Psychology, Public Policy and Law, 12, 419-441.

American Psychiatric Association. (2000). Diagnostic and statistical manual of mental disorders (4th ed, text rev.). Washington, DC: Author.

Arnold, M. M., \& Lindsay, D. S. (2002). Remembering remembering. Journal of Experimental Psychology: Learning, Memory, and Cognition, 28, 521-529.

Arnold, M. M., \& Lindsay, D. S. (2005). Remembrance of remembrance past. Memory, 13, 533-549.

Beck, A. T., Steer, R. A., Carbin, M. G. (1988). Psychometric properties of the Beck Depression Inventory: Twenty-five years of evaluation. Clinical Psychology Review, 8, 77-100.

Beck, A. T., Ward, C. H., Mendelson, M., Mock, J., \& Erbaugh, J. (1961). An inventory for measuring depression. Archives of General Psychiatry, 4, 561- 571.

Beetstra, T. A. (2004). Massahysterie in de Verenigde Staten en Nederland: De affaire rond de McMartin PreSchool en het ontuchtschandaal in Oude Pekela [Mass hysteria in the United States and the Netherlands: Discussing the McMartin Pre-School and the Oude Pekela case], in P. Burger en W. Koetsenruijter (Eds.), Mediahypes en moderne sagen: Sterke verhalen in het nieuws (pp. 53-69). Leiden: Stichting neerlandistiek Leiden.

Beetstra, T. A. (2009). Van kwaad tot erger: De sociale constructie van satanisch ritueel misbruik in de Verenigde Staten en Nederland [From bad to worse: The social construction of satanic ritual abuse in the United States and the Netherlands]. Dissertation, Maastricht University, Maastricht.

Belli, R. F., \& Loftus, E.F. (1994). Recovered memories of childhood abuse: A source monitoring perspective. In S.J. Lynn \& J.W. Rhue (Eds.) Dissociation: Clinical and theoretical perspectives (pp. 415-433). New York: Guilford Press.

Belli, R. F., Winkielman, P., Read, J.D., Schwarz, N., \& Lynn, S. J. (1998). Recalling more childhood events leads to judgments of poorer memory: Implications for the recovered/false memory debate. Psychonomic Bulletin and Review, 5, 318-323.

Benner, E. L., \& Lindsay, D. S. (2007). Memory of remembering: Investigating the forgot-it-all-along effect using pictures. Psi Chi Journal of Undergraduate Research, 12.

Bernstein, E. M., \& Putnam, F. W. (1986). Development, reliability and validity of a dissociation scale. Journal of Nervous and Mental Disease, 174, 727-735.

Bigelsen, J., \& Schupak, C. (2011). Compulsive fantasy: Proposed evidence of an under-reported syndrome through a systematic study of 90 self-identified non-normative fantasizers. Consciousness and Cognition, 20, 1634-1648.

Bonanno, G.A. (2006). The illusion of repression memory. Behavioral and Brain Sciences, 29, 515-516.

Bornstein, B. H., \& Muller, S. L. (2001). The credibility of recovered memory testimony: Exploring the effects of alleged victim and perpetrator gender. Child Abuse and Neglect, 25, 1415-1426.

Bottoms, B. L., \& Davis, S. L. (1997). The creation of satanic ritual abuse. Journal of Social and Clinical Psychology, 16, 112-132.

Brainerd, C. J., \& Reyna, V. F. (1998). Fuzzy trace theory and children's false memories. Journal of Experimental Child Psychology, 71, 81-129.

Brainerd, C. J., Reyna, V. F., \& Ceci, S. J. (2008). Developmental reversals in false memory: A review of data and theory. Psychological Bulletin, 134, 343-382.

Brewin, C. R., \& Andrews, B. (1998). Recovered memories of trauma: Phenomenology and cognitive mechanisms. Clinical Psychology Review, 18, 949-970.

Briere, J., \& Conte, J. (1993). Self-reported amnesia for abuse in adults molested as children. Journal of Traumatic Stress, 6, 21-31.

Broadbent, D. E., Cooper, P. F., Fitzgerald, P., \& Parkes, L. R. (1982). The Cognitive Failures Questionnaire (CFQ) and its correlates. British Journal of Clinical Psychology, 21, 1-16. 
Brown, D., Scheflin, A. W., \& Hammond, D. C. (1998). Memory, trauma treatment, and the law. New York: Norton.

Brown, D., Scheflin, A. W., \& Whitfield, C. L. (1999). Recovered memories: The current weight of the evidence in science and in the courts. Journal of Psychiatry and Law, 27, 5-156.

Buck, J. A., \& Warren, A. R. (2010). Expert testimony in recovered memory trials: Effects on mock juror's opinions, deliberations, and verdicts. Applied Cognitive Psychology, 24, 495-512.

Candel, I., Merckelbach, H., \& Kuijpers, M. (2003). Dissociative experiences are related to commissions in emotional memory. Behaviour Research and Therapy, 41, 719-725.

Carriere, J. S. A, Cheyne, J. A., \& Smilek, D. (2007). Everyday attention lapses and memory failures: The affective consequences of mindlessness. Consciousness and Cognition, 17, 835-847.

Cheyne, J. A., Carriere, J. S. A., \& Smilek, D. (2006). Absent-mindedness: Lapses of conscious awareness and everyday cognitive failures. Consciousness and Cognition, 15, 578-592.

Clancy, S. (2005). Abducted: How people come to believe they were kidnapped by aliens. Cambridge, Massachusetts: Harvard University Press.

Clancy, S. (2010). The trauma myth: The truth about the sexual abuse of children - and its aftermath. New York: Basic Books.

Clancy, S. A., \& McNally, R. J. (2005/2006). Who needs repression? Normal memory processes can explain "forgetting" of childhood sexual abuse. Scientific Review of Mental Health Practice, 4, 66-73.

Clancy, S. A., Schacter, D. L., McNally, R. J., \& Pitman, R. K. (2000). False recognition in women reporting recovered memories of sexual abuse. Psychological Science, 11, 26-31.

Coleman, B. L., Stevens, M. J., \& Reeder, G. D. (2001). What makes recovered-memory testimony compelling to jurors? Law and Human Behavior, 25, 317-338.

Collins, A. M., \& Loftus, E. F. (1975). A spreading-activation theory of semantic processing. Psychological Review, 82, 407-428.

Conway, M. A., \& Pleydell-Pearce, C. W. (2000). The construction of autobiographical memories in the selfmemory system. Psychological Review, 107, 261-288.

Corwin, J. (1994). On measuring discrimination and response bias: Unequal numbers of targets and distractors. Neuropsychology, 8, 110-117.

Crane, C., \& Duggan, D. S. (2009). Overgeneral autobiographical memory and age of onset of childhood sexual abuse in patients with recurrent suicidal behaviour. British Journal of Clinical Psychology, 48, 93100.

Crombag, H. F. M., \& Merckelbach, H. (1996). Hervonden herinneringen en andere misverstanden [Recovered memories and other misunderstandings]. Amsterdam: Contact.

Crombag, H. F. M., \& Van Koppen, P. J. (1994). Verdringen als sociaal verschijnsel [Repression as a social phenomenon]. De Psycholoog, 29, 409-415.

Crombag, H. F. M., \& Wagenaar, W. A. (2000). Audite et alteram partem. Trema, 23, 93-96.

Dalenberg, C. J. (1996). Accuracy, timing and circumstances of disclosure in therapy of recovered and continuous memories of abuse. Journal of Psychiatry and Law, 24, 229-275.

Dalenberg, C. J., Brand, B. L., Gleaves, D. H., Dorahy, M. J., Loewenstein, R. J., Cardena, E., . . Spiegel, D. (2012). Evaluation of the evidence for the trauma and fantasy models of dissociation. Psychological Bulletin, 138, 550-588.

Deese, J. (1959). On the prediction of occurrence of particular verbal intrusions in immediate recall. Journal of Experimental Psychology, 58, 17-22.

Dehon, H., Bastin, C, \& Larøi, F. (2008). The influence of delusional ideation and dissociative experiences on the resistance to false memories in normal healthy subjects. Personality and Individual Differences, 45 , 62-67.

Delaney, P. F., Sahakyan, L., Kelley, C. M., \& Zimmerman, C. A. (2010). Remembering to forget: The amnesic effect of daydreaming. Psychological Science, 21, 1036-1042.

Drivdahl, S. B., \& Zaragoza, M. S. (2001). The role of perceptual elaboration and individual differences in the creation of false memories for suggested events. Applied Cognitive Psychology, 15, 265-281. 
Eacott, M. J., \& Crawley, R. A. (1998). The offset of childhood amnesia: Memory for events that occurred before age 3. Journal of Experimental Psychology: General, 127, 22-33.

Elliot, D. M. (1997). Traumatic events: Prevalence and delayed recall in the general population. Journal of Consulting and Clinical Psychology, 65, 811-820.

Epstein, M. A., \& Bottoms, B. L. (1998). Memories of childhood sexual abuse: A survey of college students. Child Abuse and Neglect, 22, 1217-1238.

Epstein, M. A., \& Bottoms, B. L. (2002). Explaining the forgetting and recovery of abuse and trauma memories: Possible mechanisms. Child Maltreatment, 7, 210-225.

Erdelyi, M. H. (2006). The unified theory of repression. Behavioral and Brain Sciences, 29, 499-551.

Fleiss, J. L. (1986). The design and analysis of clinical experiments. New York: Wiley.

Foa, E. B., Riggs, D. S., Dancu, C. V., \& Rothbaum, B. O. (1993). Reliability and validity of a brief instrument for assessing post-traumatic stress disorder. Journal of Traumatic Stress, 6, 459-473.

Frenda, S. J., Nichols, R. M., \& Loftus, E. F. (2011). Current issues and advances in misinformation research. Current Directions in Psychological Science, 20, 20-23.

Freyd, J. J. (1998). Science in the memory debate. Ethics \& Behavior, 8, 101-113.

Freyd, J. J., \& Gleaves, D. F. (1996). "Remembering" words not presented in lists: Relevance to the current recovered/false memory controversy. Journal of Experimental Psychology: Learning, Memory and Cognition, 22, 811-813.

Garry, M., Loftus, E. F., \& Brown, S. B. (1994). Memory: A river runs through it. Consciousness and Cognition, 3, 438-451.

Geraerts, E., Arnold, M. M., Lindsay, D. S., Merckelbach, H., Jelicic, M., \& Hauer, B. J. A. (2006). Forgetting of prior remembering in people reporting recovered memories of childhood sexual abuse. Psychological Science, 17, 1002-1008.

Geraerts, E., Lindsay, D. S., Merckelbach, H., Jelicic, M., Raymaekers, L., Arnold, M. M., \& Schooler, J. S. (2009). Cognitive mechanisms underlying recovered memory experiences of childhood sexual abuse. Psychological Science, 20, 92-98.

Geraerts, E., Schooler, J. W., Merckelbach, H., Jelicic, M., Hauer, B. J. A., \& Ambadar, Z. (2007). The reality of recovered memories: Corroborating continuous and discontinuous memories of childhood sexual abuse. Psychological Science, 18, 564-567.

Gezondheidsraad (2004). Omstreden herinneringen [Disputed memories]. Publicatie nr. 2004/02. Den Haag: Gezondheidsraad.

Giesbrecht, T, Geraerts, E., \& Merckelbach, H. (2007). Dissociation, memory commission errors, and heightened autonomic reactivity. Psychiatry Research, 150, 277-285.

Giesbrecht, T., Lynn, S. J., Lilienfeld, S. O., \& Merckelbach, H. (2008). Cognitive processes in dissociation: An analysis of core theoretical assumptions. Psychological Bulletin, 134, 617-647.

Giesbrecht, T., \& Merckelbach, H. (2004). Subjective sleep experiences are related to dissociation. Personality and Individual Differences, 37, 1341-1345.

Golding, J. M., Sanchez, R. P., \& Sego, S. A. (1996). Do you believe in repressed memories? Professional Psychology: Research and Practice, 27, 429-437.

Golding, J. M., Sego, S. A., Sanchez, R. P., \& Hasemann, D. (1995). The believability of repressed memories. Law and Human Behavior, 19, 569-592.

Goodman, G. S., Ogle, C. M., Block, S. D., Harris, L., Larsen, R., Augusti, E-M., . . Urquiza, A. (2011). False memory for trauma-related DRM lists in adolescents and adults with histories of child sexual abuse. Development and Psychopathology, 23, 423-438.

Griffith, J. D. (1999). Repressed memories in the courtroom: Trial characteristics affecting mock juror's decision making. American Journal of Forensic Psychology, 17, 5-24.

Grove, W. M., \& Lloyd, M. (2006). Meehl's contribution to clinical versus statistical prediction. Journal of Abnormal Psychology, 115, 1992-194.

Gudjonsson, G. H. (2003). The psychology of interrogations and confessions: A handbook. New York: Wiley.

Harvey, A. G., Bryant, R. A., \& Dang, S. T. (1998). Autobiographical memory in acute stress disorder. Journal of Consulting and Clinical Psychology, 66, 500-506. 
Hauer, B. J. A., Wessel, I., Geraerts, E., Merckelbach, H., \& Dalgleish, T. (2008). Autobiographical memory specificity after manipulating retrieval cues in adults reporting childhood sexual abuse. Journal of $A b$ normal Psychology, 117, 444-453.

Hayne, H., Garry, M., \& Loftus, E. F. (2006). On the continuing lack of scientific evidence for repression. Behavioral and Brain Sciences, 29, 521-522.

Henquet, C., Krabbendam, L., Dautzenberg, J., Jolles, J., \& Merckelbach, H. (2005). Confusing thoughts and speech: Source monitoring and psychosis. Psychiatry Research, 133, 57-63.

Hekkanen, S. T., \& McEvoy, C. (2002). False memories and source-monitoring problems: Criterion differences. Applied Cognitive Psychology, 16, 73-85.

Hermans, D., van den Broeck, K., Belis, G., Raes, F., Pieters, G., \& Eelen, P. (2004). Trauma and autobiographical memory specificity in depressed inpatients. Behaviour Research and Therapy, 42, 775-789.

Höing M., Van Engen A., Ensink B., Vennix P., \& Vanwesenbeeck I. (2003). Hulp aan slachtoffers van seksueel geweld. Een inventarisatie en kwaliteitsevaluatie van de behandeling van slachtoffers van seksueel geweld in de GGZ en de vrouwenopvang in Nederland [Helping victims of sexual violence]. Delft: Eburon.

Horselenberg, R., Merckelbach, H., \& Josephs, S. (2003). Individual differences and false confessions: A conceptual replication of Kassin and Kiechel (1996). Psychology, Crime and Law, 9, 1-8.

Howe, M. L. (2008). What is false memory development the development of? Comment on Brainerd, Reyna, and Ceci. Psychological Bulletin, 134, 768-772.

Howe, M. L. (2012). Memory lessons from the courtroom: Reflections on being a memory expert on the witness stand. Article to appear in Memory \& The Law: Case Studies. [Special 2013 issue of Memory edited by M.A. Conway and M.L. Howe].

Howe, M. L., Wimmer, M. C., Gagnon, N., \& Plumpton, S. (2009). An associative-activation theory of children's and adults' memory illusions. Journal of Memory and Language, 60, 229-251.

Huntjens, R. J. C., Verschuere, B., \& McNally, R. J. (2012). Inter-identity autobiographical amnesia in patients with dissociative identity disorder. PLoS One, 7, e40580.

Hyman, I. E., \& Billings, F. J. (1998). Individual differences and the creation of false childhood memories. Memory, 6, 1-20.

Hyman, I. E., Husband, T. H., \& Billings, F. J. (1995). False memories of childhood experiences. Applied Cognitive Psychology, 9, 181-197.

Janet, P. (1889). L'Automatisme psychologique [Psychological automatism]. Paris: Félix Alcan.

Jelicic, M., Smeets, T., Peters, M., Candel, I., Horselenberg, R., \& Merckelbach, H. (2006). Assassination of a controversial politician: Remembering details from a non-existent film. Applied Cognitive Psychology, 20, 591-596.

Johnson, M.K. (1997). Source monitoring and memory distortion. Philosophical Transactions of the Royal Society: Biological Sciences, 352, 1733-1745.

Johnson, M. K., Hashtroudi, S., \& Lindsay, D. S. (1993). Source monitoring. Psychological Bulletin, 114, 3-28.

Kihlstrom, J.F. (2006). Repression: A unified theory of a will-o'-the-wisp. Behavioral and Brain Sciences, 29, 523.

Kleim, B., \& Ehlers, A. (2008). Reduced autobiographical memory specificity predicts depression and posttraumatic stress disorder after recent trauma. Journal of Consulting and Clinical Psychology, 76, 231242.

Kuyken, W., \& Brewin, C. R. (1995). Autobiographical memory functioning in depression and reports of early abuse. Journal of Abnormal Psychology, 104, 585-591.

Lilienfeld, S. O., Lynn, S. J., Ruscio, J., \& Beyerstein, B. L. (2010). Fifty great myths of popular psychology. Shattering widespread misconceptions about human behaviour. Chichester, UK: Wiley.

Lindsay, D. S., Hagen, L., Read, J.D., Wade, K. A., \& Garry, M. (2004). True photographs and false memories. Psychological Science, 15, 149-154.

Lindsay, D. S., \& Johnson, M. K. (1989). The eyewitness suggestibility effect and memory for source. Memory and Cognition, 17, 349-358.

Lindsay, D. S., \& Johnson, M. K. (2000). False memories and the source monitoring framework: Reply to Reyna and Lloyd (1997). Learning and Individual Differences, 12, 145-161. 
Lindsay, D. S., \& Read, J. D. (1994). Psychotherapy and memories of childhood sexual abuse: A cognitive perspective. Applied Cognitive Psychology, 8, 281-338.

Lindsay, D. S., \& Read, J. D. (1995). "Memory work" and recovered memories of childhood sexual abuse: Scientific evidence and public, professional, and personal issues. Psychology, Public Policy, and Law, 1, 846-908.

Lindsay, D. S., \& Read, J. D. (2001). The recovered memories controversy: Where do we go from here? In G. M. Davies \& T. Dalgleish (Eds.), Recovered memories: Seeking the middle ground (pp. 71-93). Chichester, UK: Wiley.

Llewellyn, S. (in press.). Such stuff as dreams are made on? Elaborative encoding, the ancient art of memory and the hippocampus. Behavioral and Brain Sciences.

Loftus, E. F. (1993). The reality of repressed memories. American Psychologist, 48, 518-537.

Loftus, E. F. (2004). Memories of things unseen. Current Directions in Psychological Science, 13, 145-147.

Loftus, E. F. (2005). Planting misinformation in the human mind: A 30-year investigation of the malleability of memory. Learning and Memory, 12, 361-366.

Loftus, E. F., \& Cahill, L. (2007). Memory distortion: From misinformation to false memory. In J.S. Nairne (Ed.), The foundations of remembering: Essays in honor of Henry L. Roediger, III. (pp. 413-425). New York: Psychology Press.

Loftus, E. F., \& Davis, D. (2006). Recovered memories. Annual Review of Clinical Psychology, 2, 469-498.

Loftus, E. F., Joslyn, S., \& Polage, D. (1998). Repression: A mistaken impression. Development and Psychopathology, 10, 781-792.

Loftus, E., \& Ketcham, K. (1994). The myth of repressed memory: False memories and allegations of sexual abuse. New York: St. Martin's Press.

Loftus, E. F., Polonsky, S., \& Fullilove, M. (1994). Memories of childhood sexual abuse: Remembering and repressing. Psychology of Women Quarterly, 18, 67-84.

Loftus, E. F., Weingardt, K. R., \& Hoffman, H. G. (1993). Sleeping memories on trial: Reactions to memories that were previously repressed. Expert Evidence: The International Digest of Human Behavior Science and Law, 2, 51-59.

Magnussen, S., Andersson, J., Cornoldi, C., De Beni, R., Endestad, T., Goodman, G. S., Zimmer, H. (2006). What people believe about memory. Memory, 14, 595-613.

Magnussen, S., \& Melinder, A. (2012). What psychologists know and believe about memory: A survey of practitioners. Applied Cognitive Psychology, 26, 54-60.

McGraw, K. O., \& Wong, S. P. (1996). Forming inferences about some intraclass correlation coefficients. Psychological Methods, 1, 30-46.

McHugh, P. R., Lief, H. I., Freyd, P. P., \& Fetkewicz, J. M. (2004). From refusal to reconciliation: Family relationships after an accusation based on recovered memories. The Journal of Nervous and Mental Disease, 192, 525-531.

McNally, R. J. (2003a). Remembering trauma. Cambridge, MA: Belknap Press/Harvard University Press.

McNally, R. J. (2003b). Recovering memories of trauma: A view from the laboratory. Psychological Science, 12, 32-35.

McNally, R. J. (2004a). The science and folklore of traumatic amnesia. Clinical Psychology: Science and Practice, 11, 29-33.

McNally, R. J. (2004b). Conceptual problems with the DSM-IV criteria for posttraumatic stress disorder. In G. M. Rosen (Ed.), Posttraumatic stress disorder: Issues and controversies (pp. 1-14). New York: Wiley.

McNally, R. J. (2004c). Is traumatic amnesia nothing but psychiatric folklore? Cognitive Behaviour Therapy, 33, 97-101.

McNally, R. J. (2005). Debunking myths about trauma and memory. The Canadian Journal of Psychiatry, 50, 817-822.

McNally, R. J. (2006). Let Freud rest in peace. Behavioral and Brain Sciences, 29, 526-527.

McNally, R. J. (2012). Searching for repressed memory. In R. F. Belli (Ed.), True and false recovered memories: Toward a reconciliation of the debate (pp. 121-147). New York: Springer. 
McNally, R. J., \& Clancy, S. A. (2005). Sleep paralysis, sexual abuse, and space alien abduction. Transcultural Psychiatry, 42, 113-122.

McNally, R. J., Clancy, S. A., \& Barrett, H. M. (2004). Forgetting trauma? In D. Reisberg \& P. Hertel (Eds.), Memory and emotion (pp. 129-154). Oxford: Oxford University Press.

McNally, R. J., Clancy, S. A., Barrett, H. M., Parker, H. A., Ristuccia, C. S., \& Perlman, C. A. (2006). Autobiographical memory specificity in adults reporting repressed, recovered, or continuous memories of childhood sexual abuse. Cognition and Emotion, 20, 527-535.

McNally, R. J., Clancy, S. A., \& Schacter, D. L. (2001). Directed forgetting of trauma cues in adults reporting repressed or recovered memories of childhood sexual abuse. Journal of Abnormal Psychology, 110, 151-156.

McNally, R. J., \& Geraerts, E. (2009). A new solution to the recovered memory debate. Perspectives on Psychological Science, 4, 126-134.

McNally, R. J., Lasko, N. B., Clancy, S. A., Macklin, M. L., Pitman, R. K., \& Orr, S. P. (2004). Psychophysiological responding during script-driven imagery in people reporting abduction by space aliens. Psychological Science, 15, 493-497.

McNally, R. J., Lasko, N. B., Macklin, M. L., Pitman, R. K. (1995). Autobiographical memory disturbance in combat-related posttraumatic stress disorder. Behaviour Research and Therapy, 33, 619-630.

McNally, R. J., Litz, B. T., Prassas, A., Shin, L. M., \& Weathers, F. W. (1994). Emotional priming of autobiographical memory in posttraumatic stress disorder. Cognition and Emotion, 8, 351-367.

McNally, R. J., Metzger, L. J., Lasko, N. B., Clancy, S. A., \& Pitman, R. K. (1998). Directed forgetting of trauma cues in adult survivors of childhood sexual abuse with and without posttraumatic stress disorder. Journal of Abnormal Psychology, 107, 596-601.

McNally, R. J., Ristuccia, C. S., \& Perlman, C. A. (2005). Forgetting of trauma cues in adults reporting continuous or recovered memories of childhood sexual abuse. Psychological Science, 16, 336-340.

Meehl, P. E. (1997). Credentialed persons, credentialed knowledge. Clinical Psychology: Science and Practice, 4, 91-98.

Melchert, T. P. (1996). Childhood memory and history of different forms of abuse. Professional Psychology: Research and Practice, 27, 438-446.

Melchert, T. P. (1999). Relations among childhood memory, a history of abuse, dissociation, and repression. Journal of Interpersonal Violence, 14, 1172-1192.

Melchert, T. P., \& Parker, R. L. (1997). Different forms of childhood abuse and memory. Child Abuse and Neglect, 21, 125-135.

Memon, A., \& Young, M. (1997). Desperately seeking evidence: The recovered memory debate. Legal and Criminological Psychology, 2, 131-154.

Merckelbach, H., Crombag, H., Raymaekers, L., Smeets, T., \& Horselenberg, R. (2010). Hervonden herinneringen [Recovered memories]. In P.J. van Koppen, H. Merckelbach, M. Jelicic, \& J.W. de Keijser (Eds.), Reizen met mijn rechter: Psychologie van het recht, (pp. 539-560). Deventer: Kluwer.

Merckelbach, H., Horselenberg, R., \& Muris, P. (2001). The Creative Experiences Questionnaire (CEQ): A brief self-report measure of fantasy proneness. Personality and Individual Differences, 31, 987-995.

Merckelbach, H., \& Muris, P. (2001). The causal link between self-reported trauma and dissociation: A critical review. Behaviour Research and Therapy, 39, 245-254.

Merckelbach, H., Muris, P., Nijman, H., \& de Jong, P. J. (1996). Self-reported cognitive failures and neurotic symptomatology. Personality and Individual Differences, 20, 715-724.

Merckelbach, H., Muris, P., \& Rassin, E. (1999). Fantasy proneness and cognitive failures as correlates of dissociative experiences. Personality and Individual Differences, 26, 961-967.

Merckelbach, H., Smeets, T., Geraerts, E., Jelicic, M., Bouwen, A., \& Smeets, E. (2006). I haven't thought about this for years! Dating recent recalls of vivid memories. Applied Cognitive Psychology, 20, 33-42.

Merckelbach, H., \& Wessel, I. (1998). Assumptions of students and psychotherapists about memory. Psychological Reports, 82, 763-770. 
Merckelbach, H., Wiers, R., Horselenberg, R., \& Wessel, I. (2001). Effects of retrieving childhood events on metamemory judgements depend on the questions you ask. British Journal of Clinical Psychology, 40, 215-220.

Merckelbach, H., Zeles, G., van Bergen, S., \& Giesbrecht, T. (2007). Trait dissociation and commission errors in memory reports of emotional events. The American Journal of Psychology, 120, 1-14.

Meyersburg, C. A., Bogdan, R., Gallo, D. A., \& McNally, R. J. (2009). False memory propensity in people reporting recovered memories of past lives. Journal of Abnormal Psychology, 118, 399-404.

Moore, S. A., \& Zoellner, L. A. (2007). Overgeneral autobiographical memory and traumatic events: An evaluative review. Psychological Bulletin, 133, 419-437.

Naka, M., \& Maki, Y. (2006). Belief and experience of memory recovery. Applied Cognitive Psychology, 20, 649-659.

Nierop, N. M., \& van den Eshof, P. (2008). Misbruik, misleiding en misverstanden: onderzoeksverslag van de landelijke expertisegroep bijzondere zedenzaken periode 2003-2007 [Abuse, misinformation, and minsunderstanding]. Zoetermeer: LEBZ.

Nierop, N. M., \& van den Eshof, P. (2010). Herinneringen: continu, sluimerend, hervonden of gelogen? Ervaringen van de Landelijke Expertisegroep Bijzondere Zedenzaken [Memories: Continuous, latent, recovered, or feigned?]. Tijdschrift voor Psychotherapie, 36, 148-170.

Nierop, N. M., van den Eshof, P., \& Brandt, C. (2006). De beoordeling van geloofwaardigheid in zedenzaken [Evaluating the credibility in abuse cases]. Nederlands Juristenblad, 43, 2456-2464.

Ofshe, R., \& Watters, E. (1994). Making monsters: False memories, psychotherapy, and sexual hysteria. Los Angeles: University of California Press.

Ost, J. (2010). Recovered memories (invited chapter). In T. Williamson, T. Valentine \& R. Bull (Eds.), Handbook of psychology of investigative interviewing. Current developments and future directions (pp.181204). Chichester, UK: Wiley.

Ost, J., Costall, A., \& Bull, R. (2002). A perfect symmetry? A study of retractors' experiences of making and then repudiating claims of early sexual abuse. Psychology, Crime, and Law, 8, 155-181.

Ost, J., \& Nunkoosing, K. (2010). Reconstructing Bartlett and revisiting retractions of contested claims of abuse. In J. Haaken \& P. Reavey (Eds.), Memory matters: Contexts for understanding sexual abuse recollections (pp.41-62). New York: Psychology Press.

Ost, J., Vrij, A., Costall, A., \& Bull, R. (2002). Crashing memories and reality monitoring: Distinguishing between perceptions, imaginations and 'false memories'. Applied Cognitive Psychology, 16, 125-134.

Otgaar, H., Candel, I., Merckelbach, H., \& Wade, K. (2008). Abducted by a UFO: Prevalence information affects young children's false memories for an implausible event. Applied Cognitive Psychology, 23, 115-125.

Otgaar, H., Candel, I., Scoboria, A., \& Merckelbach, H. (2010). Script knowledge enhances the development of children's false memories. Acta Psychologica, 133, 57-63.

Otgaar, H., Howe, M., Peters, J. V., Sauerland, M. \& Raymaekers, L. (2012). Developmental trends in different types of spontaneous false memories: Implications for the legal field. Article submitted for publication.

Parks, T. E. (1997). False memories of having said the unsaid: Some new demonstrations. Applied Cognitive Psychology, 11, 485-494.

Parks, T. E. (1999). On one aspect of the evidence for recovered memories. American Journal of Psychology, $112,365-370$.

Peace, K. A., \& Porter, S. (2004). A longitudinal investigation of the reliability of memories for trauma and other emotional experiences. Applied Cognitive Psychology, 18, 1143-1159.

Peeters, F. P. M. L., Wessel, I., Merckelbach, H., \& Boon-Vermeeren (2002). Autobiographical memory and the course of depressive disorder. Comprehensive Psychiatry, 43, 344-350.

Peters, M. J. V., Horselenberg, R., Jelicic, M., \& Merckelbach, H. (2007). The false fame illusion in people with memories about a previous life. Consciousness and Cognition, 16, 162-169.

Peters, M. J. V., Jelicic, M., Haas, N., \& Merckelbach, H. (2006). Mild executive dysfunctions in undergraduates are related to recollecting words never presented. International Journal of Neuroscience, 116, 1065-1077. 
Piper, A., Lillevik, L., \& Kritzer, R. (2008). What's wrong with believing in repression? A review for legal professionals. Psychology, Public Policy, and Law, 14, 223-242.

Pollock, L. R., \& Williams, J. M. (2001). Effective problem solving in suicide attempters depends on specific autobiographical recall. Suicide and Life-Threatening Behavior, 31, 386-396.

Pope, H. G., \& Hudson, J. I. (1995). Can memories of childhood sexual abuse be repressed? Psychological Medicine, 25, 121-126.

Porter, S., \& Peace, K. A. (2007). The scars of memory: A prospective, longitudinal investigation of the consistency of traumatic and positive emotional memories in adulthood. Psychological Science, 18, 435-441.

Raes, F., Hermans, D., de Decker, A., Eelen, P., \& Williams, J. M. G. (2003). Autobiographical memory specificity and affect-regulation: An experimental approach. Emotion, 3, 201-206.

Rassin, E. G. C. (2001). Het bepalen van geloofwaardigheid: de methode van de alternatieve scenario's [Determining credibility: The method of alternative scenarios]. De Psycholoog, 36, 348-355.

Rassin, E. G. C. (2010). Blindness to alternative scenarios in evidence evaluation. Journal of Investigative Psychology and Offender Profiling, 7, 153-163.

Rassin, E. G. C., \& Merckelbach, H. (1999). The potential conflict between clinical and judicial decision making heuristics. Behavioral Sciences and the Law, 17, 237-248.

Rassin, E., Merckelbach, H., \& Muris, P. (2000). Paradoxical and less paradoxical effects of thought suppression: A critical review. Clinical Psychology Review, 20, 973-995.

Raymaekers, L., Peters, M. J. V., Smeets, T., Abidi, L., \& Merckelbach, H. (2011). Underestimation of prior remembering and susceptibility to false memories: Two sides of the same coin? Consciousness and Cognition, 20, 1144-1153.

Raymaekers, L., Smeets, T., Peters, M. J. V., \& Merckelbach, H. (2010). Autobiographical memory specificity among people with recovered memories of childhood sexual abuse. Journal of Behavior Therapy and Experimental Psychiatry, 41, 338-344.

Raymaekers, L., Smeets, T., Peters, M. J. V., Otgaar, H., \& Merckelbach, H. (2012). The classification of recovered memories: A cautionary note. Consciousness and Cognition, 21, 1640-1643.

Read, J. D., \& Lindsay, D. S. (2000). “Amnesia” for summer camps and high school graduation: Memory work increases reports of prior periods of remembering less. Journal of Traumatic Stress, 13, 129-147.

Roediger, H. L. III, \& McDermott, K. B. (1995). Creating false memories: Remembering words not presented in lists. Journal of Experimental Psychology: Learning, Memory, and Cognition, 21, 803-814.

Roediger, H. L. III, Watson, J. M., McDermott, K. B., \& Gallo, D. A. (2001). Factors that determine false recall: A multiple regression analysis. Psychonomic Bulletin and Review, 8, 385-407.

Rofé, Y. (2008). Does repression exist? Memory, pathogenic, unconscious and clinical evidence. Review of General Psychology, 12, 63-85.

Rosenthal, R., \& Rubin, D. B. (1978). Interpersonal expectancy effects: The first 345 studies. Behavioral and Brain Sciences, 1, 377-386.

Rubin, D. C., \& Berntsen, D. (2007). People believe it is plausible to have forgotten memories of childhood sexual abuse. Psychonomic Bulletin and Review, 14, 446-778.

Schooler, J. W. (1994). Seeking the core: The issues and evidence surrounding recovered accounts of sexual trauma. Consciousness and Cognition, 3, 452-469.

Schooler, J. W. (1999). Seeking the core: The issues and evidence surrounding recovered accounts of sexual trauma. In L. M. Williams (Ed.), Trauma and memory (pp. 203-216). Thousand Oaks, CA: Sage Publications.

Schooler, J. W. (2001). Discovering memories of abuse in the light of meta-awareness. In J. J. Freyd \& A. P. DePrince (Eds.), Trauma and Cognitive Science: A meeting of minds, science and human experience (pp. 105-136). New York: Haworth.

Schooler, J. W., Ambadar, Z., \& Bendiksen, M. A. (1997a). A cognitive corroborative case study approach for investigating discovered memories of sexual abuse. In J.D. Read \& D.S. Lindsay (Eds.), Recollections of trauma: Scientific research and clinical practices (pp. 379-388). New York: Plenum. 
Schooler, J. W., Bendiksen, M. A., \& Ambadar, Z. (1997b). Taking the middle line: Can we accommodate both fabricated and recovered memories of sexual abuse? In M.A. Conway (Ed.), Recovered memories and false memories (pp. 251-292). Oxford: Oxford University Press.

Shaffer, R. E., \& Cozolino, L. J. (1992). Adults who report childhood ritualistic abuse. Journal of Psychology and Theology, 20, 188-193.

Shobe, K. K., \& Schooler, J. W. (2001). Discovering fact and fiction: Case-based analyses of authentic and fabricated memories of abuse. In G.M. Davies \& T. Dalgleish (Eds.), Recovered memories: Seeking the middle ground (pp. 95-151). Chichester: John Wiley \& Sons.

Shrout, P. E., \& Fleiss, J. L. (1979). Intraclass correlations: Uses in assessing rater reliability, Psychological Bulletin, 2, 420-428.

Sivers, H., Schooler, J., \& Freyd, J. J. (2002). Recovered memories. In V.S. Ramachandran (Ed.), Encyclopedia of the human brain. Volume 4 (pp. 169-184). San Diego, CA: Academic Press.

Smallwood, J., Fishman, D. J., \& Schooler, J. W. (2007). Counting the cost of an absent mind: Mind-wandering as an under recognized influence on educational performance. Psychonomic Bulletin and Review, 14, 230-236.

Smeets, T., Jelicic, M., Merckelbach, H., Peters, M., Fett, A., Taverniers, J., . . . Dautzenberg, J. (2006). Enhanced memory performance on an internal-internal source monitoring test following acute psychosocial stress. Behavioral Neuroscience, 120, 1204-1210.

Smeets, T., Merckelbach, H., Horselenberg, R., \& Jelicic, M. (2005). Trying to recollect past events: Confidence, beliefs, and memories. Clinical Psychology Review, 25, 917-934.

Snodgrass, J. G., \& Corwin, J. (1988). Pragmatics of measuring recognition memory: Applications to dementia and amnesia. Journal of Experimental Psychology: General, 117, 34-50.

Spanos, N. P., Menary, E., Gabora, N. J., DuBreuil, S. C., \& Dewhirst, B. (1991). Secondary identity enactments during hypnotic past-life regression: A sociocognitive perspective. Journal of Personality and Social Psychology, 61, 308-320.

Spiegel, D., \& McHugh, P. R. (1995). The pros and cons of dissociative identity (multiple personality) disorder. Journal of Practical Psychiatry and Behavioral Health, 1, 158-166.

Stoler, L., Quina, K., DePrince, A. P., \& Freyd, J. J. (2001). Recovered memories. In J. Worrell (Ed.), Encyclopedia of women and gender, Volume 2 (pp. 905-917). San Diego, CA: Academic Press.

Sutherland, K., \& Bryant, R. A. (2007). Rumination and overgeneral autobiographical memory. Behaviour Research and Therapy, 45, 2407-2416.

Sutherland, K, \& Bryant, R. A. (2008). Social problem solving and autobiographical memory in posttraumatic stress disorder. Behaviour Research and Therapy, 46, 154-161.

Terr, L. (1991). Childhood traumas: An outline and overview. American Journal of Psychiatry, 148, 10-20. Van Bergen, S. (2011). Memory distrust in the legal context. Dissertation, Maastricht University, Maastricht.

Van der Kloet, D., Merckelbach, H., Giesbrecht, T., \& Lynn, S. J. (2012). Fragmented sleep, fragmented mind: The role of sleep in dissociative symptoms. Perspectives on Psychological Science, 7, 159-175.

Van der Kolk, B. A. (1994). The body keeps score: Memory and the evolving psychobiology of post-traumatic stress. Harvard Review of Psychiatry, 1, 253-265.

Van der Kolk, B. A., \& Fisler, R. (1995). Dissociation and the fragmentary nature of traumatic memories: Overview and exploratory study. Journal of Traumatic Stress, 8, 505-525.

Van der Kolk, B. A., \& van der Hart, O. (1995). The intrusive past: The flexibility of memory and the engraving of trauma. In C. Caruth (Ed.), Trauma: Explorations in memory (pp. 158-182). Baltimore, MD: Johns Hopkins University Press.

Van Oorsouw, K. (2006). I honestly can't remember: Dissociative amnesia as a metamemory phenomenon. Dissertation, Maastricht University, Maastricht.

Van Vreeswijk, M. F., \& De Wilde, E. J. (2004). Autobiographical memory specificity, psychopathology, depressed mood and the use of the Autobiographical Memory Test: A meta-analysis. Behaviour Research and Therapy, 42, 731-743.

Wagenaar, W. A, \& Groeneweg, J. (1990). The memory of concentration camp survivors. Applied Cognitive Psychology, 4, 77-87. 
Watkins, E., \& Teasdale, J. D. (2001). Rumination and overgeneral memory in depression: Effects of self-focus and analytic thinking. Journal of Abnormal Psychology, 110, 353-357.

Watson, D. (2001). Dissociation of the night: Individual differences in sleep-related experiences and their relation to dissociation and schizotypy. Journal of Abnormal Psychology, 110, 526-535.

Watson, D. (2003). To dream, perchance to remember: Individual differences in dream recall. Personality and Individual Differences, 34, 1271-1286.

Wessel, I., Meeren, M., Peeters, F., Arntz, A., \& Merckelbach, H. (2001). Correlates of autobiographical memory specificity: The role of depression, anxiety, and childhood trauma. Behaviour Research and Therapy, 39, 409-421.

Williams, J. M. G. (1996). Autobiographical memory in depression. In D. Rubin (Ed.), Remembering our past: Studies in autobiographical memory (pp. 244-267). Cambridge, England: Cambridge University Press.

Williams J. M. G., Barnhofer, T., Crane, C., Hermans, D., Raes, F., Watkins, E., \& Dalgleish T. (2007). Autobiographical memory specificity and emotional disorder. Psychological Bulletin, 133, 122-148.

Williams J. M. G., \& Broadbent, K. (1986). Autobiographical memory in suicide attempters. Journal of Abnormal Psychology, 95, 144-149.

Williams, J. M. G., Ellis, N. C., Tyers, C., Healy, H., Rose, G., \& MacLeod, A. K. (1996). The specificity of autobiographical memory and imageability of the future. Memory and Cognition, 24, 116-125.

Williams, J. M. G., Stiles, W. B., \& Shapiro, D. A. (1999). Cognitive mechanisms in the avoidance of painful and dangerous thoughts: Elaborating the assimilation model. Cognitive Therapy and Research, 23, 285306.

Wilson, S. C., \& Barber, T. X. (1983). Fantasy-prone personality: Implications for understanding imagery, hypnosis, and parapsychological phenomena. In A.A. Sheikh (Ed.), Imagery: Current theory, research, and application (pp. 340-387). New York: Wiley.

Wilhelm, O., Witthöft, M., \& Schipolowski, S. (2010). Self-reported cognitive failures: Competing measurement models and self-report correlates. Journal of Individual Differences, 31, 1-14.

Winkielman, P., Schwarz, N., \& Belli, R. F. (1998). The role of ease of retrieval and attribution in memory judgements: Judging your memory as worse despite recalling more events. Psychological Science, 9, 124-126.

Winograd, E., Peluso, J., \& Glover, T. A. (1998). Individual differences in susceptibility to memory illusions. Applied Cognitive Psychology, 12, S5-S27.

Wohlfarth, T. D., van den Brink, W., Winkel, F. W., \& ter Smitten, M. (2003). Screening for posttraumatic stress disorder: An evaluation of two self-report scales among crime victims. Psychological Assessment, 15, 101-109.

Yapko, M. D. (1994). Suggestibility and repressed memories of abuse: A survey of psychotherapists' beliefs. American Journal of Clinical Hypnosis, 36, 163-171.

Zaragoza, M. S., \& Lane, S. M. (1994). Source misattributions and the suggestibility of eyewitness memory. Journal of Experimental Psychology: Learning, Memory, and Cognition, 20, 934-945.

Zola, S. M. (1997). The neurobiology of recovered memories. Journal of Neuropsychiatry and Clinical Neuroscience, 9, 449-459. 

DANKWOORD 
Eindelijk kan ik iedereen bedanken die heeft bijgedragen aan een belangrijke periode in mijn leven. De afgelopen vijf jaren werden gekenmerkt door hard werken, persoonlijke groei en intellectuele uitdagingen. Dat mijn AlO-traject ondanks een moeizame start toch heel bijzonder is geworden, is mede dankzij enkele fantastische mensen en ervaringen. Gelukkig is er ruimte in dit proefschrift om hier even bij stil te staan.

In de eerste plaats wil ik graag mijn begeleiders bedanken. Dankjewel Harald, Maarten en Tom voor het vertrouwen dat jullie mij de afgelopen jaren hebben geschonken. Het idee dat ik te allen tijde met al mijn - al dan niet werkgerelateerde zorgen - bij jullie terecht kon, heeft me veel moed gegeven om steeds te blijven doorzetten. Ik had me geen betere begeleiding kunnen voorstellen!

Harald, ik vind je een bijzonder man. Allereerst als begeleider en wetenschapper. Jouw kritische blik, scherpe pen, gedetailleerde feedback en het feit dat geen enkel wetenschappelijk vraagstuk jou te moeilijk blijkt, maken van jou een excellente wetenschapper en begeleider. Je maakt altijd tijd voor me, dat apprecieer ik enorm. Maar bovenal bewonder ik jouw persoonlijkheid. Ik vind het buitengewoon jammer dat kwesties gerelateerd aan mijn project je heel wat kopzorgen en slapeloze nachten hebben bezorgd. Toch heb je me nooit het gevoel gegeven dat mijn project jou tot last is geweest. Dank hiervoor!

Maarten, samen met Tom 'adopteerde' je me toen ik plots zonder dagelijkse begeleider kwam te zitten. Dit alleen al verdient een dikke merci! Je komt regelmatig bij me langs, gewoon om te vragen hoe het met me gaat. Dat is ontzettend lief van je. Jouw kundigheid in combinatie met die typische bescheidenheid maken van jou een groot man. Ik vind je dan ook een fantastische begeleider.

Tom, ik had dit niet zonder jou gekund. Je bent een uiterst gedreven en zeer goede begeleider die altijd weer even snel en grondig feedback geeft op mijn werk. Ik heb dan ook ontzettend veel van je geleerd. Jouw grappige comments in mijn proefschrift zal ik nooit vergeten. Ze waren, zoals altijd, erg gevat en gaven me het gevoel dat ik ondanks alles, erg trots kan zijn op dit boekje. Naast een uiterst perfectionistische, getalenteerde en gedreven begeleider, ben jij iemand bij wie ik altijd terecht kan. Bedankt daarvoor!

Lieve Corine, wat een inspirerende vrouw ben je! In 2011 begon ik onder jouw supervisie aan het matchingsproject voor Reclassering Nederland. Dit was het begin van een mooie samenwerking. Ik heb tot hiertoe ontzettend hard genoten van ons teamwerk. Je stimuleert me telkens weer in mijn zelfstandigheid. Niet alleen leer ik er ontzettend veel van, ik beleef er vooral ook heel veel plezier aan. Bedankt voor alles!

Mijn twee paranimfen, Jill en Nele; Bedankt dat jullie me op deze bijzondere dag willen bijstaan. Bedankt ook voor het nastreven van een perfecte balans tussen gezelligheid en productiviteit. Jullie zijn niet alleen the best roommates ever, maar ook gewoon 
goede vriendinnen waarmee ik veel leuke momenten beleef. Onze gesprekken over het werk, maar vooral ook over de niet werkgerelateerde dingen, betekenen heel veel voor me. Ik hoop dan ook dat er geen einde komt aan deze bijzondere band die we in de afgelopen jaren hebben opgebouwd.

Anna, thank you for being such a great roommate! You are so funny and kind; I very much like sharing a room with you!

Lieve collega's van de sectie Forensische Psychologie, bedankt voor de leuke en warme sfeer op de werkvloer! Jullie zijn de reden dat ik met plezier naar het werk kom. Ik hoop dan ook dat ik nog heel lang deel ga mogen uitmaken van dit sfeervolle clubje. In het bijzonder de gezellige lunchmomenten, de spannende ping pong wedstrijden en de bezoekjes aan Sashimi heb ik erg gewaardeerd! Dus bedankt Alana, Anna, Conny, Corine, Dalena, David, Elly, Ewout, Glynis, Harald, Henry, Jill, Kim, Lieke, Maarten, Maartje, Manuela, Marko, Melanie, Thomas en Tom!

David, je bent een geweldige sectievoorzitter met een hart voor onze groep en een passie voor wetenschap. Ik weet dat je heel hard je best hebt gedaan om, samen met Corine, ervoor te zorgen dat mijn contract werd verlengd in tijden van crisis. Bedankt voor de energie dat je hier in hebt gestoken! Ook bedankt voor de vele gesprekken over die dingen die er écht toe doen in het leven.

Ook dank aan de overige CPS collega's. Wat vormen we toch een leuke vakgroep! In het bijzonder dank aan Hugo, Janneke, Katrijn, en Remco. Jullie zijn toch zo gezellig.

Lieve Sofie, jouw wijze raad en troostende woorden zijn uiterst belangrijk voor me geweest in de afgelopen jaren. Bedankt!

Saskia, je was er altijd voor me wanneer ik het even niet meer zag zitten. Je mag de uni dan wel hebben verlaten, jou zal ik nooit vergeten. Bedankt voor al die keren dat je me hebt gesteund!

Veel dank gaat natuurlijk ook uit naar al de studenten die me in de afgelopen jaren hebben geholpen met het verzamelen van onderzoeksgegevens. Latifa, jij bent gedurende lange tijd mijn studentassistente geweest. Je was er eentje uit duizenden, onvervangbaar. Bedankt! Ik wens je heel veel succes toe in je verdere carrière. Ik ben ervan overtuigd dat er jou nog heel wat mooie dingen gaan overkomen. Je oogst nu eenmaal wat je zaait... Ook dank aan Linda, Natasja, Nathalie en al de studenten die me in de afgelopen jaren op een of andere manier hebben geholpen. Jullie inzet betekende heel veel voor me! 
Sommige mensen laten een onvergetelijke indruk op je na. In mijn leven heb ik het genoegen gehad om heel wat van deze bijzondere mensen te leren kennen. Twee personen wil ik graag vermelden.

Ruben, toen je wist dat er voor jou geen hoop meer was, las je in jouw kostbare tijd mijn masterthese na. Gewoon, omdat je het interessant vond en omdat je zo trots op me was. Je stimuleerde me ook om deze uitdaging aan te gaan. Dat betekende heel veel voor me. Ik zal je nooit vergeten.

Mema, reeds op jonge leeftijd leerde ik hoeveel pijn 'houden van' kan doen. Toen jij 14 jaar geleden stierf, stond mijn wereld stil. Er waren op dat moment nog zoveel dingen die ik samen met jou wilde gaan doen. Bij jou kwam ik elke dag weer thuis. Gelukkig is jouw aanwezigheid voelbaar in alles wat ik doe. Hiervoor ben ik je heel dankbaar.

Dank aan mijn (schoon)familie en vrienden. Dank voor jullie steun en begrip. Hard werken kan je enkel blijven volhouden wanneer je af en toe een verzetje hebt. De etentjes, filmdates en meidenavonden waren dan ook broodnodig in een periode van stress en deadlines.

Mama en papa, bedankt voor alle kansen die jullie me hebben gegeven. Jullie leerden me dat je enkel faalt wanneer je iets niet probeert. De onvoorwaardelijke steun, op alle vlakken, zijn van onschatbare waarde voor mij geweest. Ik zie jullie graag!

Wim, mijn levenspartner en beste vriend. Jou bedanken in een paar zinnen is voor mij onmogelijk. Jouw sterke persoonlijkheid, ambitie, begrip, hartelijkheid en eeuwige rust geven mij tekens weer het gevoel dat ik alles aankan. Ik hou zo ontzettend veel van je!

Amélie, mijn lieve prinses. Jij vormde voor mij de sleutel tot het succesvol afronden van dit promotietraject. Je leerde me namelijk een belangrijke deugd; relativeringsvermogen. Dit proefschrift is waardevol maar niet volmaakt. Jij bent beiden. Naast jou valt dit proefschrift dan ook in het niet. Ik ben nu op de eerste plaats mama en wat geniet ik hier van! Een carrière is leuk, een gezin is alles.

Kleintje, bedankt dat ik mijn proefschrift niet alleen hoef te verdedigen. Ik kijk uit naar jouw komst! 
CURRICULUM VITAE 
Linsey H.C. Raymaekers was born in Tongeren (Belgium) on June 5th 1985. In 2003 she started studying psychology at Maastricht University where she graduated cum laude in Biological Psychology on the $31^{\text {st }}$ of May, 2007. In August 2007, she started her PhD project at the Faculty of Psychology and Neuroscience at Maastricht University. She currently holds a teaching position at the same faculty and is working on a project for the Dutch Probation Service (The Netherlands).

Linsey H.C. Raymaekers werd geboren in Tongeren (België) op 5 juni 1985. In 2003 begon ze haar opleiding psychologie aan de Universiteit Maastricht. Hier studeerde zij cum laude af (Biologische Psychologie) op 31 mei 2007. In augustus 2007 werd ze Assistent in Opleiding aan de faculteit der Psychologie en Neurowetenschappen. Momenteel is ze werkzaam als docent bij diezelfde faculteit en werkt ze aan een project voor Reclassering Nederland. 



\section{LIST OF PUBLICATIONS}




\section{International Journal Articles}

Giesbrecht, T., Abidi, K., Smeets, T., Merckelbach, H., van Oorsouw, K., \& Raymaekers, L. (2009). Adversity does not always lead to psychopathology: Cognitive reactivity is related to longitudinal changes in resilience. Netherlands Journal of Psychology, 4, 62-68.

Raymaekers, L., Peters, M.J.V., Smeets, T., Abidi, L., \& Merckelbach, H. (2011). Underestimation of prior remembering and susceptibility to false memories: Two sides of the same coin? Consciousness \& Cognition, 20, 1144-1153.

Raymaekers, L., Smeets, T., Peters, M.J.V., \& Merckelbach, H. (2010). Autobiographical memory specificity among people with recovered memories of childhood sexual abuse. Journal of Behavior Therapy and Experimental Psychiatry, 41, 338-344.

Raymaekers, L., Smeets, T., Peters, M., Otgaar, H., \& Merckelbach, H. (2012). The classification of recovered memories: Some cautionary notes. Consciousness \& Cognition, 21, 1640-1643.

Smeets, T., Giesbrecht, T., Raymaekers, L., Shaw, J., \& Merckelbach, H. (2010). Autobiographical integration of trauma memories and repressive coping predict posttraumatic stress symptoms in undergraduate students. Clinical Psychology \& Psychotherapy, 17, 211-218.

Smeets, T., Otgaar, H., Raymaekers, L., Peters, M.J.V., \& Merckelbach, H. (2012). Survival processing in times of stress. Psychonomic Bulletin and Review, 19, 113-118.

\section{Dutch Journal Articles}

Raymaekers, L. (2008). Neurowetenschap in de rechtszaal. Maandblad Geestelijke Volksgezondheid, 63, 243-245.

Raymaekers, L., Geraerts, E., \& Merckelbach, H. (2008). Hervonden herinneringen: de stand van zaken. Tijdschrift voor Psychotherapie, 4, 242-259.

Raymaekers, L., Peters, M.J.V., Otgaar, H., \& Smeets, T. (2010). Het classificatieprobleem bij onderzoek naar hervonden herinneringen. GZ-Psychologie, 8, 20-27.

\section{Book Contributions}

Merckelbach, H., Crombag, H., Raymaekers, L., Smeets, T., \& Horselenberg, R. (2010). Hervonden herinneringen. In P.J. van Koppen, H. Merckelbach, M. Jelicic, \& J.W. de Keijser (Eds.), Reizen met mijn rechter: Psychologie van het recht (pp. 539-560). Deventer: Kluwer.

Otgaar, H., Howe, M., Smeets, T., Raymaekers, L., \& van Beers, J. (in press). Memory errors in adaptive recollections. In Schwartz, B., Howe, M., Toglia, M., \& Otgaar, H. (Eds.), What is adaptive about adaptive memory? Oxford: Oxford University Press. 
Raymaekers, L., Otgaar, H., Peters, M., \& Smeets, T. (in press). The adaptive value of survival processing in childhood trauma victims. In Schwartz, B., Howe, M., Toglia, M., \& Otgaar, H. (Eds.), What is adaptive about adaptive memory? Oxford: Oxford University Press.

Van den Hout, M., Engelhard, I., \& Raymaekers, L. (2010). Een eenhoorn onder de berkenboom. In Jansen, A., Merckelbach, H., \& Van den Hout, M. (Eds.), Gek. Experimentele psychopathologie. Over angst, verslaving, depressie en andere ellende (pp. 92-110). Uitgeverij: Bohn Stafleu van Loghum.

\section{Submitted Articles}

Otgaar, H., Howe, M., Peters, M.J.V., Sauerland, M., \& Raymaekers, L. (under review). Developmental trends in different types of spontaneous false memories: Implications for the legal field.

Raymaekers, L., Otgaar, H., \& Smeets, T. (in revision). The longevity of adaptive memory: Evidence for mnemonic advantages of survival processing 24 and 48 hours later.

Raymaekers, L., Smeets, T., \& Peters, M.J.V. (submitted). Source monitoring errors are related to the underestimation of prior remembering in individuals reporting continuous and recovered memories of childhood sexual abuse.

\section{Conference Presentations}

Raymaekers, L., et al. (2011 July). The classification of recovered memories: A cautionary note. Paper presented at the conference 'Forensic Psychology Update: New developments', Maastricht, The Netherlands.

Raymaekers, L., et al. (2011 June). Adaptive memory in survivors of childhood trauma. Paper presented at the Society for Applied Research in Memory and Cognition, New York, United States.

Raymaekers, L., et al. (2010 October). Reduced autobiographical memory specificity among people with recovered memories of childhood sexual abuse. Paper presented at the Positive Psychology Symposium: From 'fix-what's-wrong' to 'buildwhat's-strong' organised by the Graduate Research Institute for Experimental Psychology, Soesterberg, The Netherlands.

Raymaekers, L., et al. (2008 November). Relating retrieval-induced forgetting (RIF) and directed forgetting (DF) to recovered memories of childhood sexual abuse (CSA). Paper presented at the Psychonomics, Chicago, United States.

Raymaekers, L., et al. (2008 July). Cognitive mechanisms underlying recovered memory experiences of childhood sexual abuse. Paper presented at the 18th Conference of the European Association of Psychology and Law, Maastricht University, Maastricht, The Netherlands. 
Raymaekers, L. (2007 October). Mechanisms underlying recovered memories of childhood sexual abuse. Invited colloquium at the University of St. Andrews, UK.

Raymaekers, L., et al. (2007 July). Distinguishing between authentic and false recovered memories of childhood sexual abuse. Poster presented at the 19th Annual Convention of the Association for Psychological Science, Washington DC, United States.

Raymaekers, L., et al. (2007 May). Linking thought suppression and recovered memories of childhood sexual abuse. Paper presented at the Society for Applied Research in Memory and Cognition, Maine, United States. 